NONLINEAR FINITE ELEMENT ANALYSIS OF PROFILED STEEL DECK COMPOSITE SLAB SYSTEM UNDER MONOTONIC LOADING

\author{
by \\ Shubhangi Attarde
Master of Civil Engineering, specialization in Structural Engineering,
Ryerson University, Toronto, ON, 2014
Bachelor of Civil Engineering,
Ryerson University, Toronto, ON, 2013 \\ A project report \\ presented to Ryerson University \\ In partial fulfillment of the requirements for the degree of \\ Master of Engineering \\ in the Program of \\ Civil Engineering
}

Toronto, Ontario, Canada, 2014

(C) Shubhangi Attarde 2014 


\section{AUTHOR'S DECLARATION}

I hereby declare that I am the sole author of this thesis. This is true copy of the thesis, including any required final revisions, as accepted by my examiners.

I authorize Ryerson University to lend this thesis to other institution or individuals for the purpose of scholarly research.

I further authorize Ryerson University to reproduce this thesis by photocopying or by other means, in total or in part, at the request of other institutions or individuals for the purpose of scholarly research.

I understand that my thesis may be made electronically available to the public.

Author's Signature:

Date: 


\title{
Nonlinear Finite Element Analysis of Profiled Steel Deck Composite Slab System under Monotonic Loading
}

Shubhangi Attarde, Master of Engineering, 2014

Department of Civil Engineering

Ryerson University, Toronto

\begin{abstract}
This research concentrated on the nonlinear finite element (FE) modeling of one-way composite floor slab system comprising of profiled steel deck and two types of concrete namely, Engineered Cementitious Composites (ECC) and Self-Consolidating Concrete (SCC). Two FE models were developed based experimental results of composite slabs subjected to in-plane monotonic loading. The simulated loaddeflection response, moment resistance, and shear bond capacity using two FE models were in reasonable good agreement with experimental results. The FE models were used in a comprehensive parametric study to investigate the effect of numerical model parameters such as mesh size, dilation angle, steel sheet-concrete interaction contact, material properties and composite slab span. In addition, FE models were used to determine shear bond parameters of ECC and SCC composite slabs that can be used for design purposes.
\end{abstract}




\section{ACKNOWLEDGEMENTS}

I would like to express my sincere gratitude to my research supervisor Dr. Khandaker M. A. Hossain without whom this study would not be accomplished. His persistent support, encouragement, and valuable suggestions have guided me throughout each stage of my graduate study. My knowledge on the specialized subject of my research study has enhanced significantly due to my supervisor's vast experience, and sophisticated understanding for which I am truly grateful.

And finally, I am deeply and forever indebted to my family, Mr. Bhaskar Attarde, Mrs. Pratibha Attarde, and Mr. Sunny Attarde for their love, encouragement, and support throughout my entire life. 


\section{TABLE OF CONTENTS}

AUTHOR'S DECLARATION

ABSTRACT ii

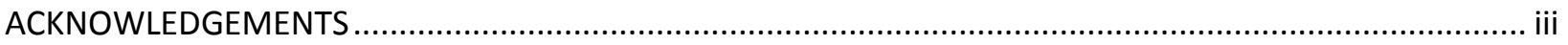

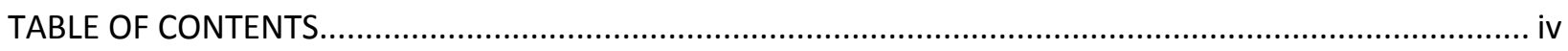

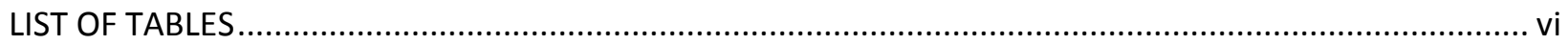

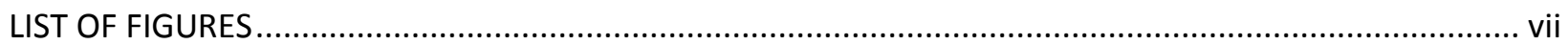

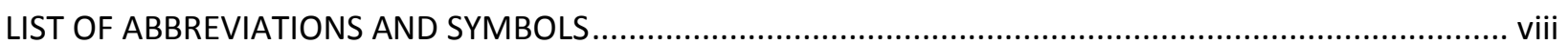

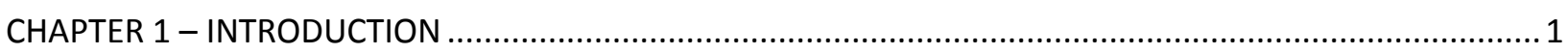

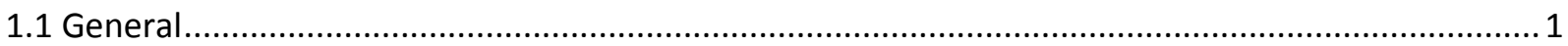

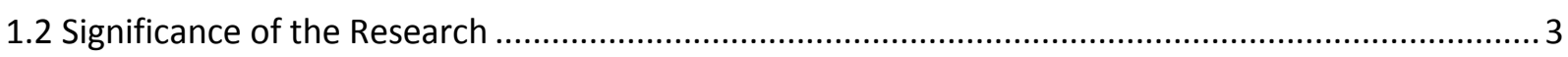

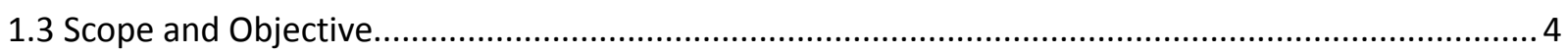

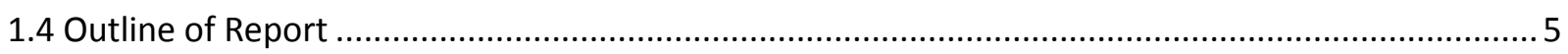

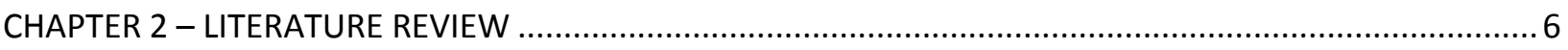

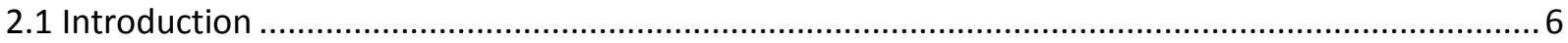

2.2 Development of Composite Steel-Deck Concrete Floor System.................................................. 6

2.3 Review of FE Methods Applicable to Composite Slabs .................................................................

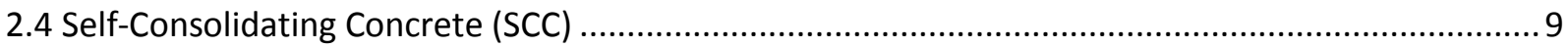

2.5 Engineered Cementitious Composites (ECC) …........................................................................... 10

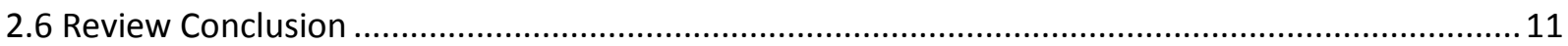

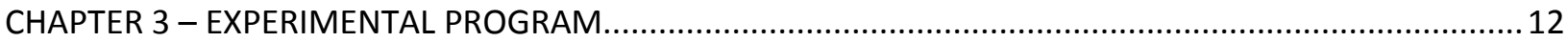

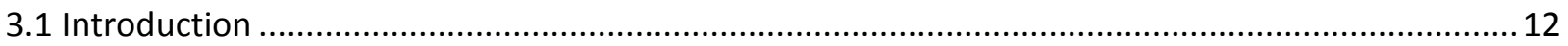

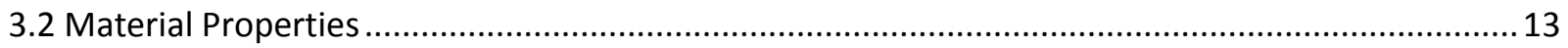

3.3 Test Results: Load-deflection Behaviour...................................................................................... 13

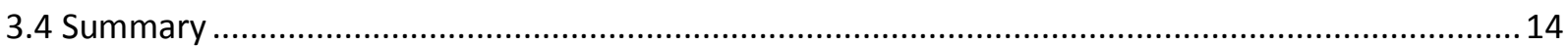

CHAPTER 4 - FINITE ELEMENT MODELING OF COMPOSITE SLAB SUBJECTED TO MONOTONIC LOADING15

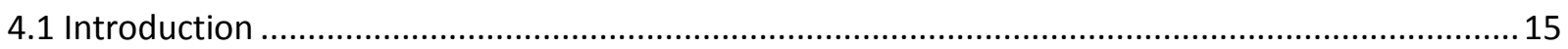

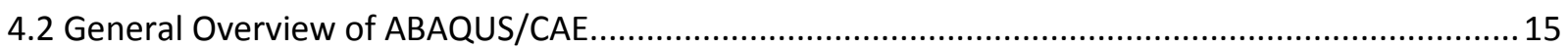

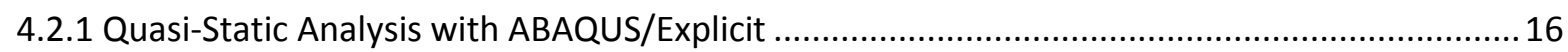

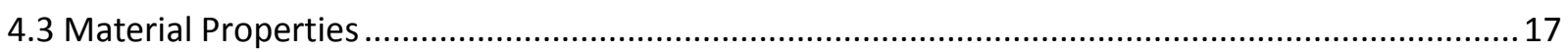

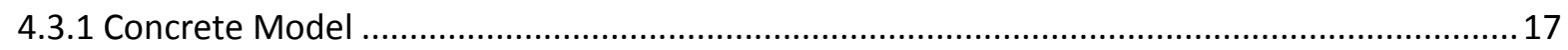

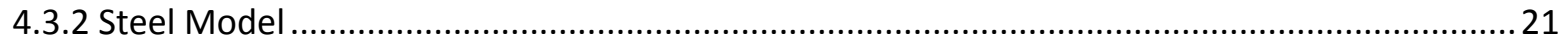

4.4 Description of the FE Model under Monotonic Loading .............................................................2 23

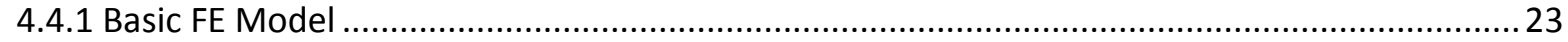




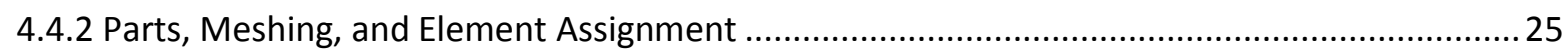

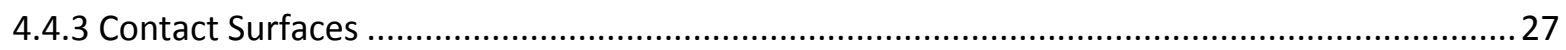

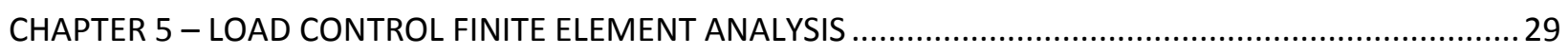

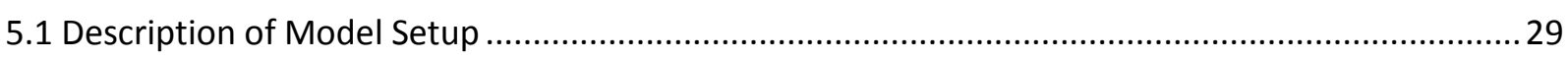

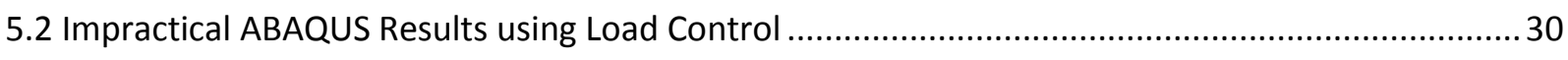

5.2.1 Deficiency with Load Control Analysis ............................................................................... 32

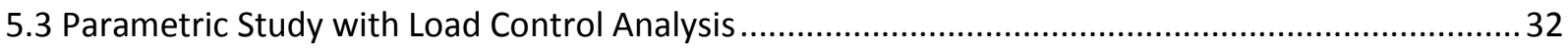

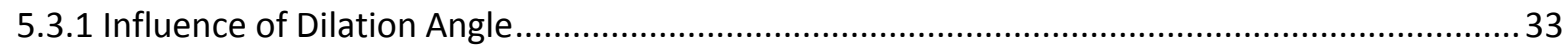

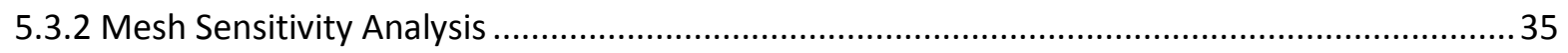

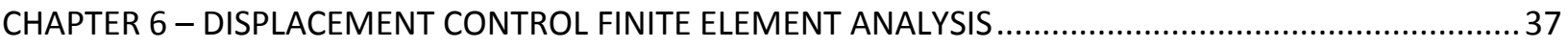

6.1 Description of Selected FE Model for Monotonic Loading ............................................................. 37

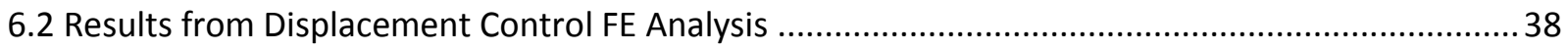

6.3 Comparison of FE Model Output with Experimental Results ......................................................... 41

6.3.1 Slab Load-Deflection Response of ECC composite slab ...................................................... 41

6.3.2 Load-Deflection Response of Self-Consolidating Concrete (SCC) Composite Slab ................... 43

6.4 Finite Element Parametric Study of P3623-300-ECC Composite Slab .......................................... 45

6.4.1 Effect of finite element model parameters on load-deflection behaviour...............................46

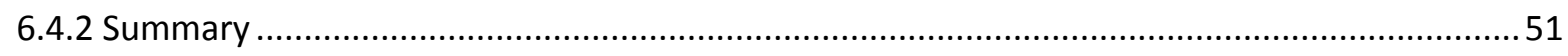

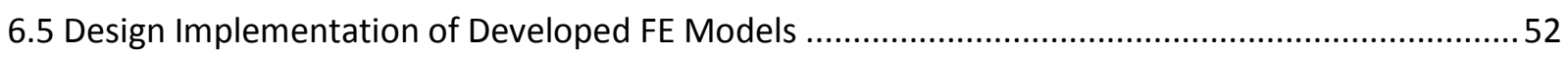

6.5.1 Comparison of the Moment Resistance with Span ............................................................... 52

6.5.2 Evaluation of shear bond characteristics for composite slabs.............................................. 55

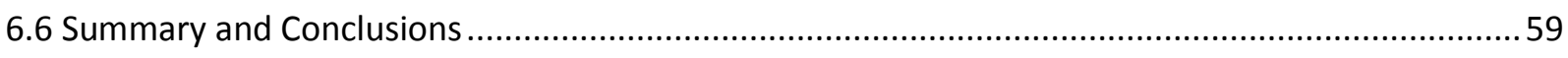

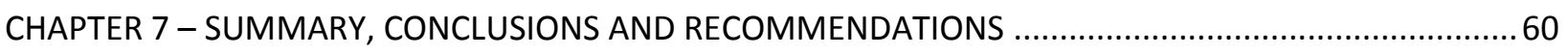

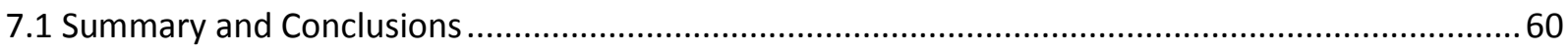

7.2 Recommendations for Future Research Studies .....................................................................61

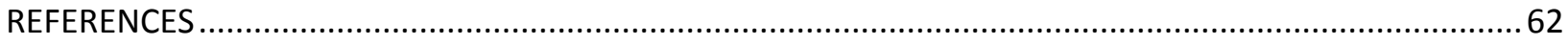

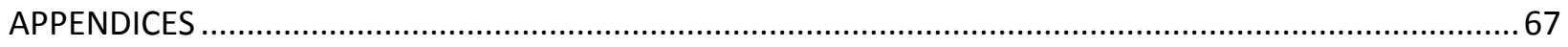

A.1 ABAQUS model results for ECC composite slab (Total Span of $1800 \mathrm{~mm}$ ):..................................67

A.2 ABAQUS model results for SCC composite slab (Total Span of $1800 \mathrm{~mm}$ ):.................................... 72 


\section{LIST OF TABLES}

Table 3.1: Concrete strength properties.

Table 3.2: Summary of experimental results for monotonic loading

Table 4.1: Major differences between ABAQUS/Standard and ABAQUS/Explicit (Dassault Systèmes

Simulia Corp. 2013) .15

Table 4.2: ABAQUS concrete and steel material characterization .23

Table 4.3: Description of stress/displacement elements .26

Table 5.1: Concrete damaged plasticity and steel sheet input parameters for P3623-300-ECC finite element model

Table 5.2: Effect of dilation angle on load-deflection behaviour of P3623-ECC finite element (FE) model

Table 5.3: Effect of mesh element size (ES) on load-deflection behaviour of P3623-ECC FE model...... 36

Table 6.1: Summary of load-displacement response for finite element (FE) model P3623-ECC

Table 6.2: Summary of results for finite element (FE) model of P3623-SCC load-displacement response 45

Table 6.3: Summary of the effect of ABAQUS interface properties on load-deflection response .47

Table 6.4: Summary of the effect of loading constraints on load-deflection behaviour. .48

Table 6.5: Effect of strain increment (SI) factor on load-deflection behaviour. .50

Table 6.6: Summary of results for P3623-300-SCC FE model for different compressive strength .51

Table 6.7: Factored resistance for CANAM P-3623 composite slab as per CANAM design catalogue 53

Table 6.8: Comparison of the ultimate moment resistance with ABAQUS FE model results. .54

Table 6.9: Experimental $\mathrm{m}-\mathrm{k}$ values and shear bond capacity... .56

Table 6.10: Parameters to plot finite element (FE) m-k curves, and shear bond capacity. .57

Table 6.11: Accuracy ratio comparison between finite element (FE) results and experimental data 59 


\section{LIST OF FIGURES}

Figure 1.1: Components of a composite slab (Gholamhoseini et al. 2014) ............................................ 1

Figure 1.2: Failure modes of composite slab subjected to bending test (Gholamhoseini et al. 2014) ........ 2

Figure 2.1: FE model of composite slab using connector elements (Abdullah 2004)................................. 8

Figure 2.2: Tensile stress-strain curve and tight crack width control of ECC (Sahmaran et al. 2009a) ......10

Figure 3.1: (a) Dimensions of P-3623 steel deck (Canam Group 2006), (b) 3D model of composite-3623

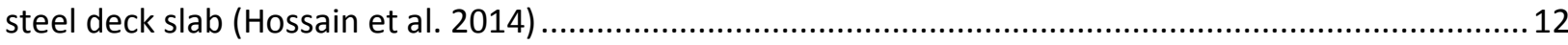

Figure 3.2: Load-deflection response of composite specimens with variable shear spans (a) P3623-ECC

and (b) P3623-SCC (Hossain et al. 2014).

Figure 4.1: Stress-strain response of concrete in tension subjected to uniaxial loading in ABAQUS

(Dassault Systèmes Simulia Corp. 2013) ............................................................................................ 18

Figure 4.2: P3623-ECC and P3623-SCC concrete tension response..................................................... 19

Figure 4.3: Compression stress-strain response of concrete subjected to uniaxial loading in ABAQUS

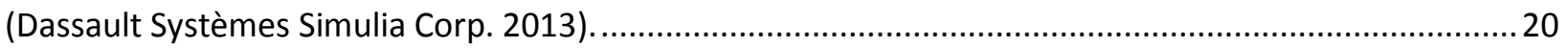

Figure 4.4: P3623-ECC and P3623-SCC concrete compression response ...............................................21

Figure 4.5: Canam composite P-3623 steel deck plastic response ..........................................................22

Figure 4.6: Meshing of profiled concrete using a linear 8-node brick (solid) element.............................24

Figure 4.7: Meshing of Canam composite P-3623 steel sheet using linear 4-node shell element.............24

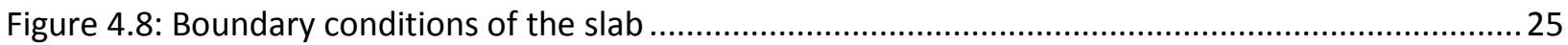

Figure 4.9: The integration points for linear elements (Rafiei 2011) ...................................................26

Figure 5.1: Load-deflection curve for load control analysis...................................................................... 31

Figure 5.2: ABAQUS/Explicit load control model response to monotonic loading................................... 31

Figure 5.3: Load control - reaction force at roller support $(\mathrm{N})$ versus step time $(100 \%)$........................... 32

Figure 5.4: Load-deflection response for dilation angles in load control analysis..................................... 34

Figure 5.5: Mesh sensitivity study with load control analysis .............................................................. 36

Figure 6.1: Location of the Reference Point (RP) and constraining the RP in Y direction to the two loading

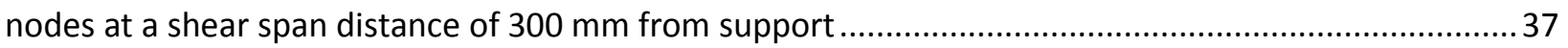

Figure 6.2: Typical deformed model output with ABAQUS/Explicit for shear span of $450 \mathrm{~mm} . . . \ldots \ldots \ldots \ldots . . . . .38$

Figure 6.3: Contour of principal stresses in $X, Y$, and $Z$ directions (MPa) for the composite slab and profiled steel sheeting after the application of two-point displacement control ..................................... 40

Figure 6.4: Comparison of experimental and FE load-displacement response ECC composite slabs ........ 42 
Figure 6.5: Comparison of experimental and FE load-displacement responses SCC composite slabs with

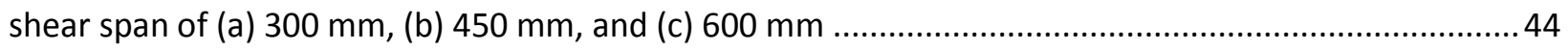

Figure 6.6: Load-displacement response of ECC composite slab for variable interaction property .......... 46

Figure 6.7: Load-displacement responses of ECC composite slab with displacement loading constraints

Figure 6.8: Load versus displacement behaviour of ECC composite slabs as a function of strain increment

Figure 6.9: Comparison of load-displacement behaviour of SCC and ECC composite slab for constant concrete compressive strength

Figure 6.10: Typical m-k curves for total span of $1800 \mathrm{~mm}$ and $2700 \mathrm{~mm}(\mathrm{a}, \mathrm{b})$ ECC composite slab, (c,d)

SCC composite slab

\section{LIST OF ABBREVIATIONS AND SYMBOLS}

$\begin{array}{ll}b & \text { Slab width } \\ L & \text { Slab Span } \\ t & \text { Slab thickness } \\ P & \text { Total applied load } \\ V_{t} & \text { Support reaction } \\ d_{p} & \text { Effective slab depth } \\ L_{S} & \text { Shear span } \\ L^{\prime} & \text { Distance in-between the slab supports } \\ \text { HPC } & \text { High performance concrete } \\ \text { ECC } & \text { Engineered cementitious composite } \\ \text { HPFRCC } & \text { High performance fiber reinforced cementitious composites } \\ \text { SCC } & \text { Self-consolidating concrete } \\ \text { FE } & \text { Finite element } \\ \text { CAE } & \text { Complete Abaqus environment }\end{array}$


FEA Finite element analysis

VMA Viscosity modifying admixtures

PVA Poly vinyl alcohol fiber

AAR

Alkali-aggregate reactivity

CDP Concrete damage plasticity

$d_{t} \quad$ Damage parameter in tension

$\bar{\varepsilon}_{t}^{c k} \quad$ Cracking strain of concrete

$\varepsilon_{t} \quad$ Total strain

$\sigma_{t} \quad$ Tensile stress

$E_{0} \quad$ Initial elastic stiffness of concrete

$\bar{\varepsilon}_{t}^{p l} \quad$ Plastic strain in tension

$\sigma_{c 0} \quad$ Initial yield stress

$\sigma_{c u} \quad$ Ultimate stress

$d_{c} \quad$ Damage parameter in compression

$\tilde{\varepsilon}_{c}^{i n} \quad$ Inelastic or crushing strain

$\tilde{\varepsilon}_{c}^{p l} \quad$ Plastic strain in compression

$\sigma_{\text {true }} \quad$ True stress

$\varepsilon_{l n}^{p l} \quad$ Logarithmic plastic strain

$\sigma_{\text {nom }} \quad$ Nominal stress

$\varepsilon_{\text {nom }} \quad$ Nominal strain

E Modulus of elasticity

3D Three-dimensional

C3D8R Linear hexahedral solid element

S4R Linear quadrilateral shell element 


\begin{tabular}{|c|c|}
\hline U1 & Displacement in $\mathrm{x}$ direction \\
\hline U2 & Displacement in y direction \\
\hline U3 & Displacement in z direction \\
\hline DOF & Degrees of freedom \\
\hline$\psi$ & Dilation angle in the $p$-q plane \\
\hline$\varepsilon$ & Flow potential eccentricity \\
\hline$\sigma_{b 0} / \sigma_{c 0}$ & Ratio of initial equibiaxial compressive yield stress to initial compressive yield stress \\
\hline Kc & Ratio of the second stress invariant on the tensile meridian \\
\hline ES & Mesh element size \\
\hline $\mathrm{RP}$ & Reference point \\
\hline $\mathrm{S} 11$ or $\sigma_{x x}$ & Principal stress in $\mathrm{x}$ direction \\
\hline $\mathrm{S} 22$ or $\sigma_{y y}$ & Principal stress in y direction \\
\hline $\mathrm{S} 33$ or $\sigma_{z z}$ & Principal stress in $z$ direction \\
\hline MPC & Multi-point constraints \\
\hline$f^{\prime}{ }_{c}$ & Compressive strength of concrete \\
\hline$m$ & Mechanical interlocking between concrete and profiled steel deck \\
\hline$k$ & Friction at the interface of concrete and steel deck \\
\hline$\tau_{u, R d}$ & Shear bond capacity of slab \\
\hline$V_{u}$ & Ultimate shear capacity of slab \\
\hline$P_{u}$ & Two load in a four-point loading test \\
\hline$A_{p}$ & Cross-section area of profiled steel sheet \\
\hline
\end{tabular}




\section{CHAPTER 1 - INTRODUCTION}

\subsection{General}

Composite slab comprises of cold-formed profiled steel sheet and structural concrete toping is an optimum flooring system commonly used nowadays for the construction of buildings (Figure 1.1). Implementation of this structural system provides several advantages such as quick installation, reduced dimensions and weight of building floors, In addition, the steel deck serves as a permanent formwork for supporting the concrete (Gholamhoseini et al. 2014). The major benefit with using steel deck is that it acts as the external reinforcement for the slab to resist the tension induced by positive bending moment of the composite structure. To serve as tension reinforcement, it is crucial to achieve the transmission of horizontal shear stresses at the interface of concrete-steel surfaces, which is dominating factor that controls the composite action between the concrete and steel sheeting. As the tension behaviour is governed by the steel sheeting, the additional reinforcement shown in Figure 1.1 provides the positive bending resistance. The strength and performance of the composite slab is also influenced by other factors such as the profile, geometry and thickness of steel sheeting, concrete compressive strength, and span length of the slab (Gholamhoseini et al. 2014). By adopting suitable shape and detailing of the steel sheet profile, sufficient resistance against vertical separation and horizontal slippage can be achieved between the hardened concrete and steel deck.

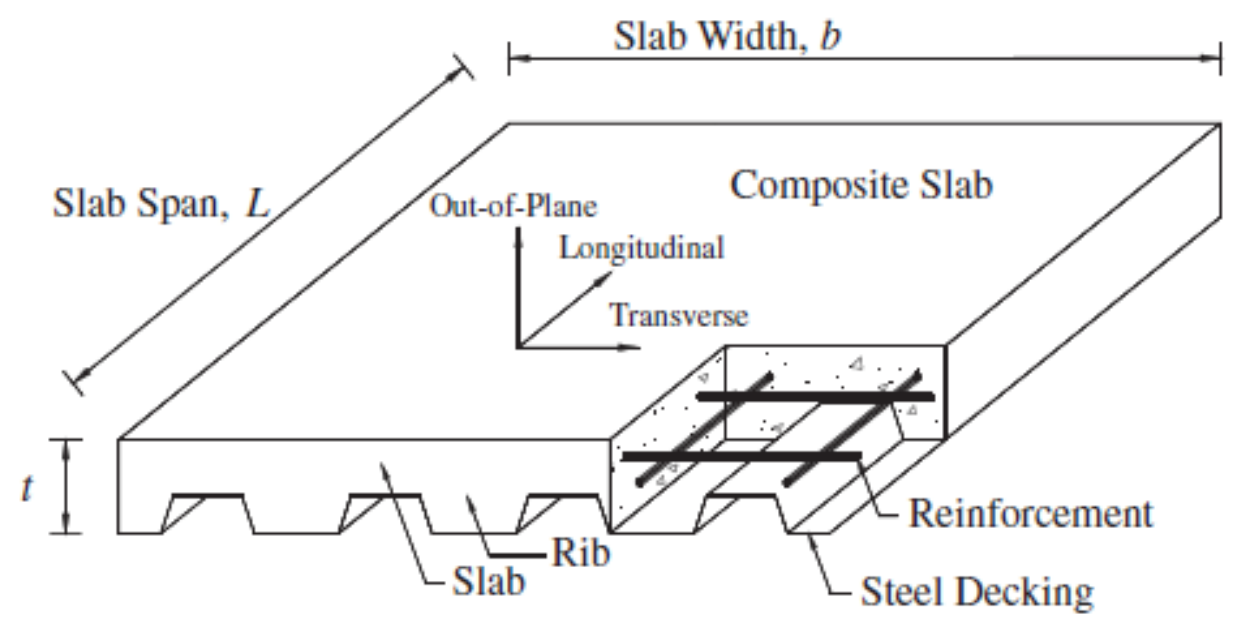

Figure 1.1: Components of a composite slab (Gholamhoseini et al. 2014)

A composite slab must be designed to sustain factored loads at the ultimate limit state. For this study, the performance of the composite slab was evaluated under a four-point bending test, for which there are 
three major modes of failure: flexure failure at section $b-b$ within peak moment region, vertical shear failure at section a-a, and horizontal shear failure at section c-c. Each of the mentioned sections correspond with the Figure 1.2, where, $P$ is the total applied load on the composite slab, $V_{t}$ is the support reaction at each support, $b$ is the slab width, $t$ is the slab thickness, $d_{p}$ is the effective slab depth, $L_{s}$ is the shear span and $L^{\prime}$ is the distance in-between the slab supports.

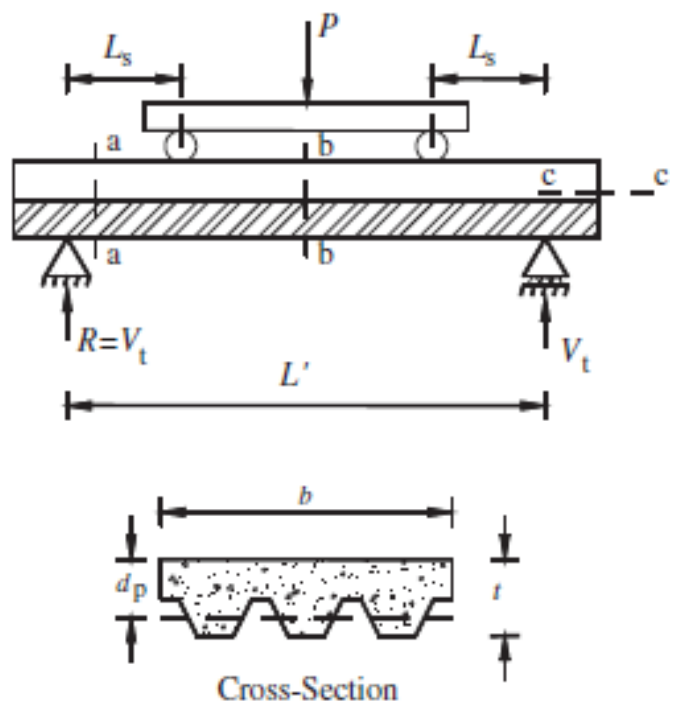

Figure 1.2: Failure modes of composite slab subjected to bending test (Gholamhoseini et al. 2014)

The flexural failure (mode b-b) requires absolute interaction between the concrete and steel sheeting surfaces, and this mode of failure usually dominates for long and thin slabs. However, as the composite slab length is generally restricted by the serviceability limit and with the lack of strong bond between the concrete and steel deck interface, this type of failure is not likely to threaten the performance of composite slab. For vertical shear failure to govern the slab must be very short and thick with a high magnitude of concentrated load positioned close to the supports, which does not resemble the setup of the four-point bending test that was imposed on the studied composite slab. The longitudinal shear failure is the most common type of failure to occur for majority of composite slab systems due to the shear failure at the interface of concrete-steel sheet. This type of failure is propagated with the development of a diagonal crack within the concentrated load region and significant end-slip between the concrete and steel sheeting, and steel sheeting, thus reducing the stiffness and strength of the composite steel deck floor slab.

According to Eurocode 4 (1994), " $m-k$ " and "partial shear connection" are the two methods can be used for evaluating the longitudinal shear capacity of composite slabs. For this research the " $m-k$ " method was 
adopted to determine the shear bond characteristics of SCC and ECC composite slabs. The longitudinal shear capacity of the composite slab specimen is dependent on the geometry and flexibility of the selected type of steel sheeting, including the size and spacing of the steel deck embossments, and the span-todepth ratio of the concrete slab (Gholamhoseini et al. 2014). The shear bond characteristics of the embossed profiled sheeting are defined with by two empirical constants $m$ and $k$, which have the dimensions of stress. This method is applicable for composite slabs that exhibit both ductile and brittle longitudinal shear failure (Lam et al. 2008). In Eurocode 4 (1994), the defined criteria for ductile failure of composite slabs is that the failure load should exceed the load at the end slip of $0.1 \mathrm{~mm}$ by more than $10 \%$, otherwise, it will be classified as brittle failure (Lam et al. 2008).

The low tensile strength of conventional concrete is the primary cause for the propagation of severe cracking in composite slabs. This leads to the development of steel reinforcement corrosion and significant increase in slab deflection. With decreasing budget allocations for infrastructure maintenance, rehabilitation, and replacement, there is a substantial need for the use new generation of high performance concrete (HPC) concrete for enhanced durability and structural performance.

\subsection{Significance of the Research}

Although structural performance of composite slabs with traditional concrete was the subject matter of numerous research studies, limited research has been conducted to envisage the behaviour of composite slabs with different profile steel sheeting and newly emerging high performance concrete (HPCs) (Mohammed et al. 2011; Mohammed, 2010; Hossain and Vinay, 2012). Structural behavior of composite slab using different concretes including rubber concrete have been investigated (Bashar 2010, Marimutu et al. 2007, Chen 2003, Makelainen and Sun 1999).

The better shear bond interaction between steel sheet and HPC can significantly improve the structural performance of composite slabs in addition to improve durability. Therefore the study of structural performance of composite slabs with different HPCs with varying profile geometry and mechanical connectors is warranted. Design of composite slabs can be achieved by using $\mathrm{m}-\mathrm{k}$ method, if $\mathrm{m}$ (parameter that defines shear bond due to mechanical interlock between steel and concrete) and $\mathrm{k}$ (parameter that defines shear bond due to friction between steel and concrete) values are known from experiments. $M$ and $\mathrm{k}$ values normally change with different concrete and different steel sheets (Mohammed 2010; Eurocode 4 1994). Composite slabs with better structural performance can be obtained by using newly 
developed high performance concretes (HPCs) especially emerging highly ductile Engineered Cementitious Composite (ECC).

Engineered Cementitious Composite (ECC) is a new generation of high performance fiber reinforced cementitious composites (HPFRCC). The primary function of ECC is to provide high tensile ductility and strain capacity while maintaining self-controlled tight micro-crack widths (Sahmaran et al. 2007, and Li et al. 2011, Afefy and Mahmoud 2014).

Cost-effective highly flowable green ECCs (developed recently at Ryerson University) made of locally available materials (Hossain 2014; Hossain and Anwar 2014; Sherir et al. 2014) could yield better composite action between the profiled steel sheeting and the concrete. The high strain capacity (300 to

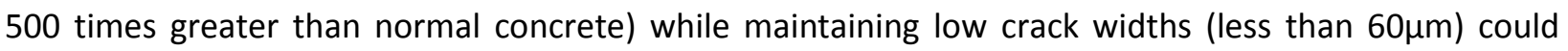
resolve the problems through shear bond optimization and improving constructability (faster construction and better concrete quality control through self-consolidation) as well as enhancing ductility and durability (Hossain and Vinay, 2012). Use of ECC for composite slabs can achieve compatible properties, such as compressive strength, thermal expansion, in addition to providing resistance against large tensile and shear forces (Hossain and Vinay, 2012).

No research has been conducted on the development of high performance composite slabs using ECC. There is an urgent need to conduct research on the structural performance of ECC based composite slabs compared to their traditional concrete counterparts and develop design specifications. Past research studies conducted on nonlinear finite element (FE) modeling of composite slabs were mainly focused on using conventional concrete material. It is also crucial to develop nonlinear FE models of composite slabs made of ECC and SCC.

\subsection{Scope and Objective}

The main objectives of this study are to:

- develop nonlinear finite element (FE) models of SCC and ECC composite slab using ABAQUS/CAE based on experimental data and validate the performance of models

- perform comprehensive parametric studies to investigate the effect of ABAQUS modeling parameters (mesh size, types of interface contact, simulation type -load/displacement control etc.), concrete/steel sheet material properties and variable composite slab span length on loaddisplacement response, stiffness, failure loads and stress characteristics of ECC and SCC composite slabs. 
- Use developed FE models to simulate the behavior of numerical ECC/SCC composite slabs having variable total and shear span to evaluate ultimate load/moment resistance and the shear bond characteristics. Compare experimental and FE predicted ultimate load/moment resistance and the shear bond to verify the accuracy of the proposed FE models.

- Suggest design aids in the form tables for the prediction of load/moment resistance and steelconcrete shear bond of ECC and SCC composite slabs for variable span length.

\subsection{Outline of Report}

This report consists of 7 chapters which can be outlined as follows:

Chapter 1 presents a brief introduction about the composite slabs, the significance of this research followed by the objectives of this study.

Chapter 2 presents a literature review on the development of steel deck composite slabs and finite element modeling methods based on previous research studies.

Chapter 3 provides a brief description of the experimental program and the material properties. It also presents the experimental test results for monotonic loading in the format of load versus displacement for SCC and ECC composite slabs that were used to develop and validate FE models results.

Chapter 4 presents a detailed description of the finite element models developed to simulate the behaviour of SCC and ECC composite slabs under monotonic loading condition. Some strategies in nonlinear dynamic explicit FE method for simulating a quasi-static response are also briefly discussed.

Chapter 5 explains the deficiency with using the load control analysis for ABAQUS/CAE nonlinear FE modeling. The outputs obtained from load control analysis are presented to verify this hypothesis. Moreover, the parametric study is conducted for load control analysis investigating the influence of dilation angle and mesh sensitivity.

Chapter 6 presents the FE models based on the displacement control analysis for ECC/SCC composite slabs. The load-deformation response from the Finite Element Analysis (FEA) and experimental results are also compared for both SCC and ECC composite slabs to evaluate the prediction accuracy of the two models. It also presents the results of parametric study to study the influence of ABAQUS modeling parameters. Developed FE models are used to determine load/moment resistance and shear bond capacity of numerical ECC/SCC composite slabs to produce design aids.

Chapter 7 presents the main conclusions and recommendations for future research studies. 


\section{CHAPTER 2 - LITERATURE REVIEW}

\subsection{Introduction}

Composite floor is a structural system that uses the composite action between the steel deck and the concrete. In this chapter, the development and recent investigations on different types of innovative composite slab systems are presented, In addition, a brief overview of research on the finite element analysis simulating the behaviour of composite slabs is also presented.

\subsection{Development of Composite Steel-Deck Concrete Floor System}

Many researchers studied the behaviour and design of steel deck composite slabs since the late 1960s. Ekberg and Schuster (1968), and Schuster (1976) introduced the construction industry to the different composite floor systems, such as the concrete slabs that utilize transverse wires, embossments on flanges and webs of the steel sheeting. In conjunction with these studies, Porter and Ekberg (1976) provided the design recommendations for the profiled composite floor slabs. Their research led to the formation of the basis for the ASCE (1984) standard procedures for designing composite slabs and established the linear regression methods for meeting the testing requirements.

Wright et al. (1987) emphasized on the structural, construction, and economical advantages of implementing profiled steel sheeting in the production of composite floor systems. The research included over 200 tests on the elements of composite steel deck slab, and the results were validated with the design methods to study the aspects of construction phase, composite slab and steel beam action phase. Makelainen and Sun (1999) studied the longitudinal shear resistance of a new steel sheeting profile for composite floor slabs, which revealed that as the depth of the embossments increased, rather than the length or the shape, it had proportionally increased the magnitude of shear stresses as well, thus providing better resistance against separation of steel deck and profiled concrete. In-plane shear resistance of the profiled steel deck, profiled concrete panels and the double skin-profiled composite shear panels were investigated (Hossain 1995, Hossain and Wright 1998, 2004a, b).

Marimutu et al. (2007) conducted an experimental investigation to study the shear bond behaviour of the embossed composite deck slab under simulated imposed loads using conventional concrete. For this research, six set of slabs were tested, each comprised of three slabs with altered shear span for each set. For testing shorter shear loading, the shear span of $320 \mathrm{~mm}, 350 \mathrm{~mm}$, and $380 \mathrm{~mm}$ were used; and for 
longer shear loading the shear span of $850 \mathrm{~mm}, 950 \mathrm{~mm}$, and $1150 \mathrm{~mm}$ were selected. Based on this test results it was determined that the behaviour of the composite slab depends on the shear span length. Failure of the shorter shear span slab was governed by shear bond failure, whereas, for longer shear spans the slab responded with flexural failure.

For studying the influence of advanced concrete properties, Bashar (2010) examined the structural response of the composite concrete slab consisting of crump rubber concrete. This experimental test included two set of slabs with shear span of $450 \mathrm{~mm}$ and $900 \mathrm{~mm}$, respectively. Each set comprised of four slabs in total, of which three slabs were composed of rubbercrete and one slab was made with conventional concrete as control slab. The test results verified the ductile response of the rubbercrete slabs. For analyzing the influence of different end restraints on shear-bond action of simply supported composite slabs, Chen (2003) tested seven simply supported one-span composite slabs and two continuous composite slabs. The experimental results revealed that the slabs with end anchorage of steel shear connectors had higher shear-bond strength capacity in comparison to the slabs without end anchorage.

\subsection{Review of FE Methods Applicable to Composite Slabs}

For composite slabs, various models have been proposed to perform the finite element (FE) analysis. Daniels and Crisinel (1993a, b) developed a FE method using the plane beam elements to evaluate the performance of single and continuous span composite slabs. The procedure accounts for the nonlinear behaviour of materials such as concrete, and the shear interaction property between the concrete and steel sheeting surfaces was defined based on the results obtained from the pull out test that was conducted by the authors. Veljkovic (1996) performed three-dimensional finite element analysis using the software DIANA to analyze the behaviour of the concrete-steel sheet interface in the composite slab. The shear interaction between the concrete and steel sheet was modeled by using the nodal interface element and its property was defined based on the results from the push tests. Abdullah and Easterling (2007) developed a design procedure that can use bending test results to produce a suitable shear bond property for a given specimen of steel deck composite slab. The generated shear-bond slip curves were used in FE models to define the properties of the connector elements and simulate the horizontal shear bond behaviour in composite slabs. The FE analysis model generated by Widjaja (1997) used two parallel EulerBernoulli beam elements to simulate the bending test response of composite slab. The key difference between the model generated by Widjaja and the others was that only one single longitudinal section of 
the composite slab model was used, and the vertical node displacements of the two elements were restricted to be equivalent in magnitude and direction.

The main shortcoming of these proposed FE procedures is that the interface contact property between the concrete and profiled steel sheeting was predefined. Moreover, it is unlikely to achieve the equivalent shear bond interface response with push-out and bending tests. The shear bond interaction in the composite slabs between the concrete and the profile steel deck is difficult to model due to its nonlinear contact which must account for concrete stickiness, allow for concrete sliding against steel sheeting, and simultaneously use the friction phenomena between the two components to minimize and slow down the sliding motion at the interface (Chen et al. 2011). Ferrer et al. (2006) performed the pull-out tests on composite slabs using the FE method, in which the interface contact elements were established between the concrete and steel sheeting and the behaviour of the slab specimen were analyzed for various friction coefficients. However, the deficiency with this method was that the failure was not executed with the rigid concrete surface.

Input via a text-based file and graphical interactive method are the two methods that can be used in ABAQUS (CAE) to conduct the finite element analysis. The text file format is suitable approach for modeling two-dimensional FE models, however, the procedure becomes complex for performing threedimensional nonlinear finite element modeling and analysis of composite slabs. Abdullah (2004) developed a finite element model for composite slabs with ABAQUS/Explicit 6.3 using the text-based file format. The interaction between the concrete and the steel deck was modeled with radial-thrust type connector elements (CONN3D2), as shown in Figure 2.1.

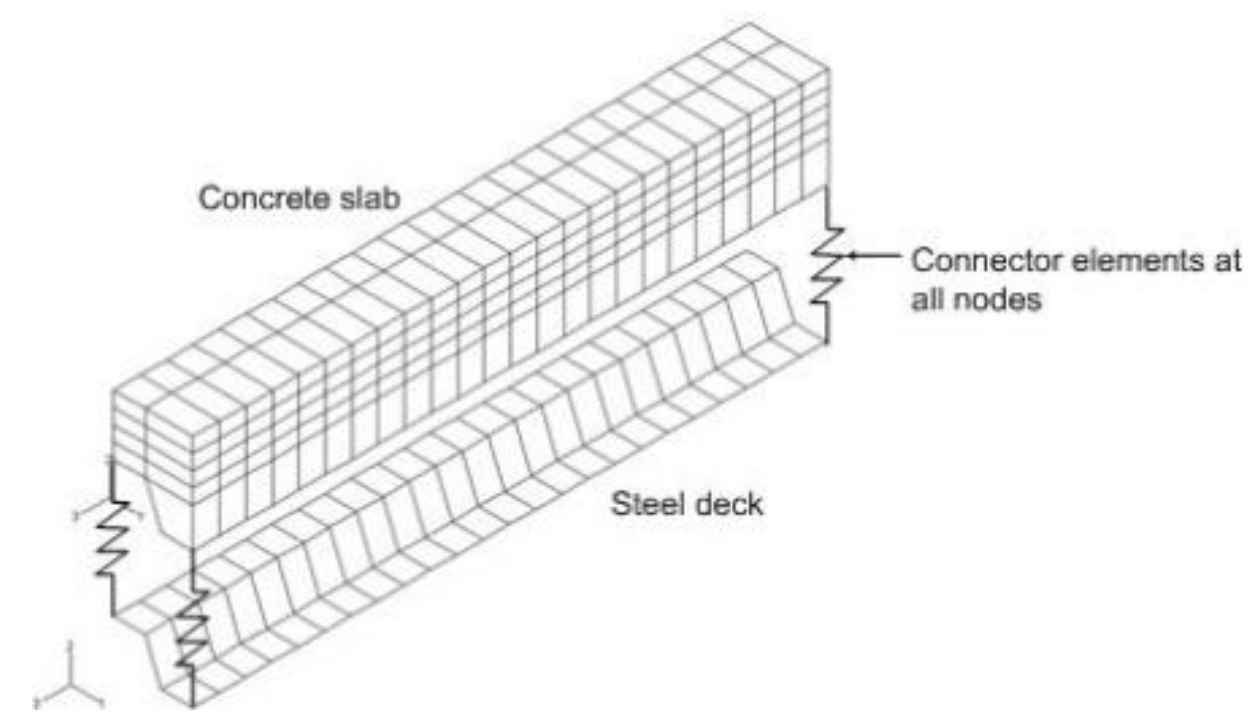

Figure 2.1: FE model of composite slab using connector elements (Abdullah 2004) 
The connector was established between the concrete and steel nodes that are closest to each other. With Abdullah (2004) model, the vertical interaction and the frictional resistance of the support was not considered due to the assumption that its effect was implicitly present in the horizontal shear property. This model is feasible for small scale specimen testing, however, for large-scale composite slab models using graphical interaction modeling is recommended.

\subsection{Self-Consolidating Concrete (SCC)}

Self-Consolidating Concrete (SCC), one of the latest innovations in high-performance concrete, is a highly flowable concrete that can easily spread into a structural formwork under its own weight. Good consolidation can be achieved with SCC, eliminating the need for external or internal vibrators and yet exhibiting homogeneous mix without segregation or excessive bleeding. Self-consolidating concrete can be used to facilitate concrete placement and the productivity of casting congested and narrow structural members such as slabs (Khayat 1999).

Self-consolidating concrete was developed in Japan during the early 1980's (Hayakawa et al. 1993). In addition to fulfilling the demand of a flowable concrete that can properly consolidate the heavily reinforced seismic members, it was also developed to improve the on-site working conditions such as reducing time and cost of construction, requiring less labour workers, and eliminating the noise and pollution caused due to vibrators.

There are several different methods that can be used for producing self-consolidating concrete mix. One approach could be to substantially increase the fine material content such as fly ash and slag cement, while maintaining constant amount of water. A research study conducted by Bouzoubaâ and Lachemi (2001) has proved that using high volume of Class F fly ash can also result in an economical mix design of SCC.

An alternative design approach would be to utilize viscosity modifying admixture (VMA) to develop the stability of the SCC mix. According to the study performed by Lachemi et al. (2003), the behaviour of twenty-one concrete mixtures were tested with three types of manufactured SCC consisting of fly ash, slag cement, and three different VMAs. Based on the test results, it was learnt that the selected three materials were able to successfully develop an economical SCC with desired properties; and VMA was capable of providing higher resistance to segregation and early strength development in comparison to fly ash and slag cement. 


\subsection{Engineered Cementitious Composites (ECC)}

Engineered Cementitious Composites (ECC), a category of ultra-ductile fiber reinforced cementitious composites, was originally invented at the University of Michigan during the early 1990s (Li 1993). ECC is characterized by high ductility in the range of 3-7\%, tight self-controlled crack width of maximum $60 \mu \mathrm{m}$, and with low fiber volume typically close to $2 \%$ (Sahmaran et al. 2009a and Zhou et al. 2010). The most common type of fiber used in engineered cementitious composites is poly vinyl alcohol (PVA) fiber with a diameter of $38 \mu \mathrm{m}$ and length of approximately $12 \mathrm{~mm}$ (Li 1993).

The main advantage of using ECC is its ability to develop pseudo strain-hardening after the first crack with a composite strain capacity that is $\mathbf{3 0 0}$ to 500 times higher than conventional concrete, similar to the response of a ductile metal (Sahmaran et al. 2009a). As shown in Figure 2.2, the crack width of ECC remains less than $60 \mu \mathrm{m}$ while sustaining large imposed deformations.

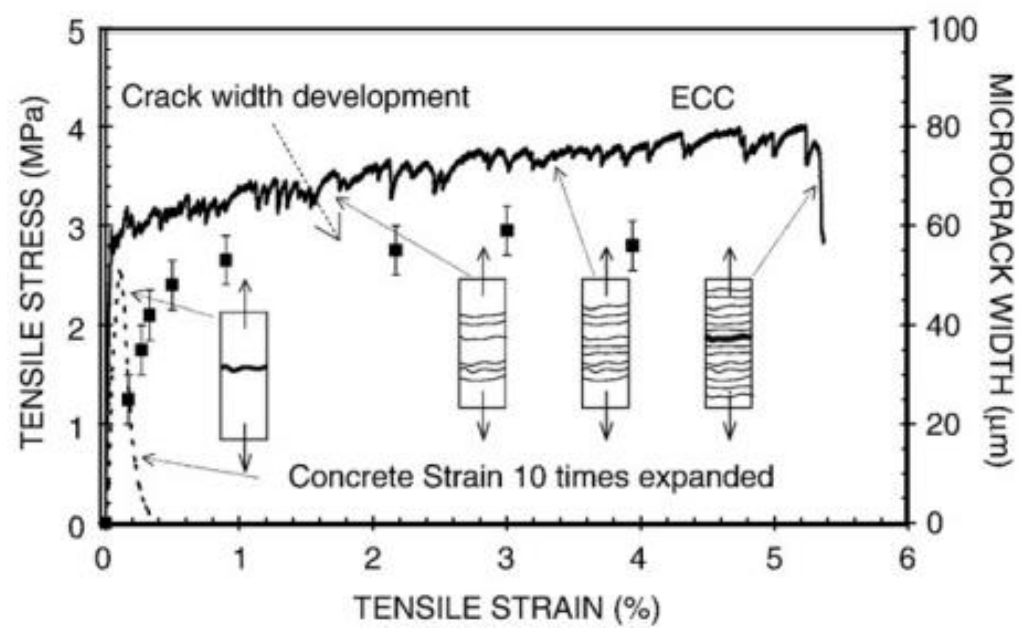

Figure 2.2: Tensile stress-strain curve and tight crack width control of ECC (Sahmaran et al. 2009a)

The reason for the high ductility and strain capacity of ECC is due to the optimization of its material properties through the application of micromechanics (Li 1993, Sahmaran et al. 2009b). Micromechanics quantify the influence of a material structure on macroscopic behaviour by accounting for bridging interaction among the fiber, the mortar matrix and fiber-mortar interface matrix. Matrix heterogeneities in ECC include the cement grain, sand particles, and mineral admixture particles, with the particle size ranging from nanometer to millimeter scale (Nawy 2008). 


\subsection{Review Conclusion}

The provided literature review demonstrates that the analysis of the profiled steel-deck composite slab behaviour is intricate. Majority of the experimental tests were performed with the conventional concrete. Little research has been conducted to date on the structural performance of composite slabs with Engineered Cementitious Composite (ECC). Moreover, FE analysis of ECC based composite slab has not yet been performed. This research focusing on finite element (FE) simulation of the profiled composite slab utilizing the ECC and SCC is a timely initiative and will contribute to the advancement of the knowledge. 


\section{CHAPTER 3 - EXPERIMENTAL PROGRAM}

\subsection{Introduction}

For this study, experimental data from the research conducted at the Ryerson University by Hossain et al. (2014) was used. A total of twelve composite slab specimens were tested with two types of profiled steel sheets (designated as P3623 and P2432) and two types of concrete (ECC and SCC). SCC and ECC composite slabs prepared with P-3623 steel deck (as shown in Figure 3.1a) was selected to perform the nonlinear FE modeling. The dimensions of ECC and SCC composite slabs are $1800 \mathrm{~mm}$ (length) x $960 \mathrm{~mm}$ (width) x 100 $\mathrm{mm}$ (depth). Of the total slab depth, $49 \mathrm{~mm}$ is the depth of the concrete and $51 \mathrm{~mm}$ is the height of the steel deck. The supports for the composite slabs were located $150 \mathrm{~mm}$ away from the span ends, and the monotonic loading was applied in the form of four-point bending test. Figures 3.1(a-b) provide detail dimensions of the chosen composite P-3623 steel deck slabs chosen for FE modelling.

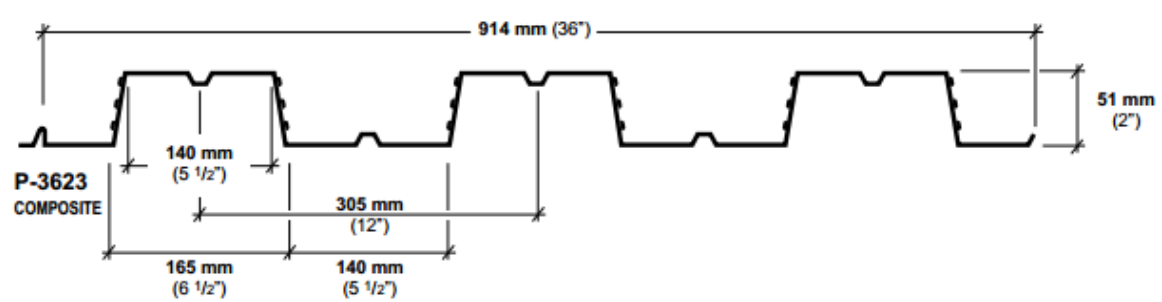

(a)

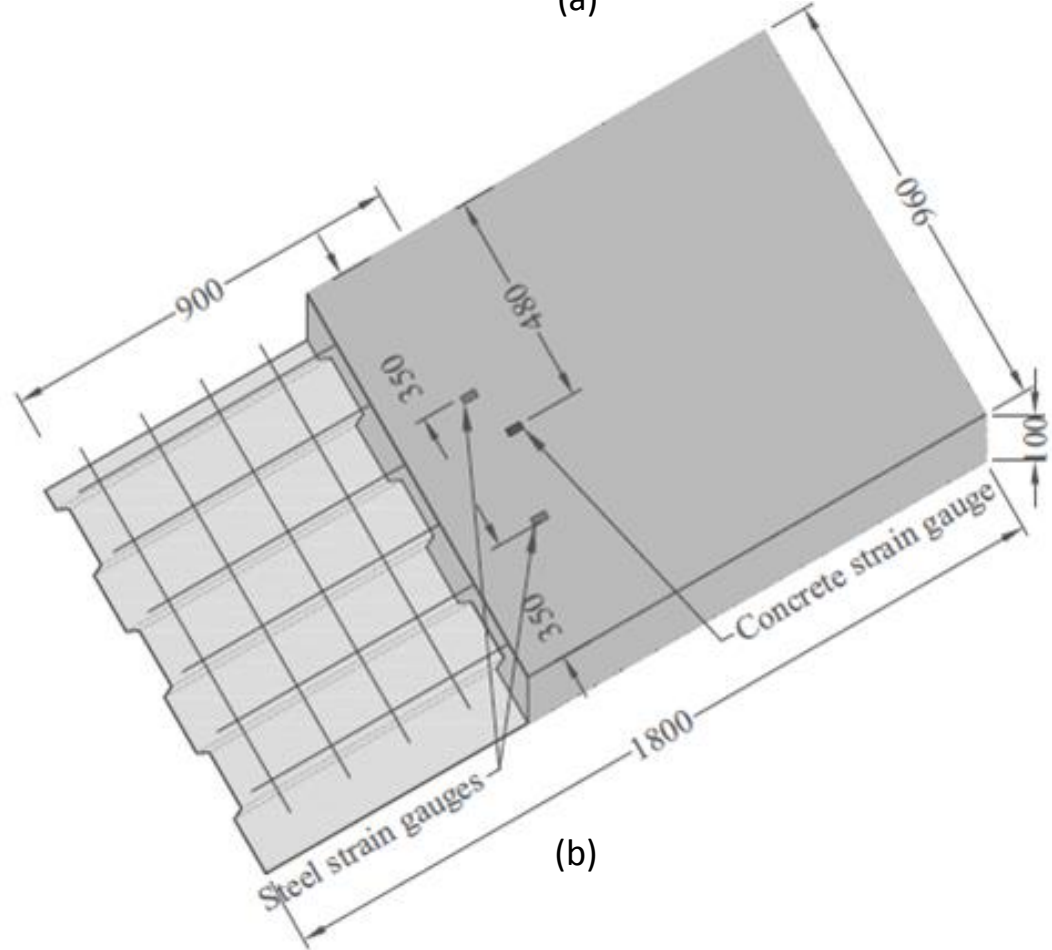

Figure 3.1: (a) Dimensions of P-3623 steel deck (Canam Group 2006), (b) 3D model of composite-3623 steel deck slab (Hossain et al. 2014) 


\subsection{Material Properties}

In reference to Hossain et al. (2014), two concrete mixtures were used for the composite slabs - a Ryerson produced green Engineered Cementitious Composite (ECC) and a commercial Self-Consolidating Concrete (SCC) produced by King Packaged Materials. ECC was composed of PVA fibers ( $8 \mathrm{~mm}$ length and diameter of $39 \mu \mathrm{m}$ diameter), local mortar sand (instead of silica sand), Portland cement, fly ash (as $55 \%$ replacement of cement content), admixtures and water-to-binder ratio of 0.27. KING SCC is a pre-blended, pre-packaged, high performance, flowable concrete material containing Portland cement, silica fume, 10 $\mathrm{mm}$ stone and other selective admixtures (KING MS-S10 SCC, 2014). KING SCC is designed with natural normal-density non-reactive fine and coarse aggregates to eliminate the potential of generating alkaliaggregate reactivity (AAR). The strength properties of the selected ECC and commercial SCC, determined from control specimens at the age of testing (at 28 days) of composite slabs, as per ASTM Standards (ASTM C39 2012; ASTM C78 / C78M 2010) are presented in Table 3.1.

Table 3.1: Concrete strength properties

\begin{tabular}{|l|c|c|}
\hline Specimen & $\begin{array}{c}\text { Cylinder Concrete } \\
\text { strength }\left(f^{\prime} c\right)(\mathrm{MPa})\end{array}$ & $\begin{array}{c}\text { Flexural strength } \\
(\mathrm{MPa})\end{array}$ \\
\hline P3623-ECC & 66 & 6.2 \\
\hline P3623-SCC & 56 & 4.8 \\
\hline
\end{tabular}

\subsection{Test Results: Load-deflection Behaviour}

According to Hossain et al. (2014), Figure 3.2 presents the load-deflection responses of six of the total twelve composite slabs selected for FE modeling. Figure 3.2a and 3.2b, each presents three loaddeflection curves for ECC and SCC composite slab with Canam composite P-3623 steel deck, respectively. ECC and SCC composite slabs were loaded to failure at three different shear span distances $-300 \mathrm{~mm}, 450$ $\mathrm{mm}$, and $600 \mathrm{~mm}$. These experimental curves were used to develop FE models presented in Chapter 6. The accuracy and performance of FE models were tested by comparing FE based load-deflection responses with those obtained from experiments. 


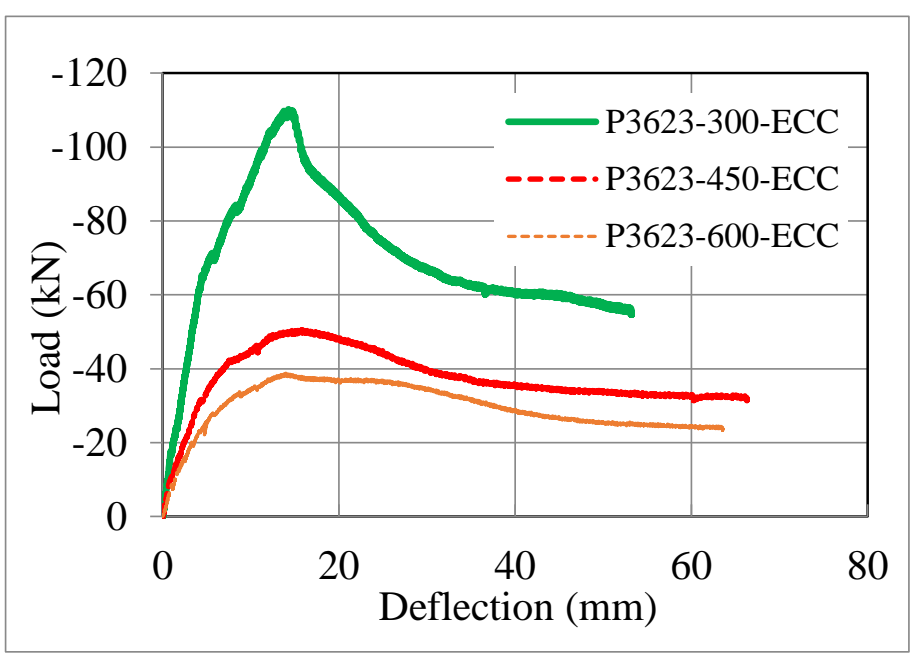

(a)

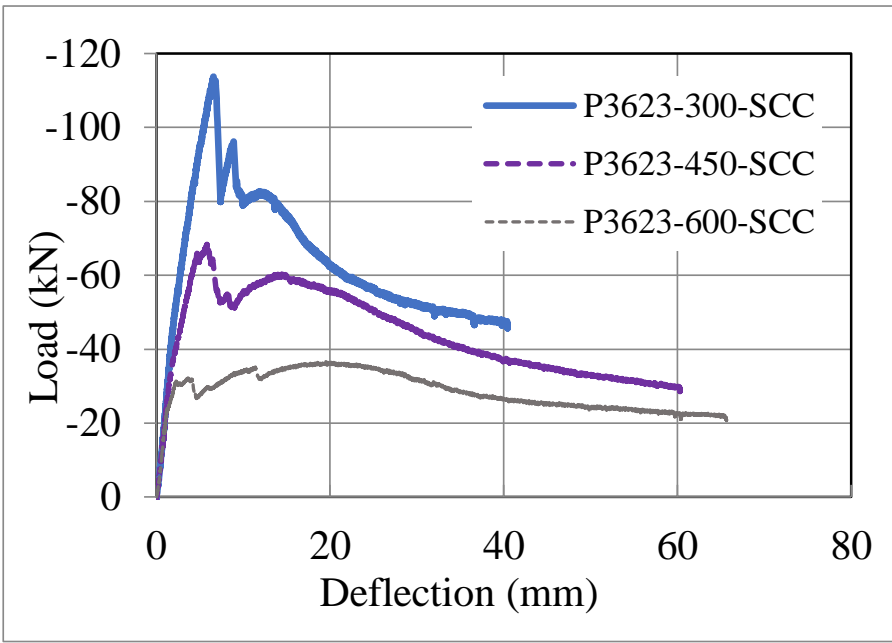

(b)

Figure 3.2: Load-deflection response of composite specimens with variable shear spans (a) P3623-ECC and (b) P3623-SCC (Hossain et al. 2014)

\subsection{Summary}

In this chapter, the experimental load-deflection results for six composite slab specimens tested under monotonic loading are presented. Summary of the key experimental results used to validate the nonlinear finite element models of ECC and SCC composite slabs are presented in Table 3.2.

Table 3.2: Summary of experimental results for monotonic loading

\begin{tabular}{|c|c|c|c|c|}
\hline Type of Composite Slab & Shear Span $(\mathrm{mm})$ & 300 & 450 & 600 \\
\hline \multirow{3}{*}{ P3623-ECC } & Ultimate Load $(\mathrm{kN})$ & 110.20 & 50.54 & 38.77 \\
\cline { 2 - 5 } & Mid-span Displacement $(\mathrm{mm})$ & 14.27 & 15.83 & 14.00 \\
\hline \multirow{3}{*}{ P3623-SCC } & Ultimate Load $(\mathrm{kN})$ & 113.75 & 68.43 & 36.66 \\
\cline { 2 - 5 } & Mid-span Displacement $(\mathrm{mm})$ & 6.58 & 5.82 & 3.51 \\
\hline
\end{tabular}




\section{CHAPTER 4 - FINITE ELEMENT MODELING OF COMPOSITE SLAB SUBJECTED TO MONOTONIC LOADING}

\subsection{Introduction}

Finite element (FE) analysis of composite slab was executed to develop models based on the experimental results. The primary objective was to develop reliable three-dimensional finite element (FE) model which can simulate the behaviour of ECC and SCC composite slabs subjected to monotonic loading. In this research, the model was developed using ABAQUS/CAE (Dassault Systèmes Simulia Corp. 2013).

\subsection{General Overview of ABAQUS/CAE}

ABAQUS/CAE provides a collaborative graphical environment that allows for simple modeling and generating complex geometry into optimized mesh regions. Material properties, loads, and boundary conditions can be discretely assigned to the geometry. ABAQUS/Standard and ABAQUS/Explicit are the two main types of analysis products in this software. Of which, ABAQUS/Standard is used for generalpurpose analysis that solves a system of equations implicitly at each result increment. It is capable of resolving an inclusive range of linear and nonlinear problems including static, dynamic, thermal, and electrical response of elements. ABAQUS/Explicit is a distinct-user analysis module that uses an explicit dynamic integration without the requirement of having equations of motion solved at each time increment. Table 4.1 provides a brief comparison between ABAQUS/Standard and ABAQUS/Explicit which was excerpted from the ABAQUS manual (Dassault Systèmes Simulia Corp. 2013).

Table 4.1: Major differences between ABAQUS/Standard and ABAQUS/Explicit (Dassault Systèmes Simulia Corp. 2013)

\begin{tabular}{|l|l|l|}
\hline Parameter & ABAQUS/Standard & ABAQUS/Explicit \\
\hline Element Library & Offers an extensive element library & $\begin{array}{l}\text { Offers an extensive library of } \\
\text { elements well suited for explicit } \\
\text { analyses. The element available in } \\
\text { ABAQUS/Standard }\end{array}$ \\
\hline $\begin{array}{l}\text { Analysis } \\
\text { procedures }\end{array}$ & $\begin{array}{l}\text { General and linear perturbation procedures } \\
\text { are available }\end{array}$ & General procedures are available \\
\hline Material models & Offers a wide range of material models & $\begin{array}{l}\text { Similar to those available in } \\
\text { ABAQUS/Standard; a notable } \\
\text { difference is that failure material } \\
\text { models are allowed }\end{array}$ \\
\hline
\end{tabular}




\begin{tabular}{|l|l|l|}
\hline $\begin{array}{l}\text { Contact } \\
\text { formulation }\end{array}$ & $\begin{array}{l}\text { Has a robust capability for solving contact } \\
\text { problems }\end{array}$ & $\begin{array}{l}\text { Has a robust contact functionality } \\
\text { that readily solves even the most } \\
\text { complex contact simulations }\end{array}$ \\
\hline Solution technique & $\begin{array}{l}\text { Uses a stiffness-based solution technique } \\
\text { that is unconditionally stable }\end{array}$ & $\begin{array}{l}\text { Uses an explicit integration solution } \\
\text { technique that is conditionally stable }\end{array}$ \\
\hline $\begin{array}{l}\text { Disk space and } \\
\text { memory }\end{array}$ & $\begin{array}{l}\text { Due to the large numbers of interactions } \\
\text { possible in an increment, disk space and } \\
\text { memory usage can be large }\end{array}$ & $\begin{array}{l}\text { Disk space and memory usage is } \\
\text { typically much smaller than that for } \\
\text { ABAQUS/Standard }\end{array}$ \\
\hline
\end{tabular}

The Finite Element Analysis (FEA) for this study was conducted using ABAQUS/Explicit mainly to enhance the following performance aspects:

- To avoid the convergence difficulties in ABAQUS/Standard (implicit) program which progressively develops due to the concrete degradation

- Using ABAQUS/Explicit reduces the computational time for the three-dimensional composite slab model

- It is efficient in modeling non-linear dynamic events with contact interaction and discontinuous geometrical or material responses.

\subsubsection{Quasi-Static Analysis with ABAQUS/Explicit}

The explicit solution is a true dynamic process that was originally established to model high-speed impact events with inertia serving as a main criterion in the solution. When applying quasi-static simulations using explicit dynamics, it is computationally impractical to analyze the model in its natural time scale. As it would require the use of large number of small time increments, the most feasible solution can be obtained by accelerating the analysis time. In this study, the following two techniques were used to simulate the quasi-static condition in the monotonic loading:

1.) Smooth amplitude curves: To achieve highly accurate and efficient results in quasi-static analyses the gradual application of displacement produces a smooth change in slope of velocity and acceleration. Instantaneous loading can cause the buildup of stress waves throughout the model, which can produce noisy or inaccurate solutions, as demonstrated in the parametric study comparison in Chapter 6. To apply the displacement in the smoothest possible manner requires the change in displacement to remain as a small amount in-between two increments. This is automatically achieved in ABAQUS/CAE with the built-in smooth step amplitude curve that efficiently commends the displacement in a quasi-static condition. 
2.) Loading rates: The time step used in the developed composite slab FE models was one second. It is practical to assume that performing an analysis within the duration of actual time required for a quasi-static process will produce accurate static results. As illustrated in Chapter 6, a series of analyses at varying displacement and load rates was performed to determine a reasonable displacement rate.

\subsection{Material Properties}

\subsubsection{Concrete Model}

ABAQUS/CAE Version 6.13-3 consists of three different models to simulate the concrete behaviour; the smeared cracking model, brittle cracking model, and the concrete damaged plasticity model (Dassault Systèmes Simulia Corp. 2013). Each of these model types have their application limitations and can serve effectively for only certain types of structures and loading conditions.

\subsubsection{Concrete Damage Plasticity}

The Concrete Damage Plasticity (CDP) (Lubliner et al. 1989, and Lee et al. 1998) is the most comprehensive continuum model that was used in the composite slab simulation to define concrete behaviour in this analysis. The CDP model is applicable to concrete that is subjected to monotonic loading for different types of structures (such as beams, trusses, shells, and solids) and it is developed based on two concrete failure mechanisms: compressive crushing and tensile cracking. For this study, the model had used isotropic damaged elasticity in correlation with isotropic compressive and tensile plasticity to characterize the inelastic nature of the concrete. Modeling more than one interaction with concrete can be difficult in ABAQUS/CAE. Thus for the simplicity of FE model analysis, the effect of including reinforcement was taken into consideration by introducing some "tension stiffening" into the composite slab modeling to simulate the load transfer across cracks through the rebar. The rebars in the composite slab mainly serve as positive reinforcement because the profiled steel sheet is the main element that provides tensile resistance. The response of concrete in compression and tension was modeled based on the guidelines described in the ABAQUS user manual (Dassault Systèmes Simulia Corp. 2013). 


\subsubsection{Concrete Behaviour in Tension and Compression}

For concrete subjected to uniaxial loading, the stress-strain response of concrete in tension exhibits a linear elastic relationship until the failure stress is achieved and beyond that point the concrete follows the softening stress-strain behaviour. When the concrete is unloaded at any point from within the strainsoftening portion of the curve, the unloading response is weakened and the elastic stiffness of concrete is damaged. This deterioration of the stiffness is defined by damage parameter in tension $(\mathrm{dt})$, which can range from zero, representing the undamaged condition of the specimen, to one, which signifies that the material has lost its total strength. Figure 4.1 illustrates the concrete behaviour in tension, when subjected to uniaxial loading.

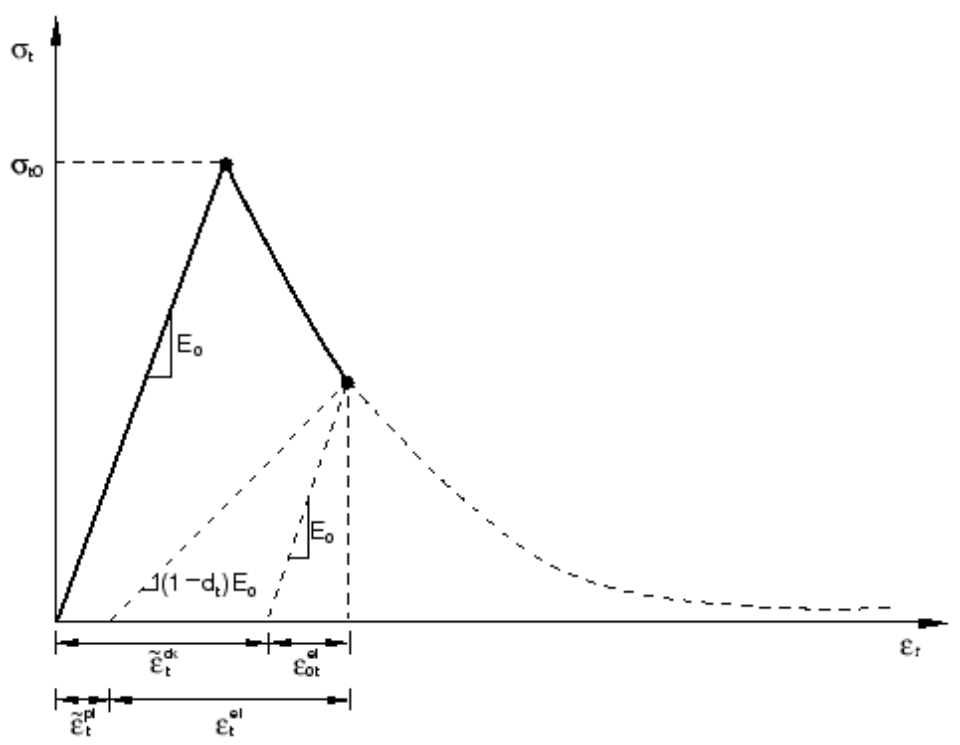

Figure 4.1: Stress-strain response of concrete in tension subjected to uniaxial loading in ABAQUS (Dassault Systèmes Simulia Corp. 2013)

The cracking strain $\left(\bar{\varepsilon}_{t}^{c k}\right)$ is calculated by ABAQUS as the difference between the total strain $\left(\varepsilon_{t}\right)$ and the elastic strain that corresponds to the undamaged material; given as Eq. 4.1:

$\bar{\varepsilon}_{t}^{c k}=\varepsilon_{t}-\sigma_{t} / E_{o}$

In this equation, $\sigma_{t}$ is the tensile stress and $E_{o}$ is the initial elastic stiffness of concrete. Tension stiffening data values are provided in terms of the cracking strain, $\bar{\varepsilon}_{t}^{c k}$. The unloading data are inputted in ABAQUS with tension damage curves $\left(d_{t}\right.$ versus $\left.\bar{\varepsilon}_{t}^{c k}\right)$. ABAQUS/CAE automatically converts the cracking strain data to plastic strain $\left(\bar{\varepsilon}_{t}^{p l}\right)$ using the following Eq. 4.2: 
$\bar{\varepsilon}_{t}^{p l}=\bar{\varepsilon}_{t}^{c k}-\frac{d_{t}}{\left(1-d_{t}\right)} \frac{\sigma_{t}}{E_{o}}$

Figure 4.2 draws a comparison between the defined tensile behaviour of SCC and ECC concrete damage plasticity model. As illustrated, the maximum yield stress for ECC is $6.2 \mathrm{MPa}$, while SCC has a yield stress capacity of 4.8 MPa. The key difference is the cracking strain of these two types of high-performance concretes. SCC tensile cracking strain represents strain factor of 1.0, based on which, the ECC tensile cracking strain values was determined as strain increment factor 2.0 to achieve the desired nonlinear FE load-deflection response, while simulating behaviour that accounts for ECC post-stiffening due to fibers. After conducting the parametric study, as presented in Chapter 6, on the effect of strain increment factor on the ECC composite slab behaviour, it was observed that the using strain multiplication factor of 2.0 provided the most feasible ECC concrete response that reasonably correlated with the experimental results.

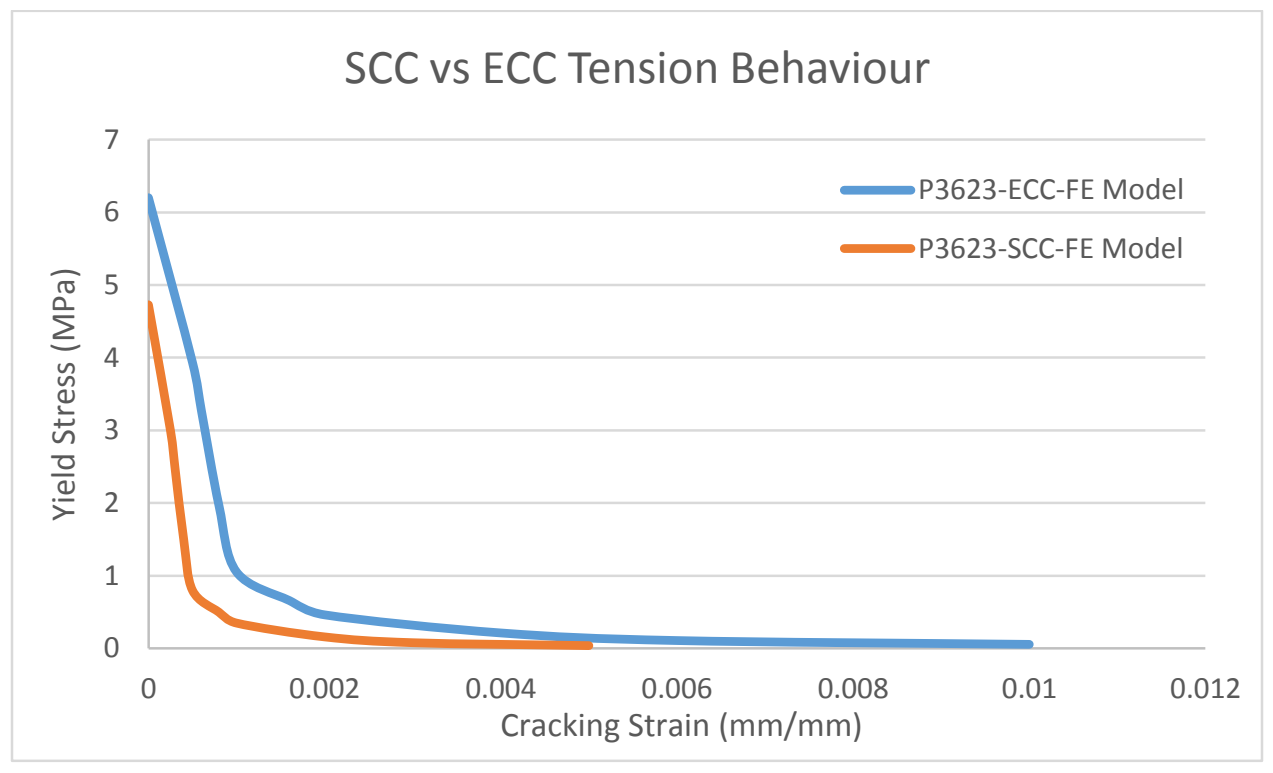

Figure 4.2: P3623-ECC and P3623-SCC concrete tension response

Under uniaxial loading, the concrete response in compression is linear until the initial yield stress $\left(\sigma_{c 0}\right)$ value is reached. In the plastic region, the characterization of concrete behaviour is typically initiated with stress hardening and then followed by strain softening beyond the ultimate stress $\left(\sigma_{c u}\right)$ value. Similar to concrete behaviour in tension, the weakened elastic stiffness of concrete in compression is characterized with damage parameter $(\mathrm{dc})$ for the equivalent scale ranging from zero to one. Figure 4.3 illustrates the concrete behaviour in compression when it is subjected to uniaxial loading. 


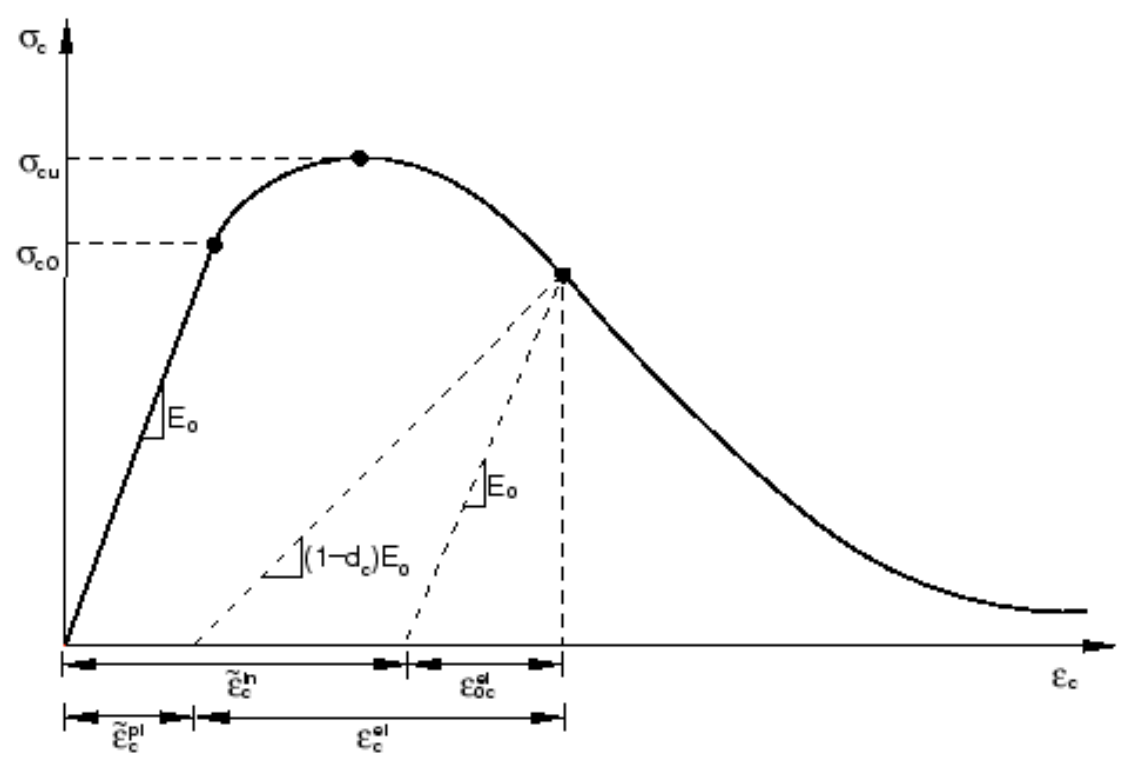

Figure 4.3: Compression stress-strain response of concrete subjected to uniaxial loading in ABAQUS (Dassault Systèmes Simulia Corp. 2013).

Compressive yield stress values are provided in ABAQUS as a tabular function of inelastic or crushing $\operatorname{strain}\left(\tilde{\varepsilon}_{c}^{i n}\right)$. The input of compressive stress and strain values are required to be positive (absolute) values. The compressive hardening data are provided in terms of inelastic $\operatorname{strain}\left(\tilde{\varepsilon}_{c}^{i n}\right)$, rather than plastic strain $\left(\tilde{\varepsilon}_{c}^{p l}\right)$, which is determined as the difference between the total strain and the elastic strain that corresponds to undamaged material as provided in Eq. 4.3:

$\tilde{\varepsilon}_{c}^{i n}=\varepsilon_{c}-\sigma_{c} / E_{o}$

In this equation, $E_{o}$ represents the elastic stiffness of concrete. The unloading concrete information is provided to ABAQUS in the form of compressive damage curves $\left(d_{c}\right.$ versus $\left.\tilde{\varepsilon}_{c}^{i n}\right)$. Similar to the tension behaviour, ABAQUS also automatically converts the inelastic strain into plastic strain $\left(\tilde{\varepsilon}_{c}^{p l}\right)$ using the following Eq. 4.4:

$\tilde{\varepsilon}_{c}^{p l}=\tilde{\varepsilon}_{c}^{i n}-\frac{d_{c}}{\left(1-d_{c}\right)} \frac{\sigma_{c}}{E_{o}}$

The stress-strain curve past the ultimate stress value is defined as strain-softening regime, due to which ABAQUS cannot model ECC, as it requires the strain hardening to progressively develop as the ultimate stress value is reached. Thus, to obtain this anticipated ECC post-failure response it is vital to modify the "Concrete Damage Plasticity" model subroutine in ABAQUS, which can be the subject matter of future research on nonlinear finite element modeling of ECC composite slab. 
Figure 4.4 illustrates two different compression responses that were used to define the "Concrete Damage Plasticity" model for ECC and SCC finite element model. ECC composite slab demonstrates superior compression response due its higher compressive strength capacity of $66 \mathrm{MPa}$ in comparison to SCC with a strength of $56 \mathrm{MPa}$. As observed, the inelastic strain values for ECC in compression is taken as strain increment of 1.1 in comparison to SCC because significant increase in the compressive strain did not produce reasonable variability in finite element results for ECC composite slab. Moreover, as $56 \mathrm{MPa}$ is relatively high compressive strength for SCC, therefore the compression response was also enhanced.

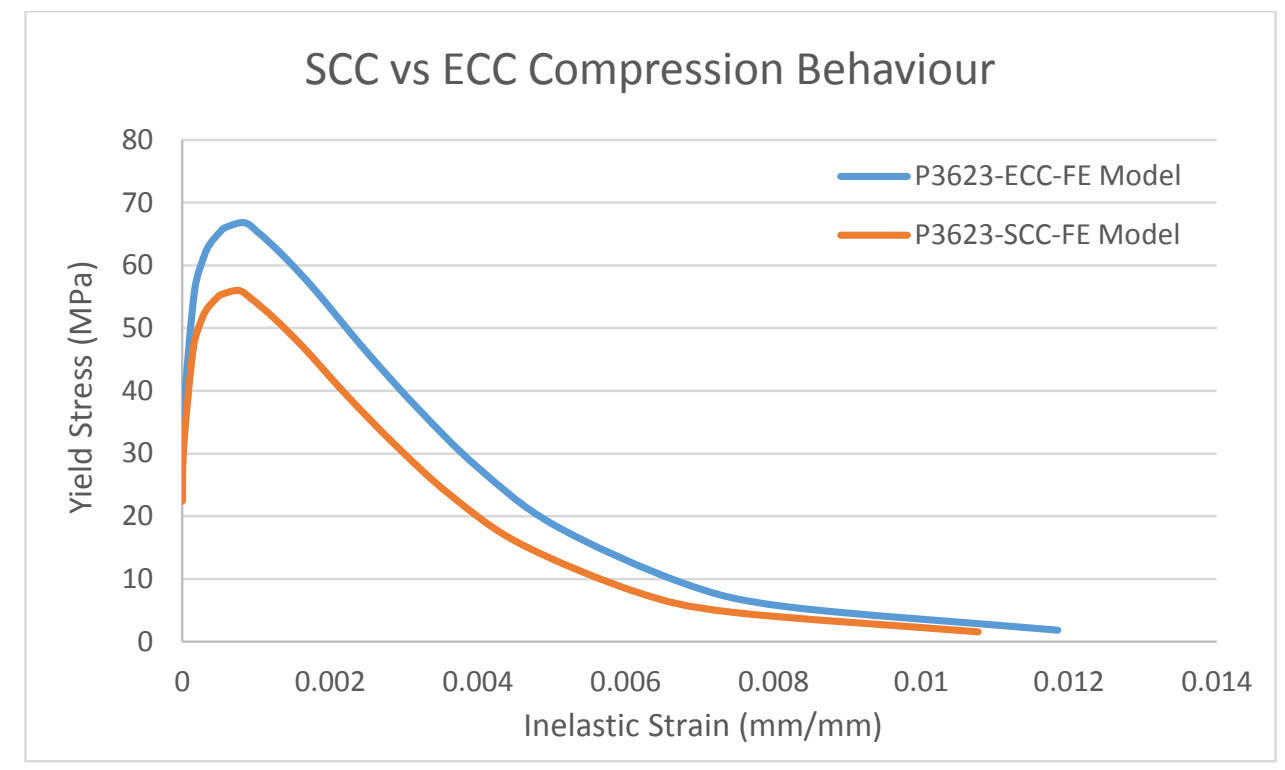

Figure 4.4: P3623-ECC and P3623-SCC concrete compression response

\subsubsection{Steel Model}

ABAQUS/CAE uses true (Cauchy) stress and logarithmic strain to perform the finite element analysis of steel, which can be derived from the tensile coupon test results. The following two equations, Eq. 4.5 and Eq. 4.6, derived by Lubliner (1990) were used in this research study to determine the true stress $\left(\sigma_{\text {true }}\right)$ and logarithmic plastic $\operatorname{strain}\left(\varepsilon_{l n}^{p l}\right)$ :

$\sigma_{\text {true }}=\sigma_{\text {nom }}\left(1+\varepsilon_{\text {nom }}\right)$

$\varepsilon_{l n}^{p l}=\ln \left(1+\varepsilon_{\text {nom }}\right)-\frac{\sigma_{\text {true }}}{E}$ 
In the provided equations, $\sigma_{\text {nom }}$ represents the nominal stress, $\varepsilon_{\text {nom }}$ is the nominal strain, and $E$ represents the modulus of elasticity. Figure 4.5 illustrates the plastic behaviour of the composite P-3623 steel deck that was used in ABAQUS to define the yield stress and plastic strain tabular data.

For specifying the initiation of plastic flow in the state of multi axial stress in ABAQUS/Explicit, the VonMises yield surface criterion was utilized. For monotonic loading in ABAQUS, isotropic hardening model was specified, which generated a yield surface that exhibited uniform changes in size with respect to each direction such that the yield stress increases (or decreases) as the plastic strain develops in all stress directions (Davis and Selvadurai 2002).

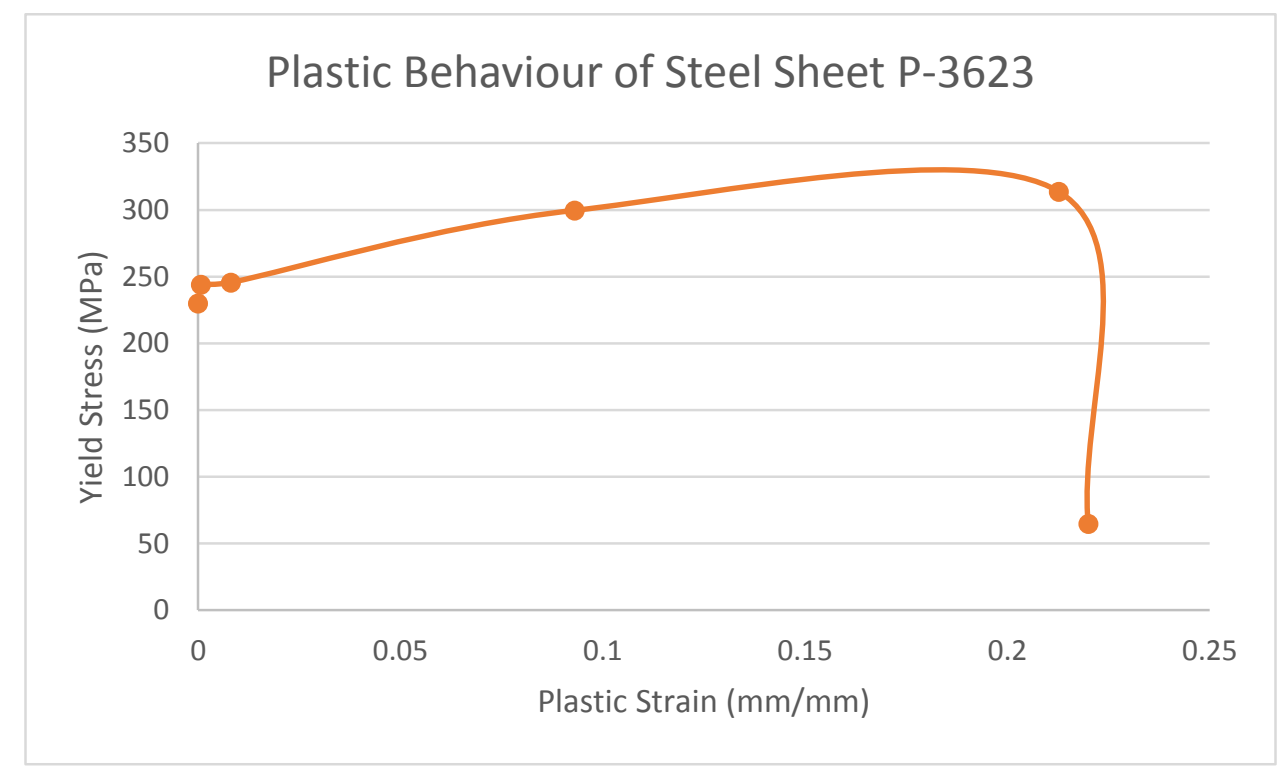

Figure 4.5: Canam composite P-3623 steel deck plastic response

For ABAQUS FE model, the provided Table 4.2 presents defined material properties for the two parts of the FE model, which are the profiled concrete and steel deck. 
Table 4.2: ABAQUS concrete and steel material characterization

\begin{tabular}{|c|c|}
\hline Property & Value \\
\hline Part 1 : Concrete & $\begin{array}{l}\text { Modeling Space: 3D } \\
\text { Type: Deformable } \\
\text { Shape: Solid, Homogenous } \\
\text { Type: Extrusion } \\
\text { Approximate size: } 1000\end{array}$ \\
\hline Part 2: Steel Sheeting & $\begin{array}{l}\text { Modeling Space: 3D } \\
\text { Type: Deformable } \\
\text { Shape: Shell, Homogenous } \\
\text { Type: Extrusion } \\
\text { Approximate size: } 1000\end{array}$ \\
\hline
\end{tabular}

\begin{tabular}{|l|l|}
\hline Concrete Properties & Value \\
\hline Density & $2400 \mathrm{~kg} / \mathrm{m}^{3}$ \\
\hline Young's Modulus & $30 \mathrm{GPa}\left(3 \times 10^{10} \mathrm{~Pa}\right)$ \\
\hline Poisson's Ratio & 0.2 \\
\hline Steel Sheeting Properties & Value \\
\hline Density & $7000 \mathrm{~kg} / \mathrm{m}^{3}$ \\
\hline Young's Modulus & $230 \mathrm{GPa}\left(2.30 \times 10^{11} \mathrm{~Pa}\right)$ \\
\hline Yield Stress & $230 \mathrm{MPa}\left(2.30 \times 10^{8} \mathrm{~Pa}\right)$ \\
\hline Poisson's Ratio & 0.30 \\
\hline Plastic (Residual) Strain & 0.2 \\
\hline
\end{tabular}

\subsection{Description of the FE Model under Monotonic Loading}

\subsubsection{Basic FE Model}

The basic FE model was created with the concrete and Canam composite P-3623 steel sheet defined as a solid element and shell element, respectively as shown in Figures 4.6 and 4.7. In addition to the dimensions provided within the following figures, the total slab has a depth of $100 \mathrm{~mm}$, the profiled concrete had a depth of $49 \mathrm{~mm}$ and the profiled steel sheet had the nominal thickness of $0.76 \mathrm{~mm}$ and total height of $51 \mathrm{~mm}$ (as per experimental slab). 


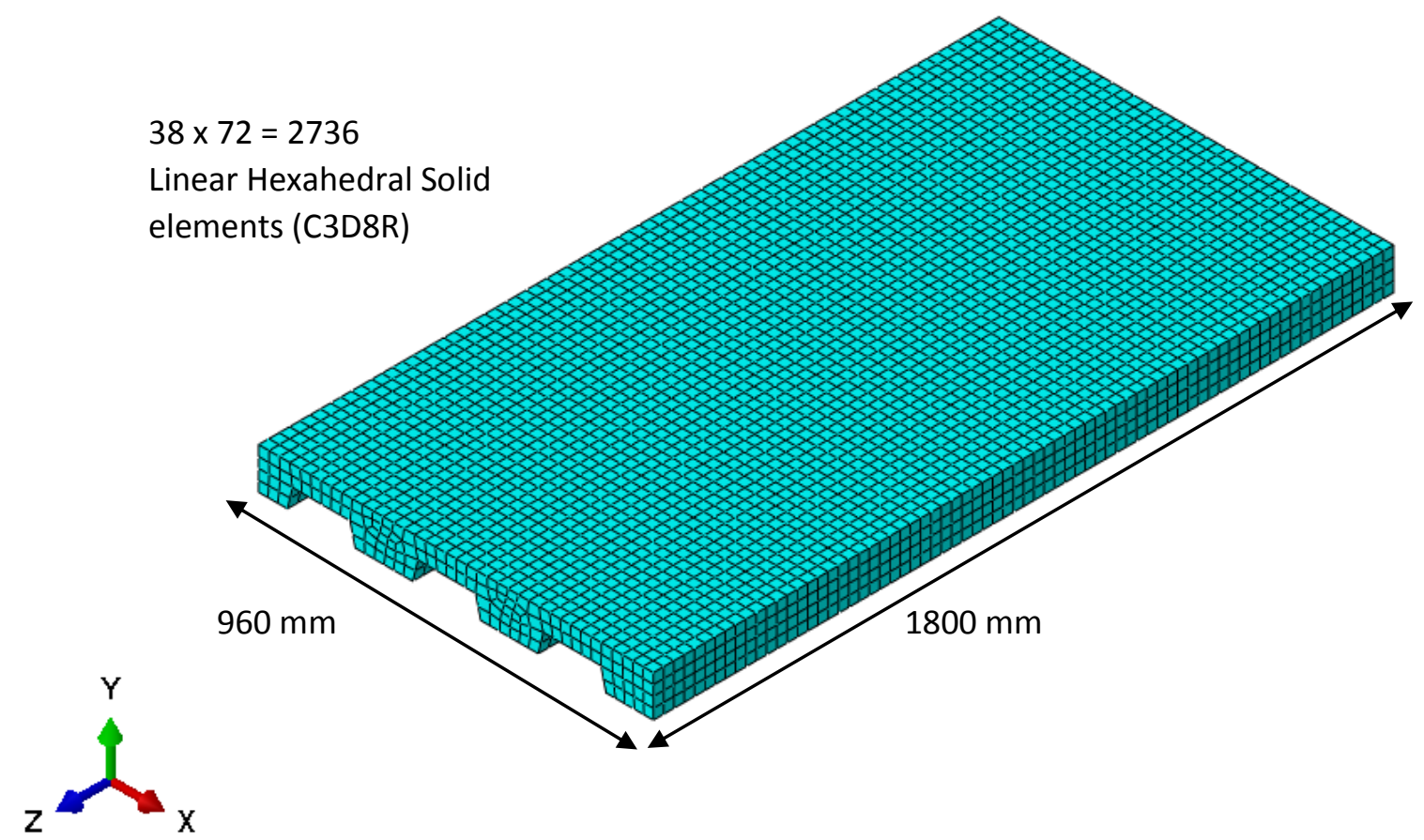

Figure 4.6: Meshing of profiled concrete using a linear 8-node brick (solid) element

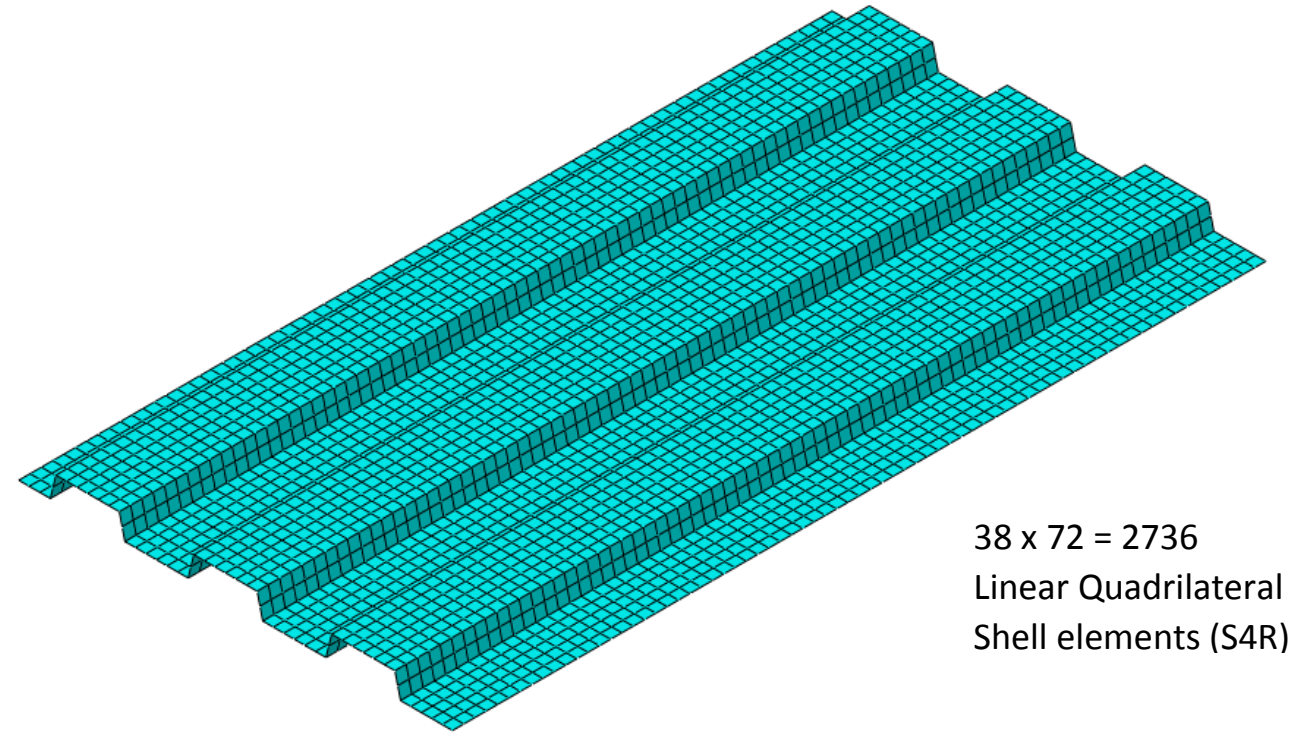

Figure 4.7: Meshing of Canam composite P-3623 steel sheet using linear 4-node shell element

In ABAQUS, the material properties for steel can be characterized as a homogeneous material. As concrete is a heterogeneous material with diversified mechanical properties, it is difficult to accurately define the concrete behaviour, thus for simplicity of FEA in this study, concrete is expressed as a homogeneous material.

The boundary conditions and prescribed transverse displacements of the composite slab are illustrated in Figure 4.8. The maximum out-of-plane deformation was applied along the depth of the slab (in Y-axis) with a linear prescribed displacement U2 (Uy) to simulate the bending deformation of the composite slab 
associated with two-point loading. At the base of the profiled steel sheet, for the left-end roller support two displacement degrees of freedom (DOF) (U1 and U2) were restrained, and for the right-end pin support three all of the three displacement degrees of freedom (DOF) (U1, U2, U3) were restrained. For simulating the FE model behaviour closest to the experimental results, the roller and pin support were placed at a distance of $150 \mathrm{~mm}$ away from the edges of the composite slab and the two-point displacement load was applied at three different shear-span distances incuding, $300 \mathrm{~mm}, 450 \mathrm{~mm}$, and $600 \mathrm{~mm}$. The uniform displacement in $Y$ direction at the top of the composite slab (as shown in Figure 4.8) was applied with an Amplitude function versus time. The Amp-1 is a function of horizontal and vertical displacement versus time, which can be defined as a smooth step tabular form in ABAQUS/CAE. The analysis was conducted with two steps defined as 'initial' and 'loading.'

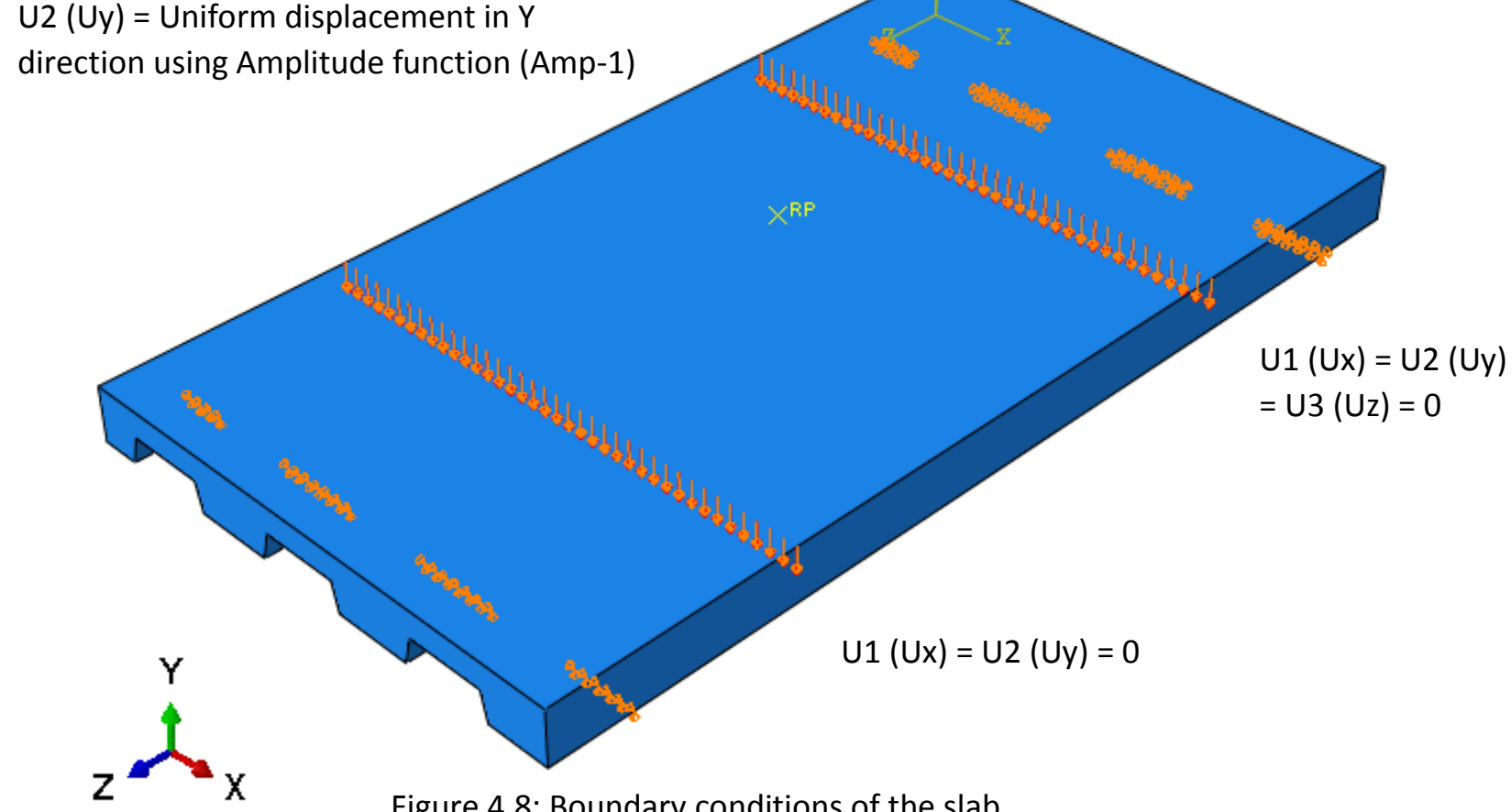

Figure 4.8: Boundary conditions of the slab

\subsubsection{Parts, Meshing, and Element Assignment}

As mentioned earlier, two parts (profiled concrete and composite P-3623 steel sheet) were created to make the finite element model of composite slab. Each of these two parts, including the meshing and assigned elements, was illustrated earlier in Figure 4.6 and Figure 4.7. These illustrations also indicate that the concrete was composed of linear hexahedral element (C3D8R) and respectively, the steel sheet was assigned the linear quadrilateral shell element (S4R). 
Generally, using reduced integration for finite element analysis reduces the accuracy of the element; however it saves the computational cost. As the focus of this study is driven with displacement-based FE formulation, more integration points were used to produce a stiff element, however, this slightly increased the difficulty level of analysis interruptions. However, as this is a non-linear FEA of composite slab, using reduced integration rather than full integration improves the behaviour simulation of the composite slab with respect to experimental. Reduced integration uses a lower-order Gaussian integration to form the element stiffness. Figure 4.9 illustrates the location of the integration points for the two linear elements that were used in this FE model.

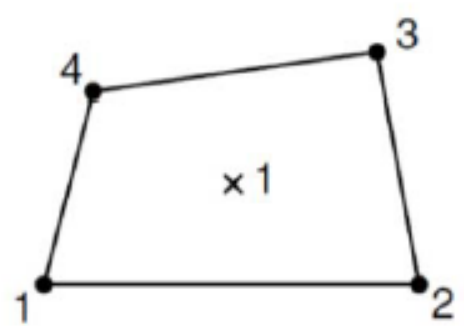

4-node reduced integration element (S4R)

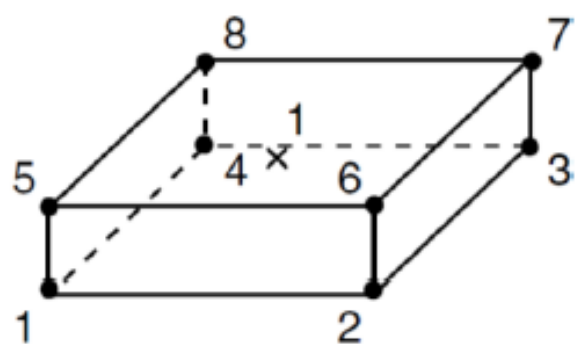

8-node reduced integration element (C3D8R)

Figure 4.9: The integration points for linear elements (Rafiei 2011)

In ABAQUS/CAE, a default amount of artificial "hourglass stiffness" is utilized in linear reduced-integration elements to restrict the development of hourglass modes in the case when a large number of elements are used in the FE model. Thus, it allows the linear reduced-integration elements to provide reliable results with the help of using reasonably finer mesh size for the model parts. A brief description of the elements that were used in this basic FE model is presented in Table 4.3. A total of 12,528 elements were utilized to generate the entire FE composite slab model, with the breakdown of 8928 elements for concrete (C3D8R) and 3600 elements for profiled steel sheet (S4R).

Table 4.3: Description of stress/displacement elements

\begin{tabular}{|c|c|}
\hline Element & Description \\
\hline $\begin{array}{c}\text { Linear Hexahedral element } \\
\text { (C3D8R) }\end{array}$ & $\begin{array}{c}\text { An 8-node linear brick element with reduced-integration and hourglass } \\
\text { control. 3D stress family with uniform strain and linear geometric order. } \\
\text { This element consists of only one integration point. }\end{array}$ \\
\hline $\begin{array}{c}\text { Linear Quadrilateral Shell } \\
\text { Element (S4R) }\end{array}$ & $\begin{array}{c}\text { A 4-node linear thick shell with reduced-integration and hourglass } \\
\text { control. Shell family with uniform finite membrane strain and linear } \\
\text { geometric order. This element consists of only single integration point. }\end{array}$ \\
\hline
\end{tabular}

Mesh refinement study was conducted in load and displacement control analyses to observe the variation in the results with changing mesh sizes, which is further discussed in Chapter 5. 


\subsubsection{Contact Surfaces}

When the profiled concrete and steel sheet surfaces are in contact with each other, it generates a normal force that acts on the two contacting bodies at the points of interaction. The interface between concrete and steel sheet was characterized with penalty friction between these two surfaces, which generated shear forces to resist the tangential sliding motion of the two parts. In ABAQUS/CAE the interaction behaviour is a distinctive property which was specified to allow the transmission of forces between the profiled concrete and steel sheet surfaces. When subjected to two-point loading conditions, it was vital to define the interaction properties such that the slip failure due to separation of two contacting surfaces was minimized. The interface contact properties between the concrete and steel sheet were defined as follows:

- To produce a friction model that enables force resisting the relative tangential motion of the surfaces in the mechanical contact analysis, the 'tangential behaviour' was specified. Friction formulation field between the contact surfaces was selected as 'penalty' to allow some relative motion of the surfaces, for a uniform friction coefficient of 0.5 the directionality of 'isotropic' was chosen. Although the input of friction coefficient in the experimental analysis was slip-rate dependent, for the simplicity of the FE model it is not included.

- The normal contact behaviour for the interface was also defined as "Hard" contact for pressureover-closure, and the "Default" constraint enforcement method was selected to enable the ABAQUS/Explicit analysis. Moreover, the separation of profiled concrete and steel sheet was prevented after these two surfaces came in contact with each other otherwise the model behaves as if no friction between the two surfaces was applicable, and thus, the two parts in the FE model do not demonstrate a composite behaviour.

The "Surface-to-surface contact" was utilized for interaction simulation in ABAQUS/Explicit, the first (master) surface was defined as concrete, and the composite P-3623 steel sheet was selected as second (slave) surface. For mechanical constraint formulation "Penalty contact method" was selected to use the penalty contact algorithm. "Finite sliding" formulation was also selected to allow any arbitrary motion of the concrete and steel sheet surfaces after slip failure between the two contacting surfaces. As a part of the parametric study, the influence of different mechanical constraint formulation and sliding formulation on the load-deflection curve was also evaluated in load control analysis. Based on which, it was learnt for a given two-point loading conditions, the Kinematic contact method with small or finite sliding formulation 
generates the lowest maximum deflection at mid-span. However, for this FE model the penalty contact method is most suitable option for modeling the interaction between the concrete and steel sheet.

The following two chapters introduce the two FE models that were developed using ABAQUS/CAE (Explicit) to analyze the behaviour of composite slab by adopting "load control analysis" and "displacement control analysis". In the first attempt, finite element analysis was performed with load control analysis. However, as further explained in Chapter 5, the load control failed to generate the expected elastic and plastic failure behaviour of the composite slab. As a result, the displacement control analysis was utilized to simulate reliable FE response, as introduced in Chapter 6. For each of the two types of analyses, the performance of the FE model was evaluated by changing multiple ABAQUS/CAE modeling parameters. 


\section{CHAPTER 5 - LOAD CONTROL FINITE ELEMENT ANALYSIS}

\subsection{Description of Model Setup}

The two-point loading was applied to the surface of the concrete by defining two sets of nodes along the entire slab width of $960 \mathrm{~mm}$ and assigned a concentrated load that was uniformly distributed over all the selected nodes in the sets. The loading was defined in the negative $Y$ direction (U2) towards the exterior concrete surface. The experimental load-deflection responses were for three different shear span locations - $300 \mathrm{~mm}, 450 \mathrm{~mm}$, and $600 \mathrm{~mm}$ away from the supports that were located $150 \mathrm{~mm}$ away from the edges of the total span length. However, for the trial of load control analysis only $300 \mathrm{~mm}$ shear span distance was modeled in ABAQUS/CAE as the results were not feasible.

The boundary conditions defined for the roller and pin support of the steel sheet, as well as the material properties and interface contact properties were kept constant variables between load control and displacement control analyses. Although the experimental study was conducted on both Engineered Cementitious Composites (ECC) and Self-Consolidating Concrete (SCC), the provided Figure 5.1 presents the load-deflection behaviour comparison between the P3623-300-ECC-Experimental and P3623-300ECC-FE Model. As a reference guideline, Table 5.1 presents the defined P3623-300-ECC-FE concrete material properties that was used to plot the load-deflection behaviour presented in Figure 5.1.

In Table 5.1, $\psi$ represents the dilation angle in the $\mathrm{p}$-q plane, $\varepsilon$ is the flow potential eccentricity, $\sigma_{b 0} / \sigma_{c 0}$ is the ratio of initial equibiaxial compressive yield stress to initial compressive yield stress, and $\mathrm{Kc}$ represents the ratio of the second stress invariant on the tensile meridian.

Table 5.1: Concrete damaged plasticity and steel sheet input parameters for P3623-300-ECC finite element model

\begin{tabular}{|c|c|}
\hline \multicolumn{2}{|c|}{ Steel } \\
\hline \multicolumn{2}{|c|}{ Plasticity } \\
\hline $\begin{array}{c}\text { Yield Stress } \\
\text { (MPa) }\end{array}$ & $\begin{array}{c}\text { Plastic Strain } \\
(\mathrm{mm} / \mathrm{mm})\end{array}$ \\
\hline 230 & 0 \\
\hline 251.3 & 0.000685 \\
\hline 232.9 & 0.008125 \\
\hline 313.2 & 0.093084 \\
\hline 251.6 & 0.21 \\
\hline
\end{tabular}




\begin{tabular}{|c|c|c|c|}
\hline \multicolumn{4}{|c|}{ Concrete Damaged Plasticity } \\
\hline \multicolumn{4}{|c|}{ Plasticity } \\
\hline$\psi$ & $\varepsilon$ & $\sigma_{b 0} / \sigma_{c 0}$ & $K c$ \\
\hline 30 & 0.1 & 1.16 & 0.667 \\
\hline \multicolumn{2}{|c|}{$\begin{array}{c}\text { Concrete Compression Behaviour } \\
\text { Concrete Compression Damage }\end{array}$} \\
\hline $\begin{array}{c}\text { Yield Stress } \\
(\mathrm{MPa})\end{array}$ & $\begin{array}{c}\text { Inelastic Strain } \\
(\mathrm{mm} / \mathrm{mm})\end{array}$ & $\begin{array}{c}\text { Damage } \\
\text { Parameter }\end{array}$ & $\begin{array}{c}\text { Inelastic Strain } \\
(\mathrm{mm} / \mathrm{mm})\end{array}$ \\
\hline 30 & 0 & 0 & 0 \\
\hline 50 & 0.0002 & 0.01 & 0.0001856 \\
\hline 60 & 0.0008 & 0.02 & 0.0007650 \\
\hline 45 & 0.0021 & 0.03 & 0.0020602 \\
\hline 30 & 0.0029 & 0.04 & 0.0028643 \\
\hline Concrete Tensile Behaviour & Concrete Tension Damage \\
\hline $\begin{array}{c}\text { Yield Stress } \\
\text { (MPa) }\end{array}$ & $\begin{array}{c}\text { Cracking Strain } \\
\text { (mm/mm) }\end{array}$ & $\begin{array}{c}\text { Damage } \\
\text { Parameter }\end{array}$ & $\begin{array}{c}\text { Cracking Strain } \\
\text { (mm/mm) }\end{array}$ \\
\hline 30 & 0 & 0 & 0 \\
\hline 0 & 0.0008 & 0.01 & 0.0002089 \\
\hline \multicolumn{2}{|c|}{} & 0.02 & 0.0005042 \\
\hline & & 0.03 & 0.0008 \\
\hline
\end{tabular}

\subsection{Impractical ABAQUS Results using Load Control}

The load-deflection response "P3623-300-ECC-FE Model" was plotted based on the results obtained from the load control analysis. This plotted curve in Figure 5.1 demonstrates that the load was gradually increased and the stiffness of the slab decreased with the increase of displacement until the peak load of $116.89 \mathrm{kN}$ (at $24.61 \mathrm{~mm}$ displacement) and then the FE model shortly failed after reaching the mid-span displacement of $31.86 \mathrm{~mm}$, which is illustrated with a cluster of points at the end of the curve. This sudden drop in the load and failure of the composite slab was observed with load control analysis possibly due to the formation of the major concrete crack. In comparison to the experimental curve, it can be concluded that by using the defined material and interaction properties was not sufficient to achieve the experimental results of ultimate peak load of $110.20 \mathrm{kN}$ at a displacement of $14.27 \mathrm{~mm}$; moreover, the similar initial stiffness for linear elastic load-deflection behaviour was not achieved for the ECC composite slab with load control analysis. After conducting an iterative model analysis by optimizing the material and contact interface properties for the profiled concrete and steel sheet, it was also learnt that the postpeak behaviour of the composite slab cannot be approximated with load control analysis due to the constant increase in load over the total duration of step time. 


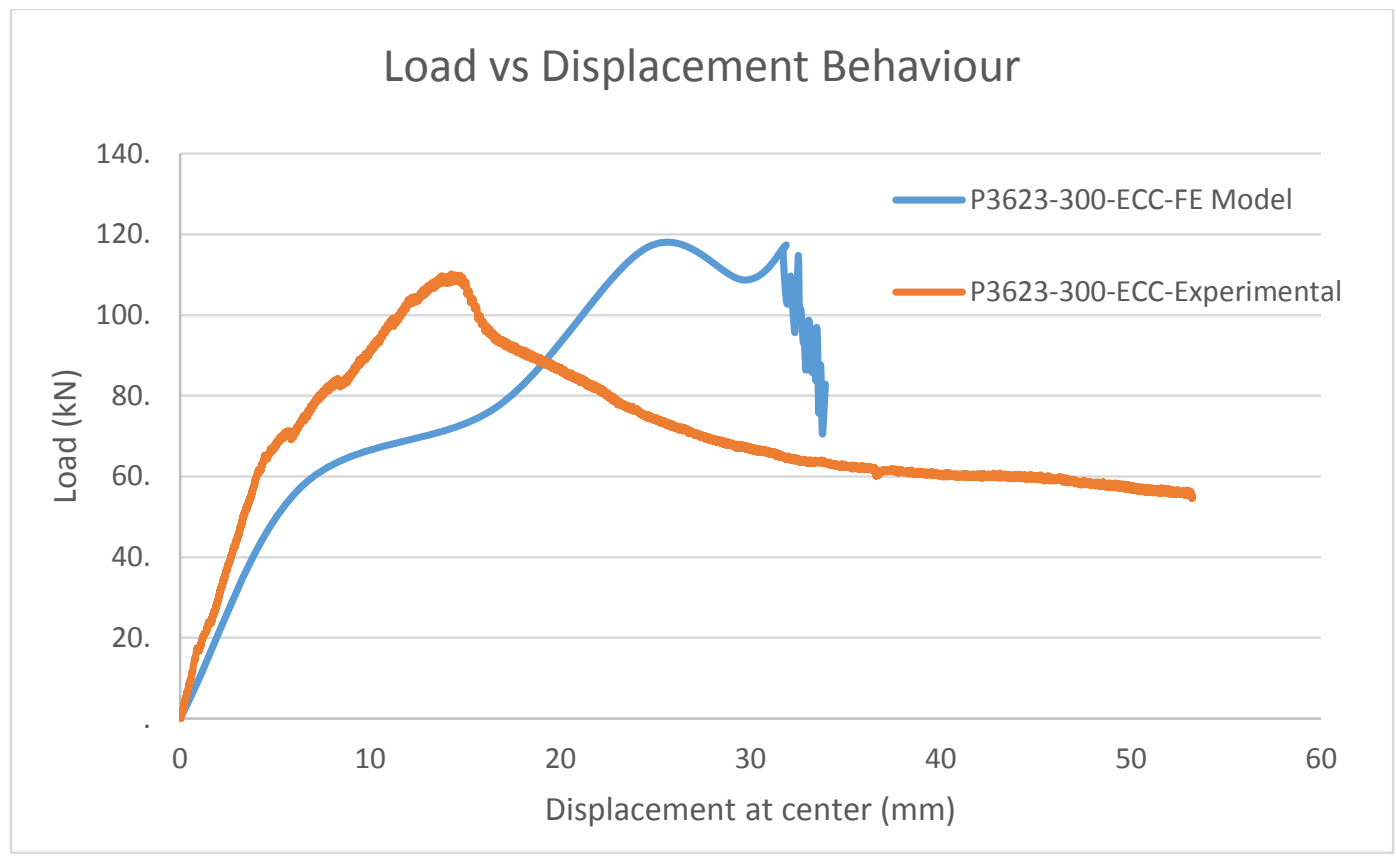

Figure 5.1: Load-deflection curve for load control analysis

In relation to the load-displacement curve presented, the following Figure 5.2 illustrates the difference between the original form and the deformed shape of that composite slab, as a response to the imposed two-point monotonic loading. Each of the two point loadings were divided into total of 78 nodes, with subdivision of 39 surface nodes across each loading width of the composite slab (along the $X$ axis). Based on the spectrum of different colour contours, it can be concluded that the dark blue region represents the maximum failure displacement which has the magnitude of $45.62 \mathrm{~mm}$. Hence, it is verified that using load control is not the best solution for controlling the maximum mid-span failure displacement or to achieve a post-failure response of composite slab, as proved in the following section.
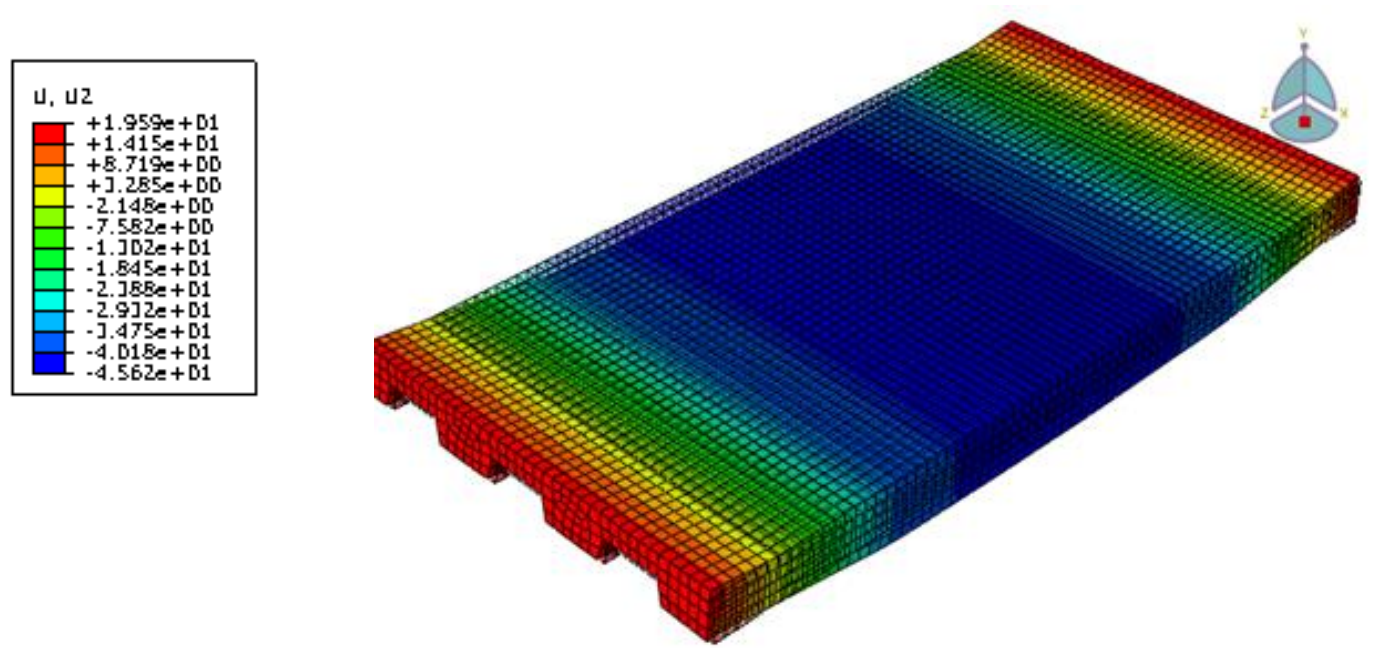

Figure 5.2: ABAQUS/Explicit load control model response to monotonic loading 


\subsubsection{Deficiency with Load Control Analysis}

The following ABAQUS output curve illustrates the "Reaction force versus step time." Based on this graphs it can be verified that the sole objective of the load control analysis is to apply the total load consistently over the total defined step time of the job. Therefore, as shown in Figure 5.3 there is no drop in the force which is crucial to identify the load at which the composite slab fails, and obtain the post-failure of loaddeflection curve. Load-control is most suitable for cyclic loading analysis or when the main objective is to determine the peak load that can be achieved by an experimental specimen. For this study, to determine the deflection response of composite slab under monotonic loading conditions, using displacement control is the most feasible analysis method.

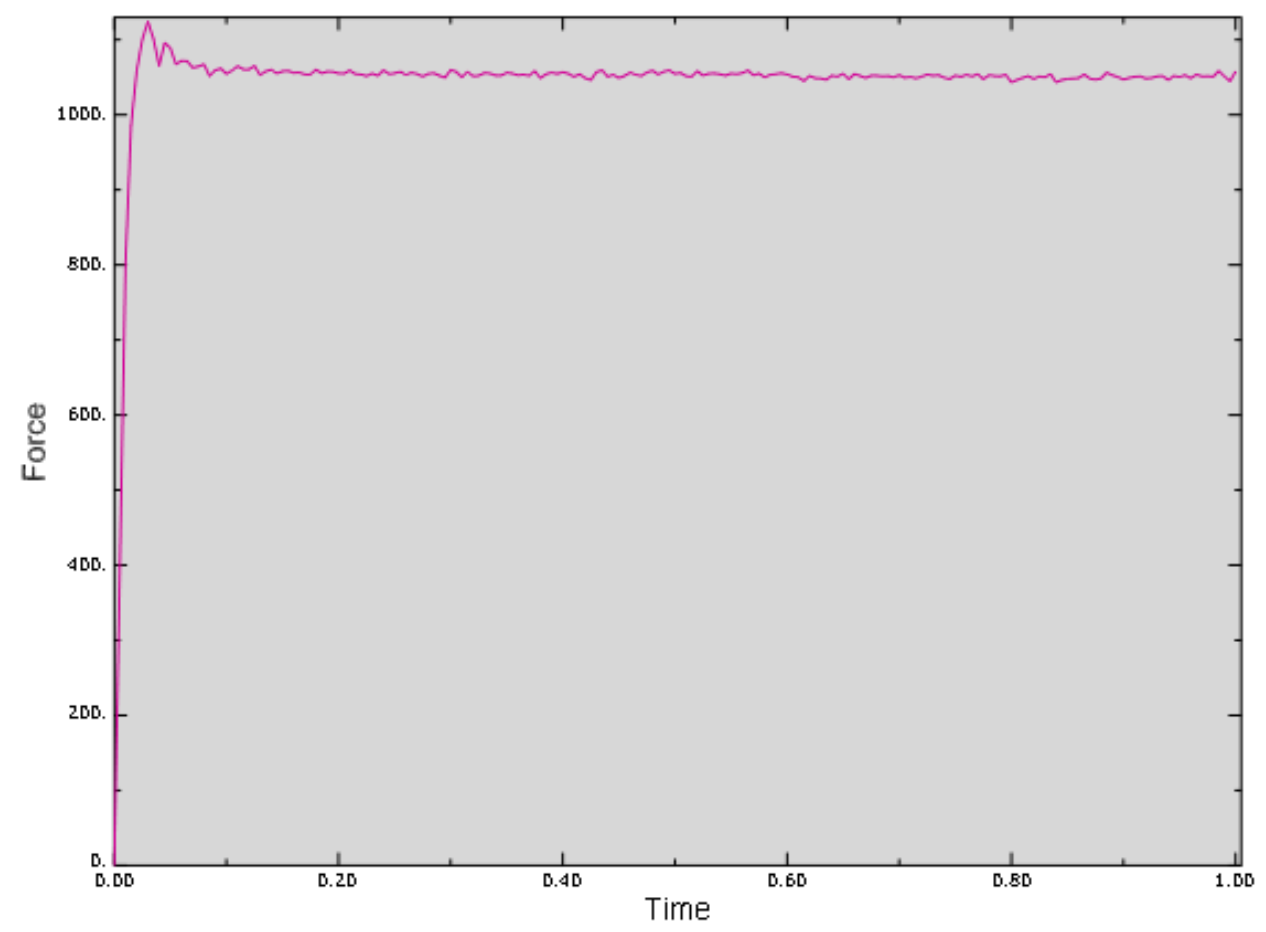

Figure 5.3: Load control - reaction force at roller support $(\mathrm{N})$ versus step time (100\%)

\subsection{Parametric Study with Load Control Analysis}

For load control analysis, the parametric investigation was performed by studying the effect of dilation angle and mesh element size on the behaviour of P3623-ECC composite slab. Based on the study of different dilation angles, the angle of 28 degrees was used to define the "Concrete Damage Plasticity (CDP)" model of ECC composite slab, and 35 degrees for SCC composite slab. Using these selected angles, reasonable simulation was achieved between the finite element and experimental slab behaviour. 
Through the investigation of different mesh element sizes, the element size of $25 \mathrm{~mm}$ was used for nonlinear finite element modeling of both P3623-SCC and P3623-ECC composite slabs with displacement control analysis, as presented in following Chapter 6 . Hence, in comparison to all mesh sizes, using $25 \mathrm{~mm}$ the simulation of load-deflection response was found to be closest to experimental curves.

\subsubsection{Influence of Dilation Angle}

Dilation angle is one of the plasticity input parameters for the concrete damage plasticity model that plays a crucial role in defining the three-dimensional surface of the concrete compression and tension damage behaviour in reference to the principal stresses axes. The defined compression yield stress with inelastic strain data table and the tension yield stress with cracking strain data table generate a 3D surface by using these plasticity parameters. If the software detects any error in producing such planes of stresses, the FE model fails to execute due to the development of negative eigenvalues. As a result of the lack of experimental material testing data, it was crucial to verify the effect of plasticity parameters on the loaddeflection response of the composite slab.

As shown in Figure 5.4, increasing the dilation angle from 20 to 25 degrees caused the reduction in the magnitude of load that can be sustained by the composite slab to generate the same amount of displacement. The default value for dilation angle is 30 degrees. However, upon increasing that value to 35 degrees, it can be concluded that although both curves are capable of withstanding the same amount of imposed load, it increased the inconsistency with the post-cracking behaviour of the composite slab, which is possibly caused due to the interface slip between concrete and profiled steel sheet. The other potential advantage of increasing the dilation angle is that it slightly reduces the maximum displacement at the mid-span of the composite slab. 


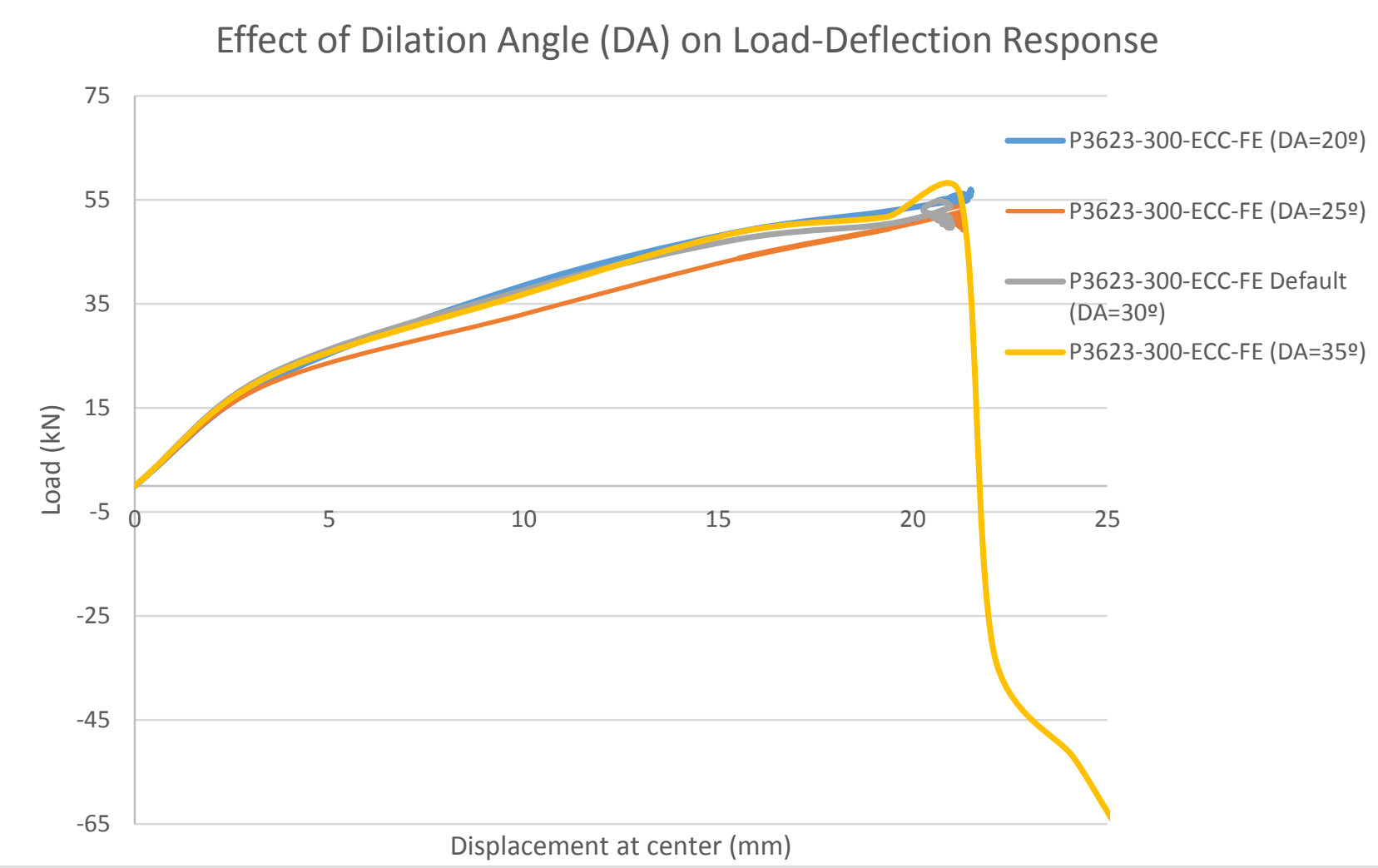

Figure 5.4: Load-deflection response for dilation angles in load control analysis

Based on the presented load-deflection curves in Figure 5.4, Table 5.2 provides a summary of the results obtained from parametric study conducted on dilation angle. The provided load and displacement ratio were calculated by using the experimental ultimate load of $110.20 \mathrm{kN}$ and mid-span displacement of 14.27 $\mathrm{mm}$. Based on the results presented in Table 5.2, it is confirmed that in order to achieve results close to experimental peak load, load control analysis is not a feasible approach as the maximum mid-span failure displacement will significantly increase and it must be controlled using displacement control analysis.

Table 5.2: Effect of dilation angle on load-deflection behaviour of P3623-ECC finite element (FE) model

\begin{tabular}{|c|c|c|c|c|c|c|}
\hline $\begin{array}{c}\text { Dilation } \\
\text { Angle }\end{array}$ & $\begin{array}{c}\text { FEA } \\
\text { Ultimate } \\
\text { Load (kN) }\end{array}$ & $\begin{array}{c}\text { Experimental } \\
\text { Load (kN) }\end{array}$ & $\begin{array}{c}\text { FEA Mid-Span } \\
\text { Displacement } \\
\mathbf{( m m})\end{array}$ & $\begin{array}{c}\text { Experimental } \\
\text { Displacement } \\
\mathbf{( m m}\end{array}$ & $\begin{array}{c}\text { Load Ratio } \\
\text { (Experimental/FEA) }\end{array}$ & $\begin{array}{c}\text { Displacement Ratio } \\
\text { (Experimental/FEA) }\end{array}$ \\
\hline 20 & 56.94 & 110.20 & 21.49 & 14.27 & 1.94 & 0.66 \\
\hline 25 & 49.48 & 110.20 & 21.31 & 14.27 & 2.23 & 0.67 \\
\hline 30 & 50.21 & 110.20 & 20.95 & 14.27 & 2.19 & 0.68 \\
\hline 35 & 55.78 & 110.20 & 28.06 & 14.27 & 1.98 & 0.51 \\
\hline
\end{tabular}




\subsubsection{Mesh Sensitivity Analysis}

In general, using finer size of mesh elements generates more accurate analyses results. It also produces more number of elements, due to which the computational cost increases with ABAQUS/CAE. However, this concept is not necessarily applicable for material such as composite slab due to the concrete softening concentration. It becomes difficult to overcome the persistent convergence problems that arise due to using smaller mesh element size. Thus, the best approach for meshing a FE model for composite slab is to use averagely small mesh element size (such as $20 \mathrm{~mm}$ ) that generates reasonably uniform mesh for the entire model. For this study, the FE model for composite slab was designed with a mesh size of $25 \mathrm{~mm}$ for both parts of the composite slab, including concrete and steel sheet, although ABAQUS suggests that using a finer mesh for the master surface improves the accuracy of the model performance. It is also recommended to use ABAQUS/Explicit to resolve the specific convergence errors that are encountered with composite specimens.

Figure 5.5 illustrates the load-deflection response of the composite slab with three different mesh element sizes of $25 \mathrm{~mm}, 35 \mathrm{~mm}$, and $50 \mathrm{~mm}$. Based on the figure, it can be concluded that mesh refinement shortens the ductile response of the composite slab. The total load of $80 \mathrm{kN}$ (divided in $40 \mathrm{kN}$ per two-point loading) was modified with respect to each of the three mesh sizes as; $2000 \mathrm{~N}$ per node for mesh size of $50 \mathrm{~mm}, 1430 \mathrm{~N}$ per node for mesh size of $35 \mathrm{~mm}$, and $1030 \mathrm{~N}$ per node for mesh size of 25 $\mathrm{mm}$. However, the failing behaviour criteria for mesh optimization with load control analysis, based on the Figure 5.5, was that the capacity of the composite slab to withstand higher load should have increased by reducing the mesh element size. However, the graph depicts the complete opposite behaviour. Thus, it can be concluded that load control analysis is not feasible to analyze the load-deflection response of the composite slab. 


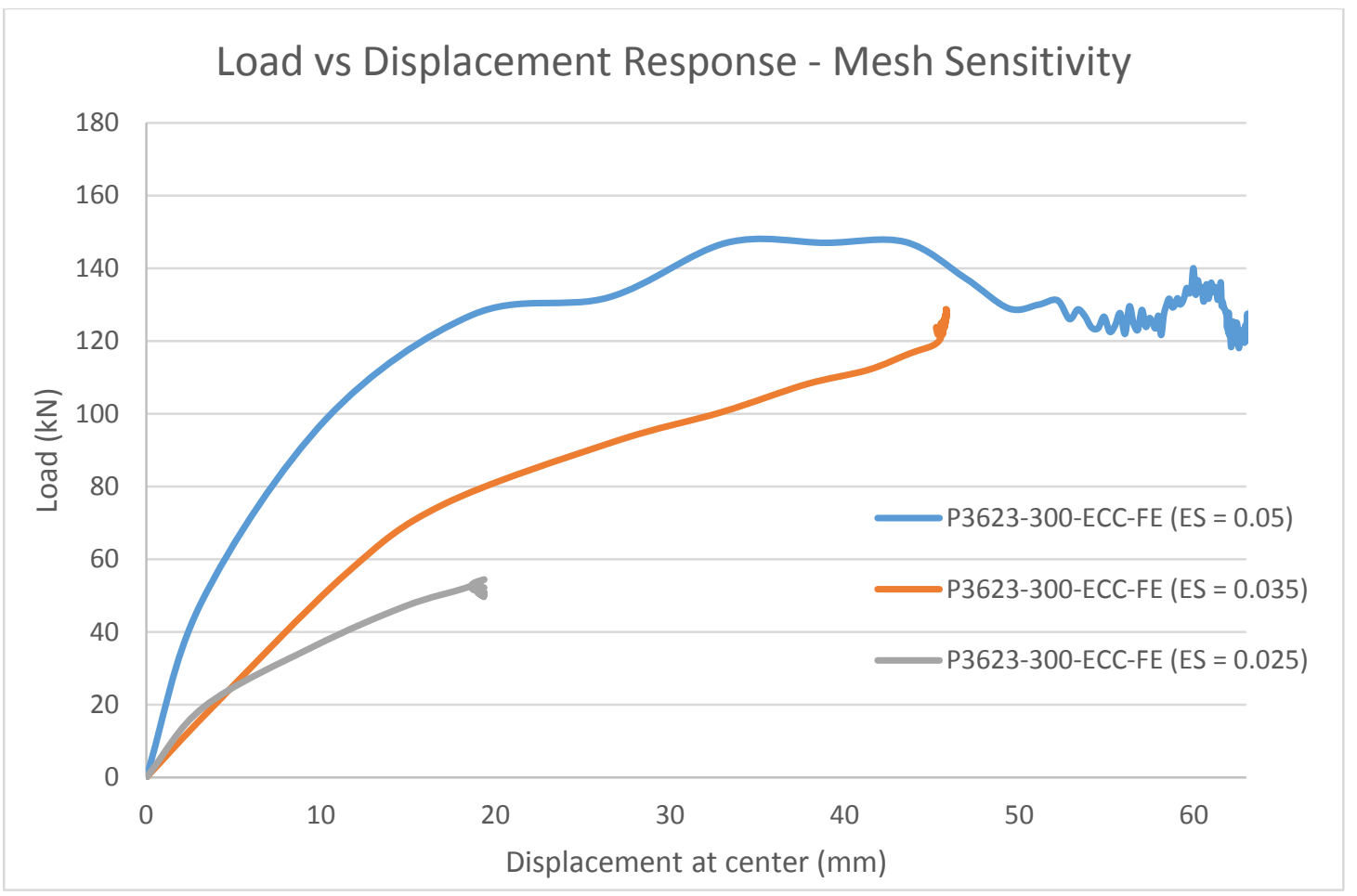

Figure 5.5: Mesh sensitivity study with load control analysis

Table 5.3 summarizes the results obtained from the parametric investigation carried out on mesh sensitivity. Similar to the previous study, the load and displacement ratio were calculated based on the experimental ultimate load of $110.20 \mathrm{kN}$ and mid-span displacement of $14.27 \mathrm{~mm}$. Table 5.3 verifies that the ultimate load capacity and failure mid-span displacement increased with the increase of mesh size in load control analysis. Table also depicts that as the mesh element size increased, the measure of accuracy between the finite element and experimental results also decreased.

Table 5.3: Effect of mesh element size (ES) on load-deflection behaviour of P3623-ECC FE model

\begin{tabular}{|c|c|c|c|c|c|c|}
\hline $\begin{array}{c}\text { Mesh } \\
\text { Element } \\
\text { Size }\end{array}$ & $\begin{array}{c}\text { FEA } \\
\text { Ultimate } \\
\text { Load } \\
\mathbf{( k N )}\end{array}$ & $\begin{array}{c}\text { Experimental } \\
\text { Load (kN) }\end{array}$ & $\begin{array}{c}\text { FEA Mid-Span } \\
\text { Displacement } \\
(\mathbf{m m})\end{array}$ & $\begin{array}{c}\text { Experimental } \\
\text { Displacement } \\
(\mathbf{m m})\end{array}$ & $\begin{array}{c}\text { Load Ratio } \\
\text { (Experimental/FEA) }\end{array}$ & $\begin{array}{c}\text { Displacement Ratio } \\
\text { (Experimental/FEA) }\end{array}$ \\
\hline 0.025 & 50.47 & 110.20 & 19.29 & 14.27 & 2.18 & 0.74 \\
\hline 0.035 & 128.68 & 110.20 & 45.85 & 14.27 & 0.86 & 0.31 \\
\hline 0.05 & 147.28 & 110.20 & 63.01 & 14.27 & 0.75 & 0.23 \\
\hline
\end{tabular}




\section{CHAPTER 6 - DISPLACEMENT CONTROL FINITE ELEMENT ANALYSIS}

\subsection{Description of Selected FE Model for Monotonic Loading}

The most suitable approach for conducting the finite element analysis of SCC and ECC profiled steel-deck composite slab using ABAQUS/Explicit is to utilize the "Displacement control" loading application. The loading was defined by specifying a Reference Point (RP) and assigning a prescribed displacement to the RP. The RP position was aligned by the center line of the composite slab span length, located $100 \mathrm{~mm}$ at the top of the specimen from the mid-span, as shown in Figure 6.1. The RP was constrained in the $Y$ direction to the two sets of loading nodes across the whole width of the composite slab (in X direction). For parametric study of the composite slab under displacement control loading, different constraints were modeled to analyze which type is most feasible to simulate the load-deflection response closest to the experimental results. The prescribed displacement was defined by using amplitude function (smooth step) and uniform distribution in the boundary condition module. The position of RP was also changed to determine the response of the composite slab for the following three shear span distances from the centerline $300 \mathrm{~mm}, 450 \mathrm{~mm}$, and $600 \mathrm{~mm}$.

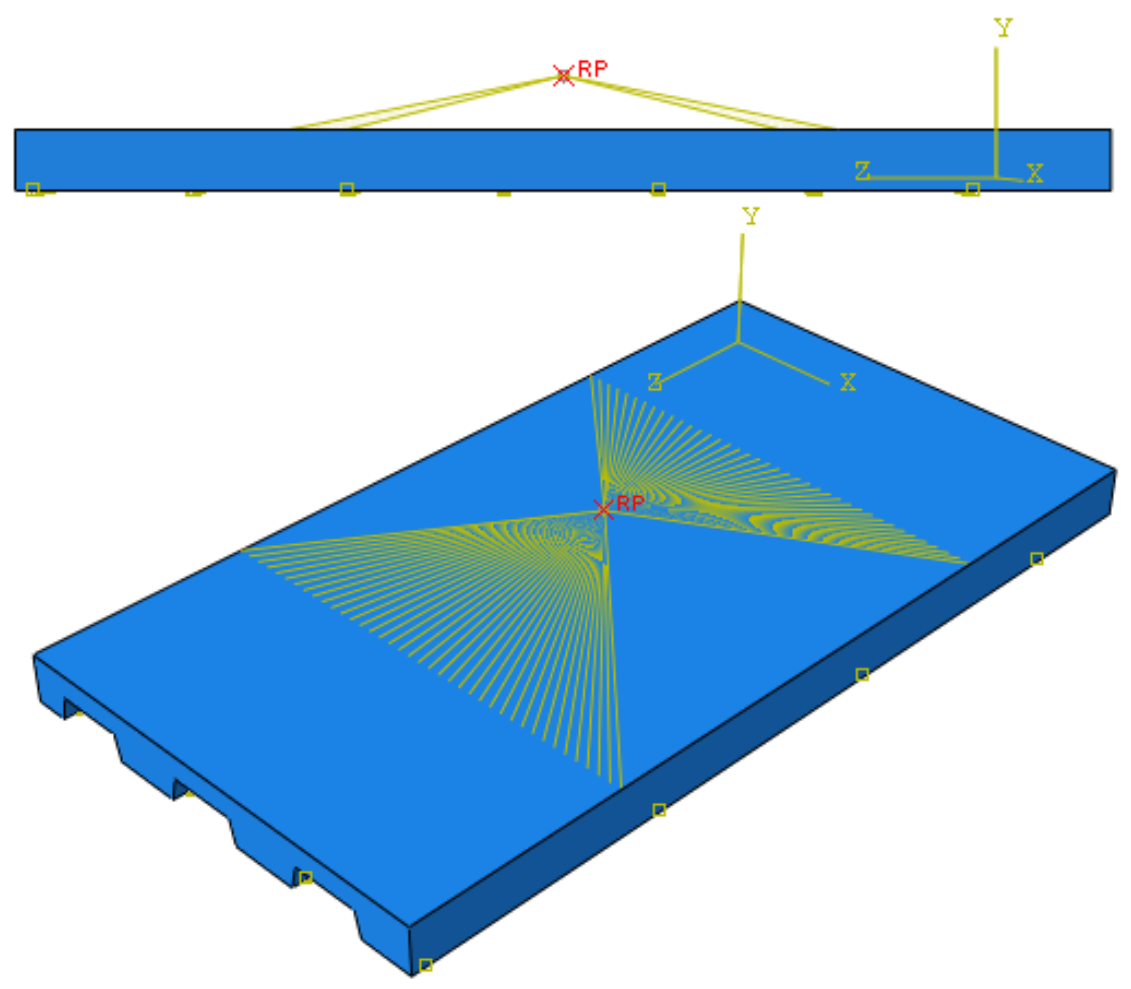

Figure 6.1: Location of the Reference Point (RP) and constraining the RP in Y direction to the two loading nodes at a shear span distance of $300 \mathrm{~mm}$ from support 
Based on the parametric study results obtained from the load control analysis, the mesh size of $25 \mathrm{~mm}$ with dilation angle of $20^{\circ}$ for SCC and $30^{\circ}$ for ECC was used to develop the displacement control finite element model for the composite slabs in ABAQUS. In addition, the eccentricity in "Concrete Damage Plasticity" model was defined as 1.12 for SCC and 1.16 for ECC composite slab models, and the remaining parameters were constant as defined previously in load control analysis.

The analysis was conducted in step-1 (Dynamic, Explicit), which is a step after the initial step. Automatic increment and total of one second "Time period" were selected. A complete run of the ABAQUS/Explicit software for monotonic loading (1 second time period) using one of the basic available Personal Computers took 2.5 hours. The average stable time increment during analysis was $2.94859 \mathrm{e}-06$ seconds.

\subsection{Results from Displacement Control FE Analysis}

For Displacement control analysis, the inelastic out of plane deformation for the entire span length of the P3623-ECC composite slab is portrayed in Figure 6.2. The maximum transversal displacement (U2 or Y direction) at the mid-span of the composite slab was determined as $16.00 \mathrm{~mm}$ when subjected to the twopoint loading control across the top surface of the composite slab. The separation of the concrete and the profiled steel deck was also observed in the ABAQUS output, which was caused by the friction slip at the interface of the two elements, exhibiting the similar failure response to the experimental study.

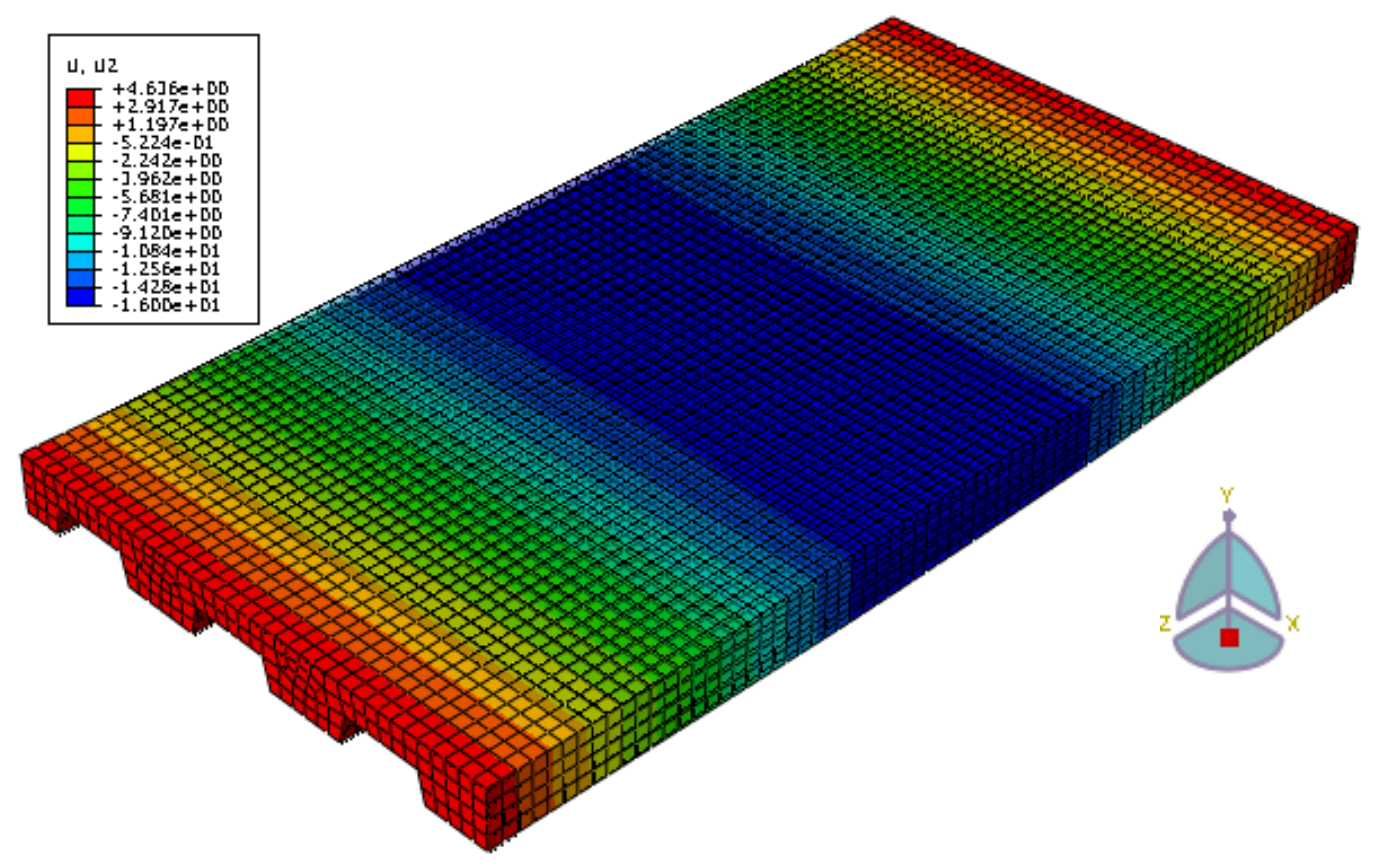

Figure 6.2: Typical deformed model output with ABAQUS/Explicit for shear span of $450 \mathrm{~mm}$ 
The contour diagrams for the three principal stresses of the P3623-450-ECC composite slab, after reaching the maximum failure deformation, are shown in the following Figure 6.3. As illustrated, the concentration of the principal stress in $X, Y$, and $Z$ direction is highest at the two shear span locations and progressively decreases towards the edges and the center of the composite slab and profiled steel deck. The failure mode of the FE model was initiated with the separation of the concrete and steel deck and lead by flexure failure due to the reduced tensile resistance, which was the primary function of the steel deck. Although the accuracy of the principal stresses from the FEA was affected by the defined interface friction contact property, it was verified that the ABAQUS model demonstrated similar failure performance to the experimental model.

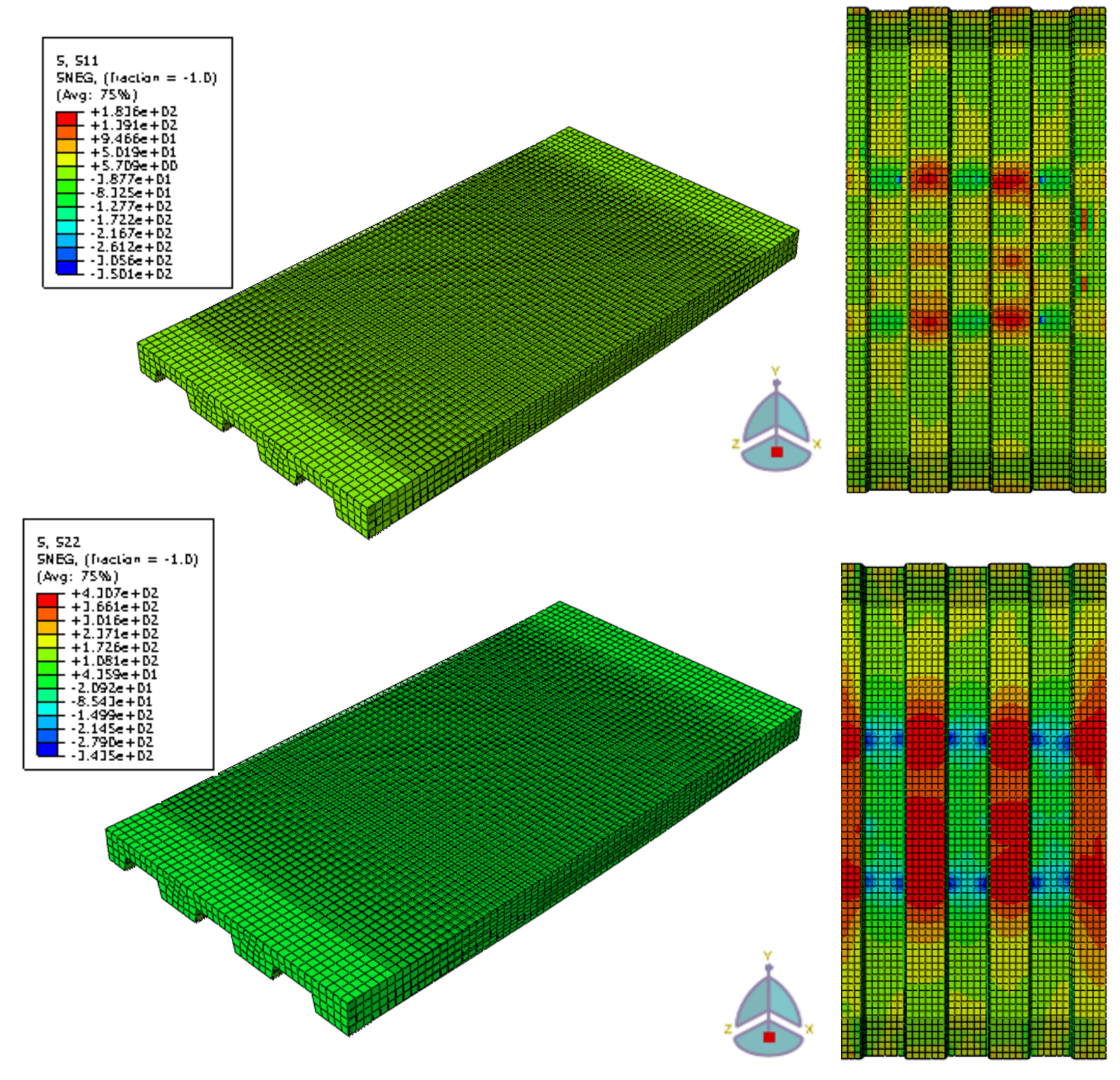

Figure 6.3: Contour of principal stresses in $X, Y$, and $Z$ directions (MPa) for the composite slab and profiled steel sheeting after the application of two-point displacement control (contd.) 


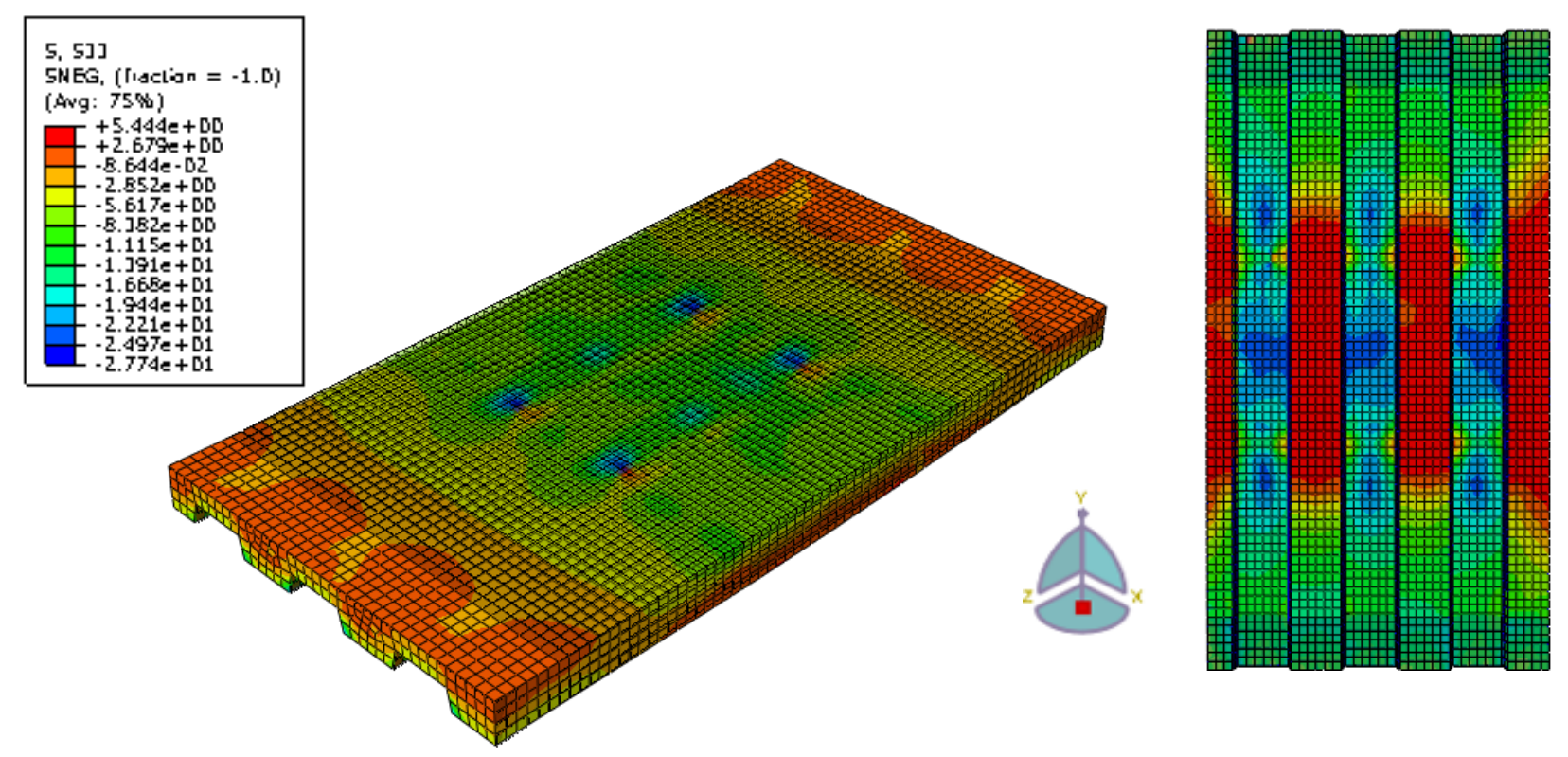

Figure 6.4: Contour of principal stresses in $\mathrm{X}, \mathrm{Y}$, and $\mathrm{Z}$ directions ( $\mathrm{MPa}$ ) for the composite slab and profiled steel sheeting after the application of two-point displacement control

According to Figure 6.3, P3623-450-ECC exhibits failure with uniformly distributed stress concentration of $\sigma_{x x}=38.77 \mathrm{MPa}$ throughout the top surface of composite slab, and with small region of highest concentration of stress $\sigma_{x x}=183.6 \mathrm{MPa}$ developed at the bottom of the ECC composite slab, along the shear span distances and at the mid-span location. In terms of stress in y direction, the composite slab experienced uniformly distributed stress concentration of $\sigma_{y y}=43.59 \mathrm{MPa}$ throughout the top exterior surface. At the bottom of the slab, high stress concentration of $\sigma_{y y}=279.0 \mathrm{MPa}$ was developed along the location of applied displacement control point loads; for the entire distance between the shear span locations where the profiled span length had a depth of $100 \mathrm{~mm}$, high $\sigma_{y y}$ stress concentration was developed ranging from 237.10 MPa to 430.70 MPa. The failure stresses in z direction (span length of the slab) was found to be the lowest of all three principal stresses, indicating that P3623-450-ECC composite slab had not completely yielded at failure point, due to which the magnitude of highest concentrated region of $\sigma_{z z}=27.74 \mathrm{MPa}$ developed mostly throughout the region between the supports and shear span locations. The lack of stress development was potentially caused due to the early interface failure between P3623 steel sheeting and profiled ECC surface. 


\subsection{Comparison of FE Model Output with Experimental Results}

\subsubsection{Slab Load-Deflection Response of ECC composite slab}

Figure 6.4 demonstrates the load-central displacement response of the finite element model of P3623ECC composite slab model in comparison to experimental slabs for different shear spans of $300 \mathrm{~mm}, 450$ $\mathrm{mm}$, and $600 \mathrm{~mm}$. As illustrated, there is relatively good correlation between the FE and experimental responses till the ultimate/peak load. Post peak failure response was not achieved because the stiffening effect after first tension cracking for ECC was not accurately defined or modeled in FE analysis. As part of further research, it is recommended to improve the accuracy of the nonlinear FE model by defining the post stiffening behavior of the ECC in the subroutine of the "Concrete Damage Plasticity" model.

The plotted curves verify that for a given slab span length of $1800 \mathrm{~mm}$, the ultimate load capacity of the ECC composite slab was the highest $(110.40 \mathrm{kN})$ for lowest shear span of $300 \mathrm{~mm}$, and a significant reduction in load capacity was observed as the shear span increases to $450 \mathrm{~mm}$ (48 kN) and followed by the lowest ultimate load of $38.50 \mathrm{kN}$ for shear span of $600 \mathrm{~mm}$. According to the experimental curve, the first cracking and ultimate loads for ECC composite slab for a shear span of $300 \mathrm{~mm}$ were $16.33 \mathrm{kN}$ and $110.20 \mathrm{kN}$, respectively compared to $17.56 \mathrm{kN}$ and $110.40 \mathrm{kN}$, respectively for FE slabs. Based on the comparison of the ultimate load capacity, it can be concluded that the accuracy of FE models was excellent (less than $5 \%$ difference). A summary of this information is provided in Table 6.1. 


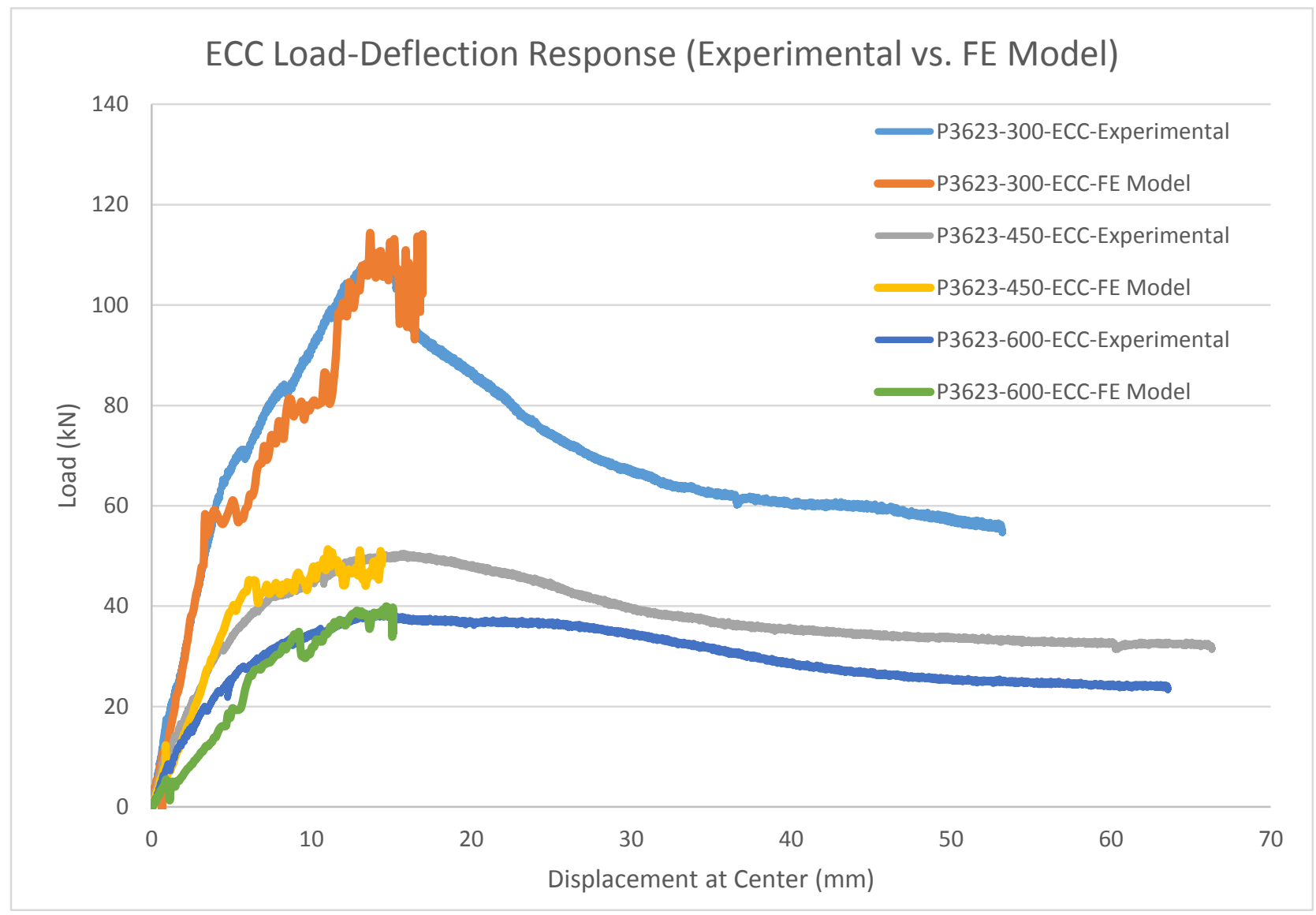

Figure 6.5: Comparison of experimental and FE load-displacement response ECC composite slabs

Based on the results provided in Table 6.1, it is observed that the accuracy of nonlinear finite element model of P3623-ECC was reasonably well in comparison to the results obtained from the experimental test results. Moreover, the load and displacement associated with first crack for each of the three shear span distances of ECC composite slab and total span length of $1800 \mathrm{~mm}$ falls within reasonable range of accuracy as well. 
Table 6.1: Summary of load-displacement response for finite element (FE) model P3623-ECC

\begin{tabular}{|c|c|c|c|c|c|c|c|c|c|c|c|c|}
\hline \multirow[b]{2}{*}{ Specimen } & \multirow{2}{*}{$\begin{array}{c}\text { FEA } \\
\text { Ultimate } \\
\text { Load } \\
(\mathrm{kN})\end{array}$} & \multirow{2}{*}{$\begin{array}{l}\text { Experimental } \\
\text { Load (kN) }\end{array}$} & \multirow{2}{*}{$\begin{array}{c}\text { FEA Mid- } \\
\text { Span } \\
\text { Displacement } \\
(\mathrm{mm})\end{array}$} & \multirow{2}{*}{$\begin{array}{l}\text { Experimental } \\
\text { Displacement } \\
(\mathrm{mm})\end{array}$} & \multicolumn{2}{|c|}{ Exper./FEA Ratio } & \multicolumn{2}{|c|}{ FEA First Crack } & \multicolumn{2}{|c|}{$\begin{array}{c}\text { Experimental First } \\
\text { Crack }\end{array}$} & \multicolumn{2}{|c|}{$\begin{array}{c}\text { First Crack Exper./FEA } \\
\text { Ratio }\end{array}$} \\
\hline & & & & & Load & Displacement & $\begin{array}{l}\text { Load } \\
\text { (kN) }\end{array}$ & $\begin{array}{l}\text { Displacement } \\
(\mathrm{mm})\end{array}$ & $\begin{array}{l}\text { Load } \\
\text { (kN) }\end{array}$ & $\begin{array}{l}\text { Displacement } \\
(\mathrm{mm})\end{array}$ & Load & Displacement \\
\hline $\begin{array}{l}\text { P3623- } \\
\text { 300-ECC- }\end{array}$ & 110.71 & 110.20 & 15.905 & 14.27 & 0.99 & 0.925 & 17.56 & 1.304 & 16.33 & 0.85 & 0.930 & 0.652 \\
\hline $\begin{array}{l}\text { P3623- } \\
\text { 450-ECC- }\end{array}$ & 51.08 & 50.54 & 15.203 & 15.83 & 0.99 & 1.041 & 8.59 & 0.707 & 9.89 & 0.76 & 1.151 & 1.075 \\
\hline $\begin{array}{l}\text { P3623- } \\
\text { 600-ECC- }\end{array}$ & 39.97 & 38.77 & 15.110 & 14.00 & 0.96 & 0.943 & 3.75 & 0.679 & 6.44 & 0.73 & 1.718 & 0.679 \\
\hline
\end{tabular}

6.3.2 Load-Deflection Response of Self-Consolidating Concrete (SCC) Composite Slab

Figure 6.5 shows the comparison between the load-deflection curves for P3623-SCC composite slabs for the three shear spans. The linear prepeak response was accurately matched between the experimental FE models. However, FE model failed to simulate the inelastic post-peak response possibly due to the inadequate modelling of interaction between the concrete and steel deck which was difficult to precisely define within ABAQUS/Explicit software. Another deficiency with this model was that the reinforcement detailing was not modeled within the FE model due to the modelling complication and it was taken into account within the "Concrete Damage Plasticity" model through increasing the tension stiffening. For future research purposes, it is recommended to also model the reinforcement in order to enhance the accuracy of nonlinear finite element model. 


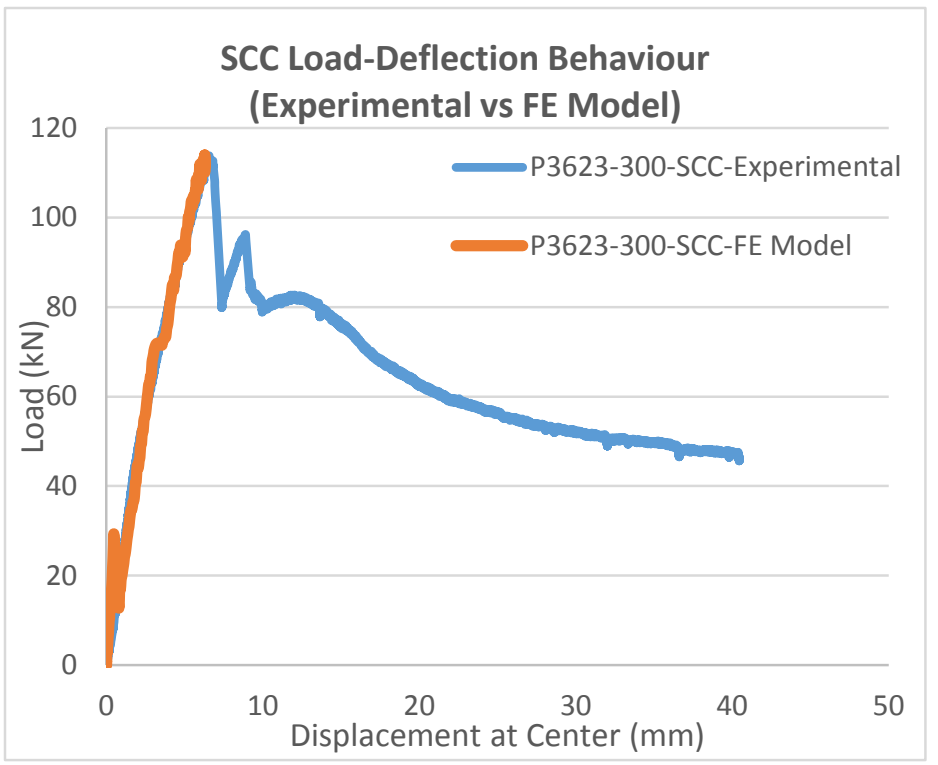

(a)

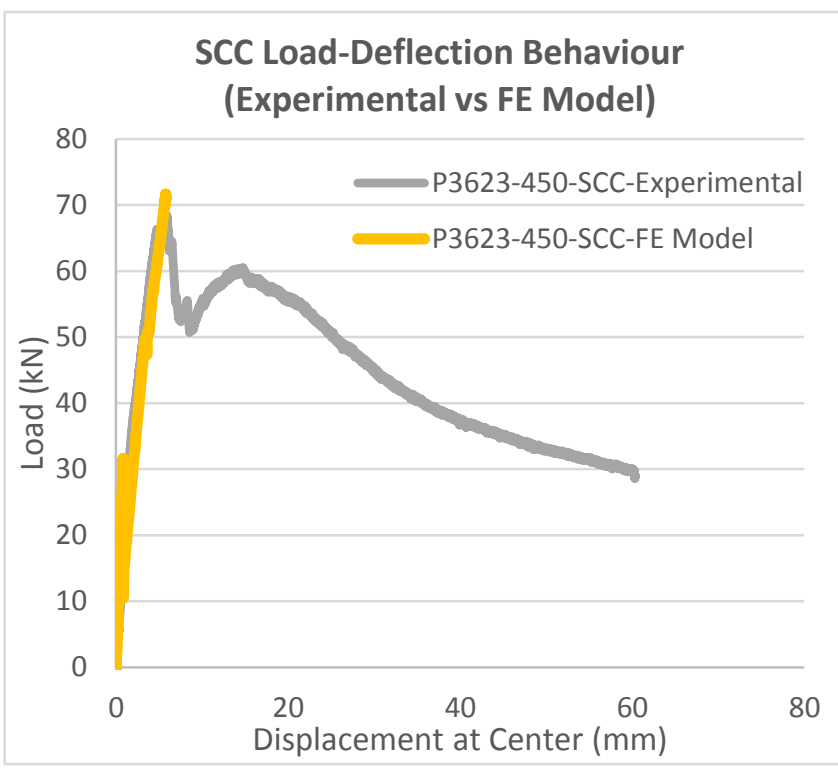

(b)

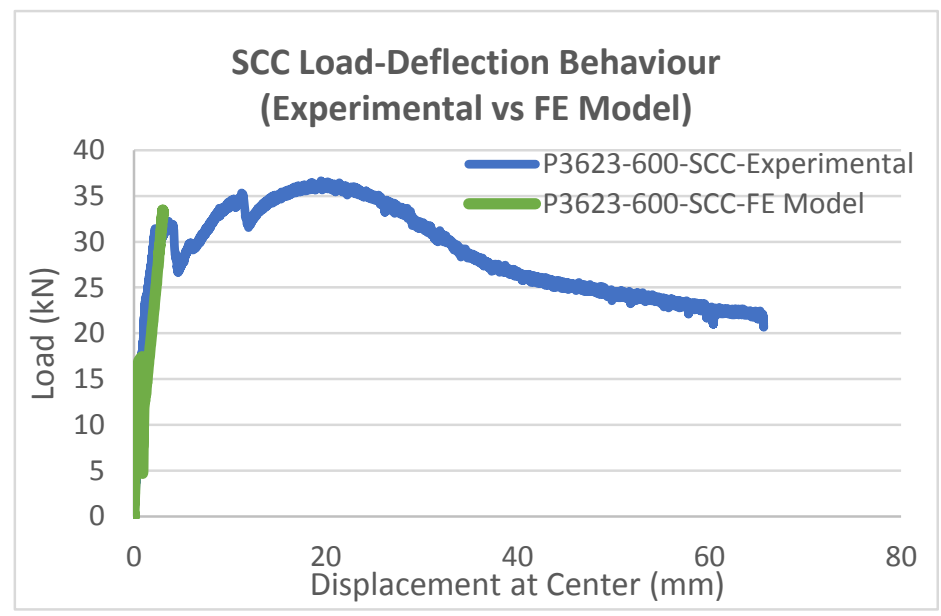

(c)

Figure 6.6: Comparison of experimental and FE load-displacement responses SCC composite slabs with shear span of (a) $300 \mathrm{~mm}$, (b) $450 \mathrm{~mm}$, and (c) $600 \mathrm{~mm}$

Figure 6.5 shows that FE models accurately predicted the ultimate load of SCC slabs as the ratio of experimental to FE predicted values are close to 1. Based on the displacement comparison for two types of composite slabs, it can be concluded that ECC composite slab provides higher ductility (with approximately $40 \%$ higher mid-span displacement) with a slightly lower ultimate load capacity. 
Table 6.2: Summary of results for finite element (FE) model of P3623-SCC load-displacement response

\begin{tabular}{|c|c|c|c|c|c|c|}
\hline \multirow[b]{2}{*}{ Specimen } & \multirow{2}{*}{$\begin{array}{c}\text { FEA } \\
\text { Ultimate } \\
\text { Load (kN) }\end{array}$} & \multirow[t]{2}{*}{$\begin{array}{l}\text { Experimental } \\
\text { Load (kN) }\end{array}$} & \multirow{2}{*}{$\begin{array}{c}\text { FEA Mid-Span } \\
\text { Displacement } \\
(\mathrm{mm})\end{array}$} & \multirow{2}{*}{$\begin{array}{l}\text { Experimental } \\
\text { Displacement } \\
\text { (mm) }\end{array}$} & \multicolumn{2}{|c|}{$\begin{array}{c}\text { Experimental/FEA } \\
\text { Ratio }\end{array}$} \\
\hline & & & & & Load & Displacement \\
\hline $\begin{array}{l}\text { P3623-300-SCC- } \\
\text { FE Model }\end{array}$ & 113.96 & 113.75 & 6.285 & 6.58 & 0.998 & 1.047 \\
\hline $\begin{array}{l}\text { P3623-450-SCC- } \\
\text { FE Model }\end{array}$ & 71.40 & 68.43 & 5.781 & 5.82 & 0.958 & 1.019 \\
\hline $\begin{array}{l}\text { P3623-600-SCC- } \\
\text { FE Model }\end{array}$ & 33.46 & 36.66 & 3.023 & 3.51 & 0.963 & 1.161 \\
\hline
\end{tabular}

\subsection{Finite Element Parametric Study of P3623-300-ECC Composite Slab}

For conducting the parametric study with displacement control analysis, the load-deflection behaviour of P3623-300-ECC composite slab was analyzed for the following variables:

- Effect of different types of ABAQUS interaction properties, including kinematic - finite or small sliding, and penalty contact;

- Influence of different displacement loading constraint, such as coupling, MPC, and tie;

- Effect of using strain increment factor on concrete behaviour (tested with factor 1.5, 2, 2.5) and,

- Influence of increasing compressive strength of P3623-300-SCC (from f'c $=56$ to $66 \mathrm{MPa}$ )

Kinematic and penalty contact are two types of mechanical constraint enforcement methods that are used in ABAQUS/Explicit to model the pure master-slave surface interface contact. Finite sliding allows for any arbitrary motion of the two surfaces, whereas, small sliding assumes that although the two bodies may undergo large motions, there will be relatively little sliding of one surface along the other. In the case of composite slab where the interface slip is expected, small sliding is not feasible for FE modeling. Kinematic coupling is a rigid constraint between a reference node and the master surface nodes. Tie constraint provides permanent bonding between two surfaces (master-slave), thus, preventing the separation or sliding of the slave nodes in reference to master surface. Lastly, MPC, also known as multipoint constraint, imposed as a control point between a beam element and the slave surface nodes. 


\subsubsection{Effect of finite element model parameters on load-deflection behaviour}

The response of P3623-300-ECC Composite slab was analyzed as a function of the different ABAQUS/Explicit modeling parameters and material properties. ECC composite slab load-displacement response for shear span of $300 \mathrm{~mm}$ was selected to perform this analysis. The variation of the load versus displacement curve in correspondence to the different ABAQUS interaction properties is presented in Figure 6.6. Based on the graph, it is verified that the "Penalty Contact" interaction provides the highest accuracy in simulating nearly identical load-deflection response as the experimental one. Using each of those three types of interaction properties results in approximately same slope for the linear (pre-peak) portion of the load versus displacement curve. For ECC composite slabs, "Kinematic Contact - Small Sliding" and "Penalty Contact" generated equivalent ultimate load capacity and maximum displacement at the mid-span. However, the ultimate load capacity is reduced significantly by using "Kinematic Contact - Finite Sliding" because this ABAQUS property accelerates the friction loss at the steel deck-concrete interface at a much earlier loading stage. Thus this form of interaction method is not feasible for profiled steel-deck composite slabs. It is also noted that the maximum deflection is roughly constant among all three types of interaction properties. However, pre-peak stiffness/slope, curvature of load-deflection response, and the ultimate load capacity of the composite slabs changed significantly for various contacts.

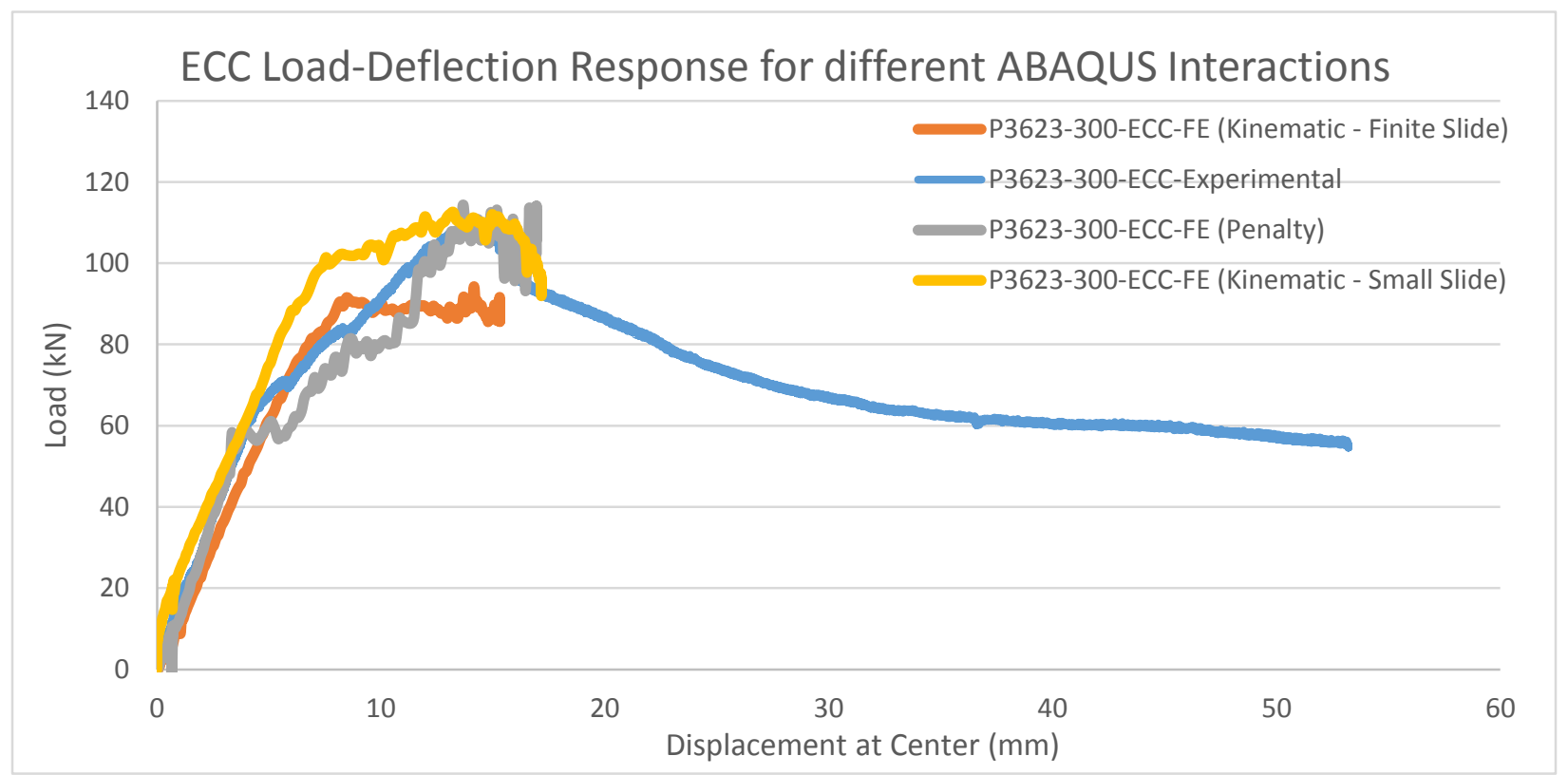

Figure 6.7: Load-displacement response of ECC composite slab for variable interaction property 
Table 6.3 provides a summary of the results illustrated in the load-deflection curves shown in Figure 6.6. As stated in Chapter 5, the experimental ultimate load of $110.20 \mathrm{kN}$ and mid-span displacement of 14.27 mm for P3623-300-ECC composite slab was utilized for measuring the accuracy of the nonlinear FE model results. Based on the tabular data, it is noted that the use of either of the three contact methods provides reasonably same accuracy in terms of the ratio of Experimental to FEA predicted values. However, using "Kinematic Contact with Small Sliding" generates the lowest magnitude of mid-span displacement with reasonably high peak ultimate load.

Table 6.3: Summary of the effect of ABAQUS interface properties on load-deflection response

\begin{tabular}{|l|c|c|c|c|c|c|}
\hline $\begin{array}{l}\text { Interaction } \\
\text { Contact } \\
\text { Property: }\end{array}$ & $\begin{array}{c}\text { FEA } \\
\text { Ultimate } \\
\text { Load } \\
\text { (kN) }\end{array}$ & $\begin{array}{c}\text { FEA Mid- } \\
\text { Span } \\
\text { Displacement } \\
\text { (mm) }\end{array}$ & $\begin{array}{c}\text { Experimental } \\
\text { Load (kN) }\end{array}$ & $\begin{array}{c}\text { Experimental } \\
\text { Displacement } \\
\text { (mm) }\end{array}$ & $\begin{array}{c}\text { Load Ratio } \\
\text { (Experimental/FEA) }\end{array}$ & $\begin{array}{l}\text { Displacement Ratio } \\
\text { (Experimental/FEA) }\end{array}$ \\
\hline $\begin{array}{l}\text { Kinematic } \\
\text { Contact - } \\
\text { Finite Sliding }\end{array}$ & 91.63 & 15.312 & 110.20 & 14.27 & 1.203 & 0.932 \\
\hline $\begin{array}{l}\text { Penalty } \\
\text { Contact }\end{array}$ & 113.12 & 15.183 & 110.20 & 14.27 & 0.974 & 0.940 \\
\hline $\begin{array}{l}\text { Kinematic } \\
\text { Contact - } \\
\text { Small Sliding }\end{array}$ & 112.04 & 14.968 & 110.20 & 14.27 & 0.984 & \\
\hline
\end{tabular}

Figure 6.7 illustrates how the load-deflection behaviour of the P3623-300-ECC-FE composite slab varies based on the application of three ABAQUS displacement control loading constraints namely coupling, MPC, and tied. The figure proves that using "Coupling Constraint" for ABAQUS FE modeling is the most suitable load control approach for simulating the load versus displacement response of the ECC composite slab. Based on the Figure, it is also learnt that both MPC and Tie Constraints demonstrate similar loaddisplacement relationship with the same ultimate load and mid-span displacement. However, it is not feasible to correspond with the experimental results as the slope of linear portion of the curve, maximum displacement, and ultimate peak load point does not match. This significant difference between the "Coupling" and the other two constraints was caused due to the different behavioural characteristics of these constraints that change the imposed displacement control loading. Hence, this parametric study also reveals that the selection of the ABAQUS FE modeling features should be based on the objective of simulating the experimental behaviour. 


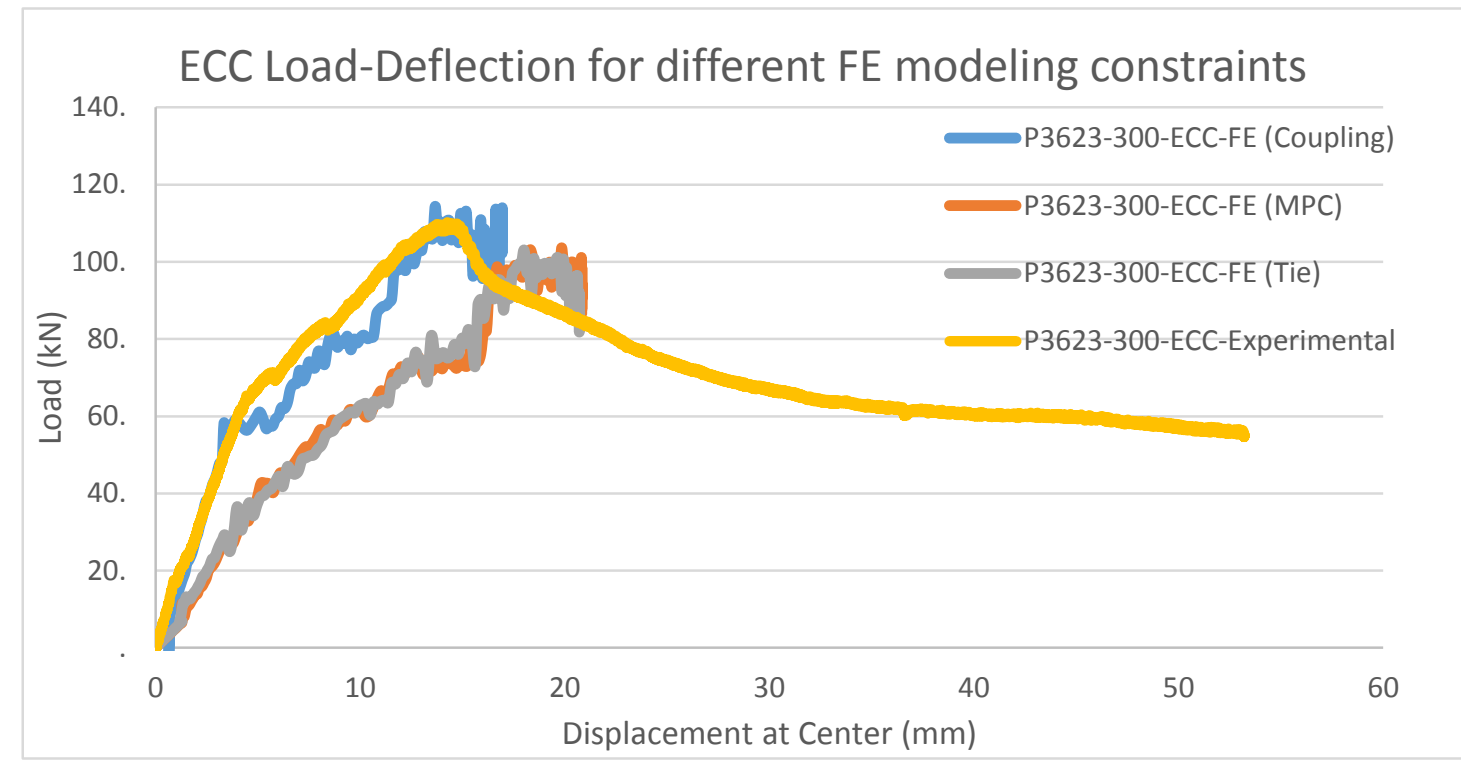

Figure 6.8: Load-displacement responses of ECC composite slab with displacement loading constraints

The load-deflection results illustrated in Figure 6.7 are briefly summarized in the Table 6.4. The presented tabular data emphasize that among all three types of constraints, coupling generates the highest ultimate peak/failure load. Although the ultimate load capacity is approximately same for both MPC and tie constraints, MPC generates higher mid-span displacement in comparison to coupling and tie constraints. Hence it can be concluded that with coupling constraint, the maximum mid-span displacement can be controlled to achieve the desired ultimate load capacity.

Table 6.4: Summary of the effect of loading constraints on load-deflection behaviour

\begin{tabular}{|l|c|c|c|c|c|c|}
\hline $\begin{array}{l}\text { Displacement } \\
\text { Loading } \\
\text { Constraints: }\end{array}$ & $\begin{array}{c}\text { FEA } \\
\text { Ultimate } \\
\text { Load } \\
\mathbf{( k N )}\end{array}$ & $\begin{array}{c}\text { FEA Mid- } \\
\text { Span } \\
\text { Displacement } \\
(\mathbf{m m})\end{array}$ & $\begin{array}{c}\text { Experimental } \\
\text { Load (kN) }\end{array}$ & $\begin{array}{c}\text { Experimental } \\
\text { Displacement } \\
(\mathbf{m m})\end{array}$ & $\begin{array}{c}\text { Load Ratio } \\
\text { (Experimental/FEA) }\end{array}$ & $\begin{array}{c}\text { Displacement Ratio } \\
\text { (Experimental/FEA) }\end{array}$ \\
\hline $\begin{array}{l}\text { Coupling } \\
\text { Constraint }\end{array}$ & 114.37 & 16.95 & 110.20 & 14.27 & 0.963 & 0.842 \\
\hline $\begin{array}{l}\text { MPC } \\
\text { Constraint }\end{array}$ & 103.55 & 19.85 & 110.20 & 14.27 & 1.064 & 0.719 \\
\hline Tie Constraint & 103.015 & 18.02 & 110.20 & 14.27 & 1.070 & 0.792 \\
\hline
\end{tabular}

As another part of the parametric study for P3623-300-ECC composite slab, the influence of defined material properties on the load versus displacement response was analyzed. For the "Concrete Damage Plasticity" model in ABAQUS/CAE, the concrete cracking strain in tension behaviour for SCC composite slab represented the standard "Strain Increment Factor of 1.0. Based on that, the cracking strain for ECC 
composite slab was increased by a factor of $1.5,2.0$, and 2.5 to observe the variation in the load-deflection response. Based on Figure 6.8, use of the "Strain Increment Factor of 2.0" yields better simulation in terms of ultimate load and maximum displacement. It is also implied that as the increment factor for cracking strain values becomes larger, higher ultimate load capacity is achieved for a given displacement. Moreover, the maximum displacement at ultimate load is also reduced with higher strain increment factor. In practice, this strain increment approach was adopted to model the "Concrete Damage Plasticity" for ECC due to the lack of available experimental data that made it difficult to achieve the accurate concrete compression and tension damage behaviour. However, for future research it is recommended that precise inelastic strain, cracking strain, and yield stress values should be developed to define the nonlinear post-stiffening performance of FE composite slab model that is composed ECC.

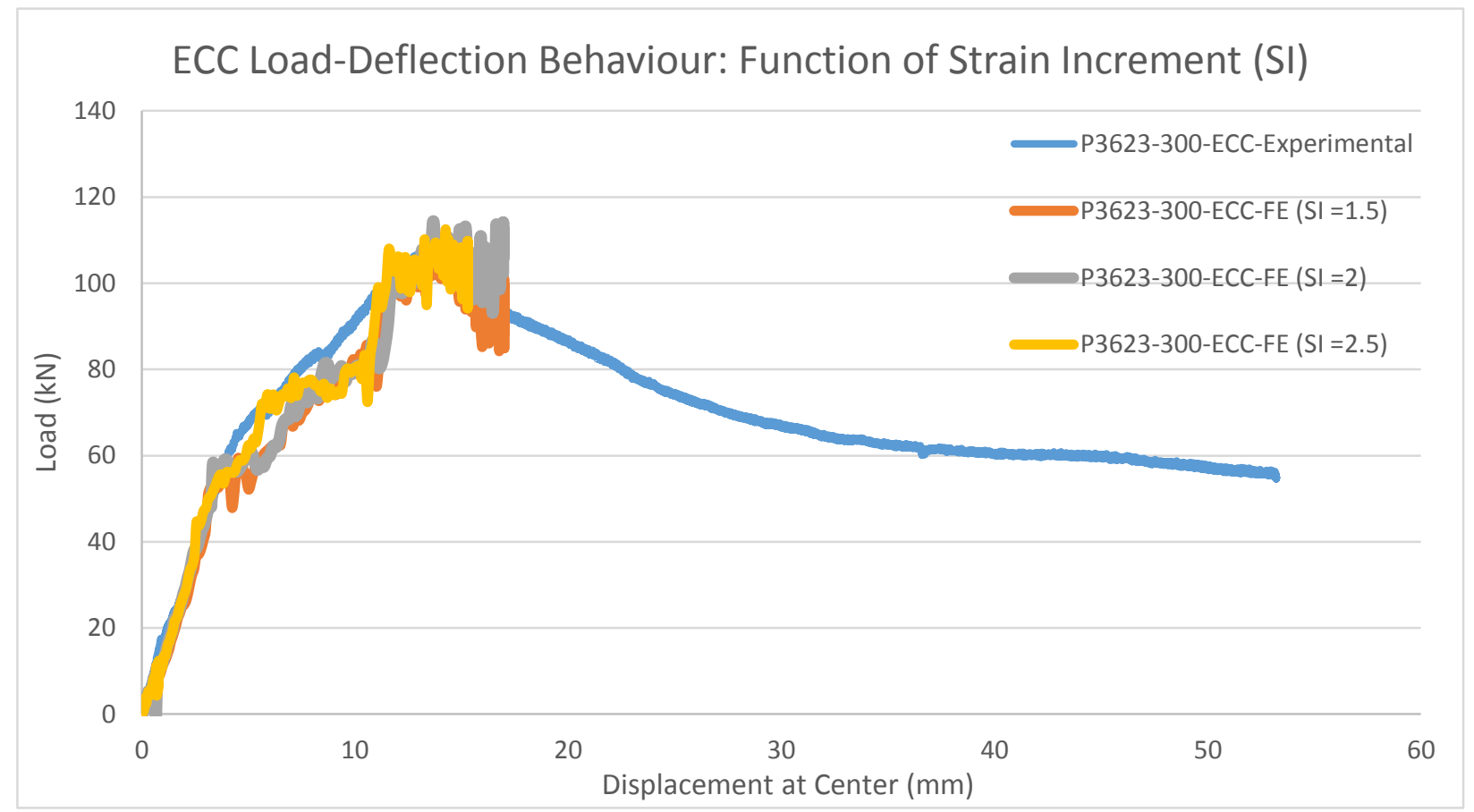

Figure 6.9: Load versus displacement behaviour of ECC composite slabs as a function of strain increment

Table 6.5 provides a summary of the results presented via load-deflection curves in Figure 6.8. The tabular information validates the fact that when the tensile strain values of ECC are increased by a factor of 2.0 it generates the highest ultimate load and lowest maximum mid-span failure displacement compared to 1.5 and 2.5. However, with factor of 2.5, the curvature of load-deflection response is closer to the experimental curve. Hence, composite slabs having different shear spans were modelled and found that 
the tensile strain increment of 2.0 was the most feasible factor for simulating the nonlinear finite element behaviour of P3623-ECC composite slab.

Table 6.5: Effect of strain increment (SI) factor on load-deflection behaviour

\begin{tabular}{|c|c|c|c|c|c|c|}
\hline $\begin{array}{l}\text { Strain } \\
\text { Increment } \\
\text { Factor: }\end{array}$ & $\begin{array}{c}\text { FEA } \\
\text { Ultimate } \\
\text { Load (kN) }\end{array}$ & $\begin{array}{c}\text { Experimental } \\
\text { Load (kN) }\end{array}$ & $\begin{array}{c}\text { FEA Mid-Span } \\
\text { Displacement } \\
(\mathbf{m m})\end{array}$ & $\begin{array}{c}\text { Experimental } \\
\text { Displacement } \\
(\mathbf{m m})\end{array}$ & $\begin{array}{c}\text { Load Ratio } \\
\text { (Experimental/FEA) }\end{array}$ & $\begin{array}{c}\text { Displacement Ratio } \\
\text { (Experimental/FEA) }\end{array}$ \\
\hline 1.5 & 109.02 & 110.20 & 14.403 & 14.27 & 1.007 & 1.022 \\
\hline 2 & 114.38 & 110.20 & 13.671 & 14.27 & 0.960 & 1.077 \\
\hline 2.5 & 112.19 & 110.20 & 14.266 & 14.27 & 0.978 & 1.032 \\
\hline
\end{tabular}

For displacement control analysis, the last parametric study was performed on both P3623-300-SCC and P3623-300-ECC FE composite slab models to, compare the load versus displacement response when both materials had concrete compressive strength of $66 \mathrm{MPa}$. Hence, for compressive behaviour of both SCC and ECC in the "Concrete Damage Plasticity" model was developed by defining the same chart of yield stress values for different inelastic strain values. The orange curve in Figure 6.9 illustrates that the use of $66 \mathrm{MPa}$ (in comparison to f'c of $56 \mathrm{MPa}$ ) allowed SCC slab to achieve higher ultimate load for the same maximum displacement of $6.13 \mathrm{~mm}$, thus, improving the performance of the SCC composite slab. In comparison to ECC, the ultimate load capacity $(7.68 \mathrm{kN})$ of SCC composite slab was higher with maximum displacement of $7.51 \mathrm{~mm}$ at the peak load less than ECC slab. However, the plotted curves also verify that the ductility of ECC composite slab is was significantly higher as confirmed from the gradual decline in the post peak load with the increase of displacement. It is also verified that the pre-peak stiffness of both SCC and ECC composite slabs were identical. 


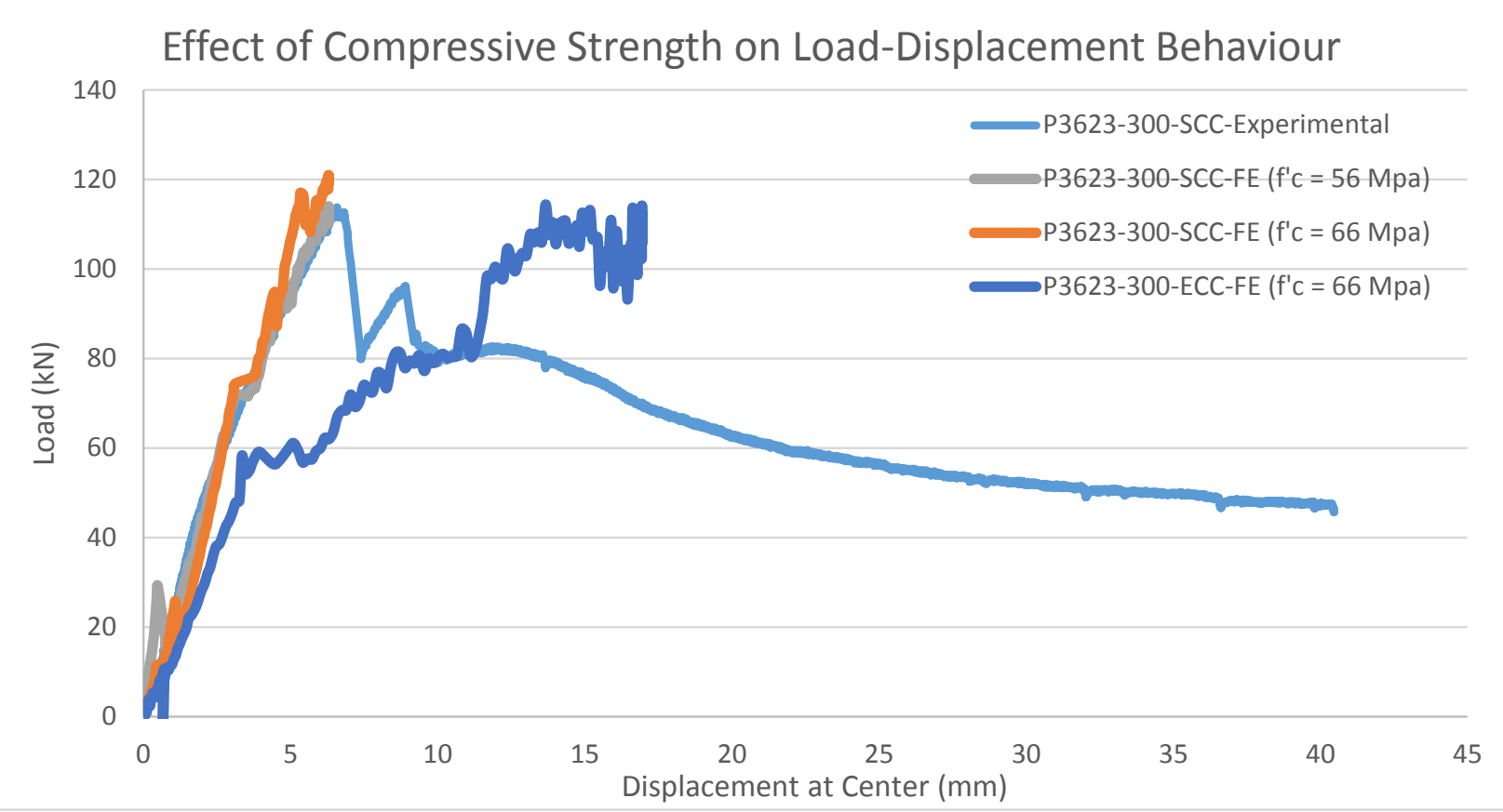

Figure 6.10: Comparison of load-displacement behaviour of SCC and ECC composite slab for constant concrete compressive strength

Table 6.6 provides a summary of the main results that are obtained for P3623-300-SCC finite element model. An increase of the compressive strength of SCC did not improve the maximum mid-span failure displacement. This can be attributed to the increased brittleness of SCC at higher compressive strength.

Table 6.6: Summary of results for P3623-300-SCC FE model for different compressive strength

\begin{tabular}{|c|c|c|c|c|c|c|}
\hline $\begin{array}{c}\text { SCC } \\
\text { Compressive } \\
\text { Strength f'c } \\
\text { (Mpa) }\end{array}$ & $\begin{array}{c}\text { FEA } \\
\text { Ultimate } \\
\text { Load (kN) }\end{array}$ & $\begin{array}{c}\text { Experimental } \\
\text { Load (kN) }\end{array}$ & $\begin{array}{c}\text { FEA Mid-Span } \\
\text { Displacement } \\
(\mathbf{m m})\end{array}$ & $\begin{array}{c}\text { Experimental } \\
\text { Displacement } \\
(\mathbf{m m})\end{array}$ & $\begin{array}{c}\text { Load Ratio } \\
\text { (Experimental/ } \\
\text { FEA) }\end{array}$ & $\begin{array}{c}\text { Displacement } \\
\text { Ratio } \\
\text { (Experimental/ } \\
\text { FEA) }\end{array}$ \\
\hline 56 & 113.96 & 113.75 & 6.284 & 6.58 & 0.998 & 1.047 \\
\hline 66 & 120.94 & 113.75 & 6.289 & 6.58 & 0.941 & 1.046 \\
\hline
\end{tabular}

\subsubsection{Summary}

According to parametric studies, the "penalty contact method" provided the best simulation of experimental load-deflection behaviour among other interface contacts. Among the different displacement loading constraints, the use of "coupling constraint" was the only suitable approach for simulating reasonable composite slab response. Through comparison of different strain increment factors, it was observed that the use of tensile strain increment of 2.0 provides highest accuracy in 
simulating load-deflection behaviour of P3623-300-ECC composite slab. Lastly, increase of concrete compressive strength of P3623-300-SCC slab from $56 \mathrm{MPa}$ to $66 \mathrm{MPa}$ was able to achieve a higher peak load with slightly lower mid-span displacement. However, the slope/stiffness of the pre-peak loaddeflection curve remained unchanged.

\subsection{Design Implementation of Developed FE Models}

The developed FE models were used to simulate the behavior of a number of ECC and SCC numerical slabs having variable spans under four point loading static monotonic loading. The results obtained from such simulations are summarized and presented in the following sections in terms of ultimate load capacity, mid-span displacement, and moment resistance capacity as a function of different span lengths (1500 $\mathrm{mm}, 1800 \mathrm{~mm}$, and $2100 \mathrm{~mm}$ ) of P3623-ECC-FE and P3623-SCC-FE composite slab models. For each span length, a constant ratio of shear span distances was used to compare the behaviour of composite slab. The results of these numerical slabs are used to determine the moment resistance and shear bond capacity of the composite slabs using $\mathrm{m}-\mathrm{k}$ method. ECC composite slab exhibited better shear resistance compare to their SCC counterparts with the increase of span. The detail data from FE simulations are also presented in Appendices.

\subsubsection{Comparison of the Moment Resistance with Span}

The behavior of P3623-ECC and P3623-SCC numerical composite slabs were simulated under four pointed loading using developed FE models for different span lengths (provided in Table 6.8) while keeping constant ratio of shear span distances as $1 / 6,1 / 4$, and $1 / 3$ of the total span length following the design table produced by CANAM Group. The factored load resistance (uniformly distributed load ' $w$ ') of these slabs for a concrete compressive strength $\left(f^{\prime} c\right)$ of $20 \mathrm{MPa}$ was provided in Canam Group 2006 catalogue for P3623 composite slabs. Table 6.7 presents the calculated moment and deflection values as per CANAM catalogue. However, these factored resistance values based on CANAM catalogue can be compared with FE model resistance as the concrete compressive strength of $20 \mathrm{MPa}$ is significantly lower than $56 \mathrm{MPa}$ (for SCC) and $66 \mathrm{MPa}$ (for ECC). Hence for design purposes, the ultimate load capacity, failure mid-span displacement and the moment capacity of FE model composite slabs (P3623-ECC and P3623-SCC) having total span lengths ranging from $1500 \mathrm{~mm}$ to $2700 \mathrm{~mm}$ with three different shear spans are presented in Table 6.8. 
Table 6.7: Factored resistance for CANAM P-3623 composite slab as per CANAM design catalogue

\begin{tabular}{|l|c|c|c|c|}
\hline \multicolumn{5}{|c|}{ CANAM P-3623 Specified Standards: } \\
\hline Total Span Length $(\mathrm{mm})$ & 1500 & 1800 & 2100 & 2700 \\
\hline Factored Load $\mathrm{w}(\mathrm{kPa})$ for $\mathrm{f}^{\prime} \mathrm{c}=20 \mathrm{MPa}$ & 20.00 & 16.05 & 12.20 & 7.87 \\
\hline Moment Resistance $(\mathrm{kNm})$ for $\mathrm{f}^{\prime} \mathrm{c}=20 \mathrm{MPa}$ & 5.63 & 6.50 & 6.73 & 7.17 \\
\hline Deflection Limit $(\mathrm{mm})$ using $\mathrm{wf}$ for $\mathrm{f}^{\prime} \mathrm{c}=20 \mathrm{MPa}$ & 1.14 & 1.89 & 2.66 & 4.69 \\
\hline
\end{tabular}

For both SCC and ECC composite slabs, the ultimate load and moment resistance decreased with the increase of total span length. On the other hand, the ultimate load and moment resistance generally increased with the decrease of shear span for all composite slab. Although the ultimate peak load and moment capacity were higher for SCC composite slab, ECC composite slabs exhibited superior ductile performance. 
Table 6.8: Comparison of the ultimate moment resistance with ABAQUS FE model results

\begin{tabular}{|c|c|c|c|c|c|c|c|c|c|c|c|c|}
\hline \multicolumn{13}{|c|}{ ABAQUS FE Model Results - P3623-ECC Composite Slab: } \\
\hline Total Span Length $(\mathrm{mm})$ & \multicolumn{3}{|c|}{1500} & \multicolumn{3}{|c|}{1800} & \multicolumn{3}{|c|}{2100} & \multicolumn{3}{|c|}{2700} \\
\hline Shear Span Distance $(\mathrm{mm})$ : & 250 & 375 & 500 & 300 & 450 & 600 & 350 & 525 & 700 & 450 & 675 & 900 \\
\hline Ultimate Load Capacity (kN): & 152.54 & 98.74 & 80.90 & 110.40 & 50.77 & 39.48 & 100.27 & 47.89 & 36.63 & 86.98 & 37.42 & 27.10 \\
\hline $\begin{array}{l}\text { Uniformly distributed force } \\
(\mathrm{w}):(\mathrm{kPa})\end{array}$ & 105.93 & 68.57 & 56.18 & 63.89 & 29.38 & 22.85 & 49.74 & 23.76 & 18.17 & 33.56 & 14.44 & 10.45 \\
\hline $\begin{array}{l}\text { Moment Resistance }(\mathrm{PL} / 4) \\
(\mathrm{kNm}) \text { for } \mathrm{f}^{\prime} \mathrm{c}=66 \mathrm{MPa}\end{array}$ & 57.20 & 37.03 & 30.34 & 49.68 & 22.84 & 17.77 & 52.64 & 24.14 & 19.23 & 58.71 & 25.26 & 18.29 \\
\hline $\begin{array}{l}\text { Moment Resistance }\left(\frac{w l^{2}}{8}\right) \\
(\mathrm{kNm}) \text { for } \mathrm{f}^{\prime} \mathrm{c}=66 \mathrm{MPa}\end{array}$ & 29.79 & 19.28 & 15.80 & 25.88 & 11.90 & 9.25 & 27.42 & 13.10 & 10.02 & 30.58 & 13.16 & 9.526 \\
\hline Deflection (mm) & 16.56 & 14.86 & 15.11 & 16.95 & 15.01 & 15.11 & 18.02 & 16.42 & 16.50 & 18.57 & 17.79 & 15.47 \\
\hline \multicolumn{13}{|c|}{ ABAQUS FE Model Results - P3623-SCC Composite Slab: } \\
\hline Total Span Length (mm) & \multicolumn{3}{|c|}{1500} & \multicolumn{3}{|c|}{1800} & \multicolumn{3}{|c|}{2100} & \multicolumn{3}{|c|}{2700} \\
\hline Shear Span Distance (mm): & 250 & 375 & 500 & 300 & 450 & 600 & 350 & 525 & 700 & 450 & 675 & 900 \\
\hline Ultimate Load Capacity (kN): & 197.62 & $\begin{array}{c}133.7 \\
8\end{array}$ & 90.32 & 113.0 & 70.65 & 31.11 & 104.58 & 55.94 & 27.77 & 79.92 & 44.03 & 20.27 \\
\hline $\begin{array}{l}\text { Uniformly Distributed Force } \\
(\mathrm{w}):(\mathrm{kPa})\end{array}$ & 137.23 & 92.90 & 62.72 & 65.39 & 40.89 & 18.002 & 51.87 & 27.75 & 13.78 & 30.84 & 16.99 & 7.82 \\
\hline $\begin{array}{l}\text { Moment Resistance }(\mathrm{PL} / 4) \\
(\mathrm{kNm}) \text { for } \mathrm{f}^{\prime} \mathrm{c}=56 \mathrm{MPa}\end{array}$ & 74.11 & 50.17 & 33.87 & 50.85 & 31.79 & 13.998 & 54.90 & 29.37 & 14.58 & 53.95 & 29.72 & 13.68 \\
\hline $\begin{array}{l}\text { Moment Resistance }\left(\frac{w l^{2}}{8}\right) \\
(\mathrm{kNm}) \text { for } \mathrm{f}^{\prime} \mathrm{c}=56 \mathrm{MPa}\end{array}$ & 38.60 & 26.13 & 17.64 & 26.49 & 16.58 & 7.29 & 28.60 & 15.30 & 7.59 & 28.10 & 15.48 & 7.13 \\
\hline Deflection (mm) & 5.91 & 5.56 & 3.09 & 6.28 & 5.78 & 3.05 & 8.16 & 7.12 & 3.42 & 8.31 & 6.42 & 3.42 \\
\hline
\end{tabular}




\subsubsection{Evaluation of shear bond characteristics for composite slabs}

The results from the simulation of numerical slabs presented in Table 6.8 were used to determine the $\mathrm{m}$ and $\mathrm{k}$ values, defining the shear transferring capacity of the profiled composite deck. The variable " $m$ " represents the empirical value of mechanical interlocking between concrete and profiled steel sheeting, the parameter " $k$ " is the empirical value for friction at the interface of concrete and steel deck, and $\tau_{u, R d}$ represents the shear bond capacity of the ECC and SCC composite slabs. Table 6.9 provides the calculated value of $\mathrm{m}, \mathrm{k}$, and $\tau_{u, R d}$ for four different span lengths $1500 \mathrm{~mm}, 1800 \mathrm{~mm}, 2100 \mathrm{~mm}$, and $2700 \mathrm{~mm}$. Numerical slabs with each of these span lengths were modeled for three different shear spans maintaining a constant shear span to total span length ratio.

The main objective of this finite element analysis was to compare the shear bond capacities of SCC and ECC composite slabs. The design equation recommended by Porter et al. (1971) and Eurocode 4 (1994) for shear bond capacity (based on $\mathrm{m}$ and $\mathrm{k}$ values) of profiled steel deck composite slab is utilized for numerical and experimental composite slabs. Bashar (2010) and Marimuthu et al (2007) also used this method to determine the $\mathrm{m}-\mathrm{k}$ values. The equation used in this method is given by Eq. 6.1.

$$
\frac{V_{u}}{b d}=\tau_{u, R d}=m \frac{A_{p}}{b L_{s}}+k \sqrt{f_{c}^{\prime}}
$$

The provided Eq. 6.1 can also be rearranged in the format $y=m x+b$ as Eq. 6.2:

$$
\frac{V_{u}}{b d \sqrt{f_{c}^{\prime}}}=m \frac{A_{p}}{b L_{s} \sqrt{f_{c}^{\prime}}}+k
$$

Where $V_{u}$ is the ultimate shear capacity of the slab which is equivalent to $P_{u} / 2, P_{u}$ being the two load in four point loading, $b$ is the width of the profiled sheet (given as $914 \mathrm{~mm}$ ), $d$ is the average depth of the composite deck slab (calculated as $75 \mathrm{~mm}$ ), $A_{p}$ represents the cross sectional area of the profiled steel sheet (given as $1016 \mathrm{~mm}^{2}$ ), $L_{s}$ is the shear span, and $f_{c}^{\prime}$ is the concrete compressive strength (used as 56 MPa for SCC and $66 \mathrm{MPa}$ for ECC).

Numerical and experimental results are plotted in Figure 6.10 to determine $m$ and $k$ values. $M$ and $k$ values are determined as slope and intercept, respectively from the best fit straight line as per Eq. 6.2. 
Then the following Eq. 6.3 was used to calculate the shear bond capacity of the composite slabs for different shear span distances:

$\tau_{u, R d}=\left(\frac{m A_{p}}{b L_{s}}+k \sqrt{f_{c}^{\prime}}\right)$

The discussed parameters for calculating shear bond capacity of experimental and numerical composite slabs (ECC/SCC) are presented in Tables 6.9 and 6.10, respectively. Shear bond capacity of ECC and SCC composite slabs decreased with the increase of shear span.

Table 6.9: Experimental $\mathrm{m}-\mathrm{k}$ values and shear bond capacity

\begin{tabular}{|c|c|c|c|c|c|c|c|c|c|}
\hline $\begin{array}{c}\text { Concrete } \\
\text { Type }\end{array}$ & $\begin{array}{c}\text { Span } \\
\text { Length } \\
(\mathrm{mm})\end{array}$ & $\begin{array}{c}\text { Shear } \\
\text { Span, Ls } \\
(\mathrm{mm})\end{array}$ & $\begin{array}{l}\mathrm{Pu} \\
(\mathrm{kN})\end{array}$ & $\begin{array}{l}\mathrm{Vu} \\
(\mathrm{kN})\end{array}$ & $V_{u} / b d \sqrt{f_{c}^{\prime}}$ & $A_{p} / b L_{s} \sqrt{f_{c}^{\prime}}$ & $\mathrm{m}$ & k & $\begin{array}{c}\tau_{u, R d} \\
\left(N / \mathrm{mm}^{2}\right)\end{array}$ \\
\hline \multirow{3}{*}{$\begin{array}{c}\text { P3623- } \\
\text { ECC }\end{array}$} & \multirow{3}{*}{1800} & 300 & 110.20 & 55.10 & 0.0942 & 0.000434 & \multirow[b]{3}{*}{291.38} & \multirow[b]{3}{*}{0.0345} & 1.3085 \\
\hline & & 450 & 50.54 & 25.27 & 0.0432 & 0.000289 & & & 0.9658 \\
\hline & & 600 & 38.77 & 19.39 & 0.0331 & 0.000217 & & & 0.7945 \\
\hline \multirow{3}{*}{$\begin{array}{l}\text { P3623- } \\
\text { SCC }\end{array}$} & \multirow{3}{*}{1800} & 300 & 113.75 & 56.88 & 0.1056 & 0.000471 & \multirow[b]{3}{*}{298.38} & \multirow[b]{3}{*}{0.0339} & 1.3063 \\
\hline & & 450 & 68.43 & 34.22 & 0.0635 & 0.000314 & & & 0.9554 \\
\hline & & 600 & 36.66 & 18.33 & 0.0340 & 0.000236 & & & 0.780 \\
\hline
\end{tabular}


Table 6.10: Parameters to plot finite element (FE) m-k curves, and shear bond capacity

\begin{tabular}{|c|c|c|c|c|c|c|c|c|c|}
\hline $\begin{array}{l}\text { Concrete } \\
\text { Type }\end{array}$ & $\begin{array}{c}\text { Span } \\
\text { Length } \\
(\mathrm{mm})\end{array}$ & $\begin{array}{c}\text { Shear Span, Ls } \\
(\mathrm{mm})\end{array}$ & $\mathrm{Pu}(\mathrm{kN})$ & $\mathrm{Vu}(\mathrm{kN})$ & $V_{u} / b d \sqrt{f_{c}^{\prime}}$ & $A_{p} / b L_{s} \sqrt{f_{c}^{\prime}}$ & $\mathrm{m}$ & $\mathrm{k}$ & $\begin{array}{c}\tau_{u, R d} \\
\left(N / m m^{2}\right) \\
\end{array}$ \\
\hline \multirow{12}{*}{$\begin{array}{l}\text { P3623-ECC- } \\
\text { FEA Model }\end{array}$} & \multirow{3}{*}{1500} & 250 & 152.537 & 76.269 & 0.13039 & 0.000521 & \multirow{3}{*}{239.29} & \multirow{3}{*}{0.00459} & 1.050284 \\
\hline & & 375 & 98.735 & 49.368 & 0.0844 & 0.000347 & & & 0.712619 \\
\hline & & 500 & 80.895 & 40.448 & 0.06915 & 0.000261 & & & 0.543787 \\
\hline & \multirow{3}{*}{1800} & 300 & 110.40 & 55.20 & 0.09437 & 0.000434 & \multirow{3}{*}{289.63} & \multirow{3}{*}{0.033662} & 1.295218 \\
\hline & & 450 & 50.765 & 25.383 & 0.0434 & 0.000289 & & & 0.954635 \\
\hline & & 600 & 39.482 & 19.741 & 0.03375 & 0.000217 & & & 0.78434 \\
\hline & \multirow{3}{*}{2100} & 350 & 100.269 & 50.135 & 0.08571 & 0.000372 & \multirow{3}{*}{302.12} & \multirow{3}{*}{0.02856} & 1.145586 \\
\hline & & 525 & 47.894 & 23.947 & 0.04094 & 0.000248 & & & 0.841068 \\
\hline & & 700 & 36.625 & 18.313 & 0.03131 & 0.000186 & & & 0.688809 \\
\hline & \multirow{3}{*}{2700} & 450 & 86.98 & 43.490 & 0.07435 & 0.000289 & \multirow{3}{*}{365.84} & \multirow{3}{*}{0.03332} & 1.131107 \\
\hline & & 675 & 37.423 & 18.712 & 0.03199 & 0.000193 & & & 0.844306 \\
\hline & & 900 & 27.096 & 13.548 & 0.023162 & 0.000145 & & & 0.70091 \\
\hline \multirow{12}{*}{$\begin{array}{l}\text { P3623-SCC- } \\
\text { FEA Model }\end{array}$} & \multirow{3}{*}{1500} & 250 & 197.617 & 98.809 & 0.18339 & 0.000566 & \multirow{3}{*}{346.62} & \multirow{3}{*}{0.01117} & 1.550911 \\
\hline & & 375 & 133.781 & 66.891 & 0.12415 & 0.000377 & & & 1.061791 \\
\hline & & 500 & 90.319 & 45.160 & 0.08382 & 0.000283 & & & 0.817232 \\
\hline & \multirow{3}{*}{1800} & 300 & 113.0 & 56.50 & 0.104863 & 0.000471 & \multirow{3}{*}{312.08} & \multirow{3}{*}{0.03982} & 1.398963 \\
\hline & & 450 & 70.65 & 35.325 & 0.065563 & 0.000314 & & & 1.031980 \\
\hline & & 600 & 31.107 & 15.554 & 0.02887 & 0.000236 & & & 0.84849 \\
\hline & \multirow{3}{*}{2100} & 350 & 104.575 & 52.288 & 0.09704 & 0.000404 & \multirow{3}{*}{350.25} & \multirow{3}{*}{0.04397} & 1.388140 \\
\hline & & 525 & 55.936 & 27.968 & 0.05191 & 0.000269 & & & 1.035111 \\
\hline & & 700 & 27.772 & 13.886 & 0.02577 & 0.000202 & & & 0.858596 \\
\hline & \multirow{3}{*}{2700} & 450 & 79.924 & 39.962 & 0.07417 & 0.000314 & \multirow{3}{*}{347.37} & \multirow{3}{*}{0.03423} & 1.07315 \\
\hline & & 675 & 44.029 & 22.015 & 0.04086 & 0.00021 & & & 0.800824 \\
\hline & & 900 & 20.272 & 10.136 & 0.01881 & 0.000157 & & & 0.664664 \\
\hline
\end{tabular}




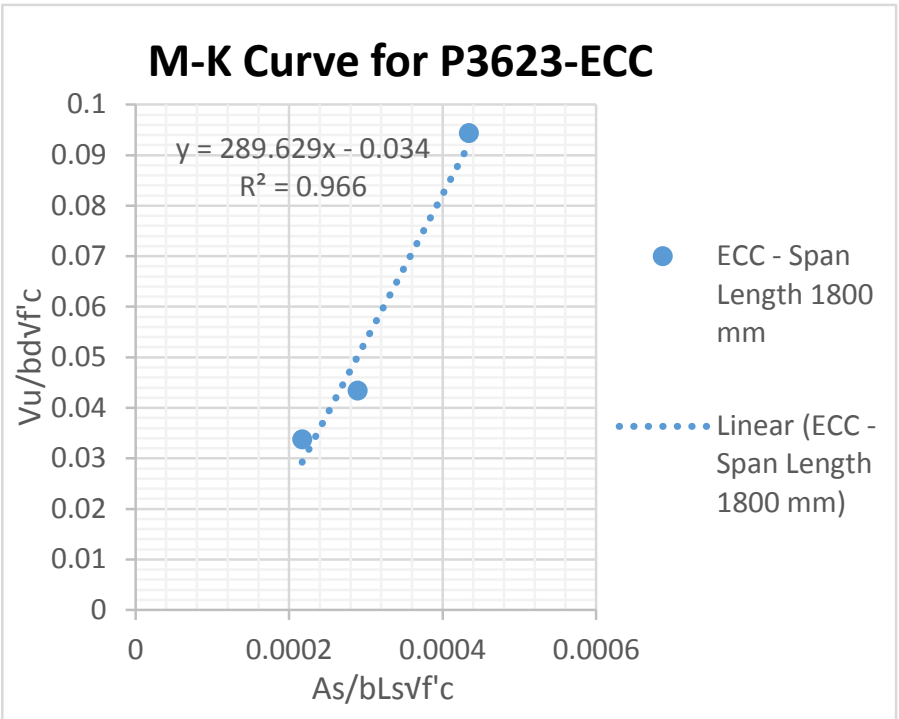

(a)

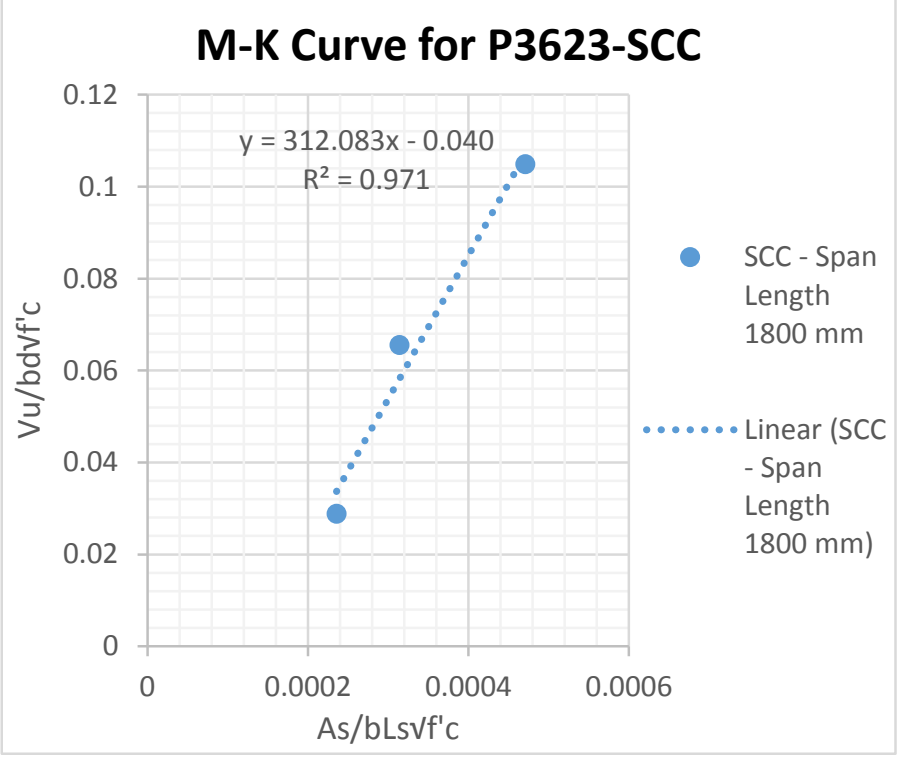

(c)

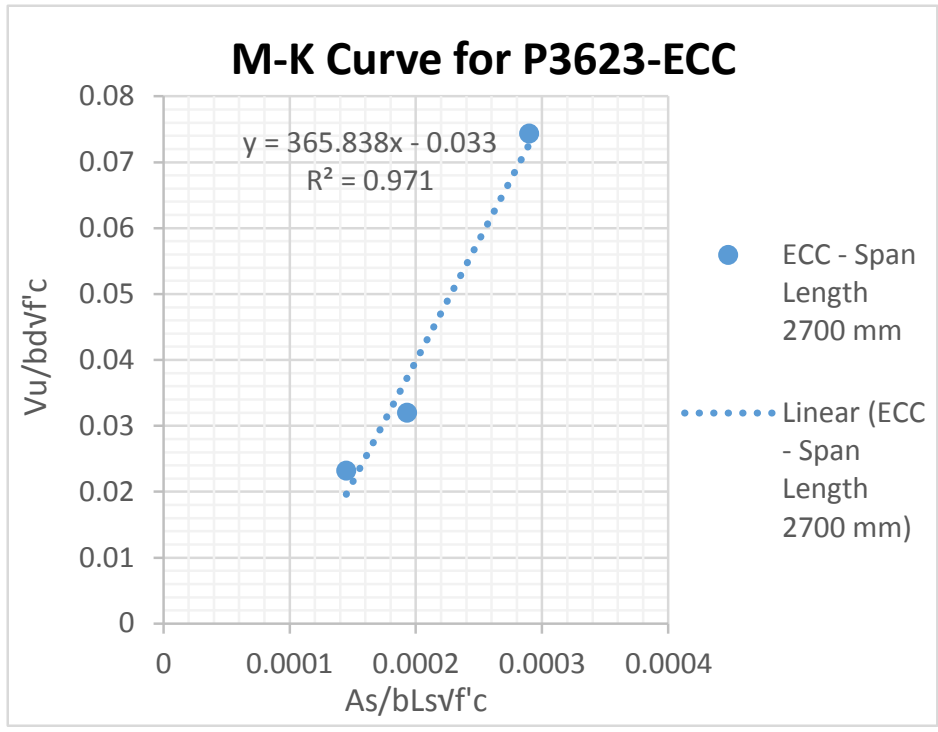

(b)

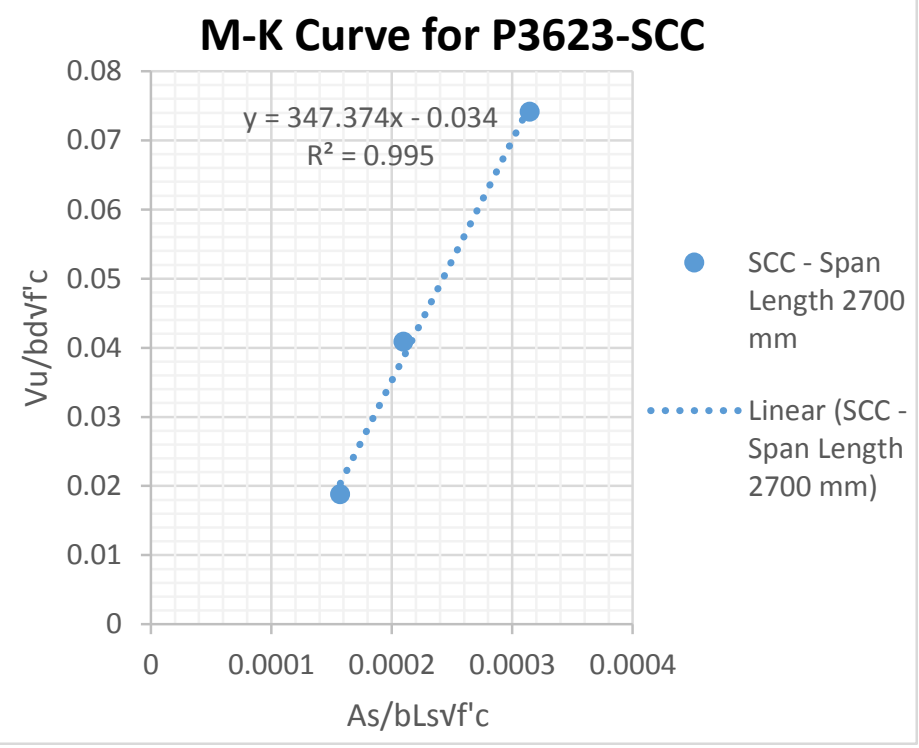

(d)

Figure 6.11: Typical m-k curves for total span of $1800 \mathrm{~mm}$ and $2700 \mathrm{~mm}(\mathrm{a}, \mathrm{b})$ ECC composite slab, (c,d) SCC composite slab 
Table 6.11: Accuracy ratio comparison between finite element (FE) results and experimental data

\begin{tabular}{|c|c|c|c|c|c|c|}
\hline \multirow[b]{2}{*}{ Composite slab } & \multirow[b]{2}{*}{$\mathrm{m}$} & \multirow[b]{2}{*}{$\mathrm{k}$} & \multirow{2}{*}{$\begin{array}{c}\tau_{u, R d} \\
\left(N / m m^{2}\right)\end{array}$} & \multicolumn{3}{|c|}{ Ratio (Experimental/FEA) } \\
\hline & & & & $\mathrm{m}$ & $\mathrm{k}$ & $\tau_{u, R d}$ \\
\hline \multirow[b]{3}{*}{ P3623-ECC-1800-FE Model } & \multirow[b]{3}{*}{289.63} & \multirow[b]{3}{*}{0.0337} & 1.295218 & \multirow{6}{*}{1.006} & \multirow{6}{*}{1.0259} & \multirow[t]{2}{*}{1.01024} \\
\hline & & & 0.954635 & & & \\
\hline & & & 0.78434 & & & 1.01174 \\
\hline \multirow[b]{3}{*}{ P3623-ECC-1800-Experimental } & \multirow[b]{3}{*}{291.38} & \multirow[b]{3}{*}{0.0345} & 1.30848 & & & \\
\hline & & & 0.96584 & & & \multirow[t]{2}{*}{1.01297} \\
\hline & & & 0.79452 & & & \\
\hline \multirow[b]{3}{*}{ P3623-SCC-1800-FE Model } & \multirow[b]{3}{*}{312.08} & \multirow[b]{3}{*}{0.0398} & 1.39896 & \multirow{6}{*}{0.956} & \multirow{6}{*}{0.8511} & \multirow[t]{2}{*}{0.9337} \\
\hline & & & 1.03198 & & & \\
\hline & & & 0.84849 & & & 0.9258 \\
\hline \multirow[b]{3}{*}{ P3623-SCC-1800-Experimental } & \multirow[b]{3}{*}{298.38} & \multirow[b]{3}{*}{0.0339} & 1.30627 & & & \\
\hline & & & 0.9554 & & & \multirow[t]{2}{*}{0.91923} \\
\hline & & & 0.77996 & & & \\
\hline
\end{tabular}

Shear bond parameters ( $\mathrm{m}$ and $\mathrm{k}$ ) and shear bond capacity of SCC and ECC composite slab are compared in Table 6.11. It is found that FE models and experimental slabs produced close values of $m, k$ and shear bond (ratio experimental to FEA value ranges between 0.91 and 1.01) which shows FE models are reliable in predicting shear bond capacity of both SCC and ECC composite slabs. On the other hand, shear bond capacity of ECC and SCC composite slabs are found to be identical. This can be attributed to the presence of only embossments as shear transfer device in the tested slab. The use of embossments and shear stud connectors together was found to produce higher shear bond resistance of ECC composite slab compared to their SCC counterparts (Hossain et al. 2014).

\subsection{Summary and Conclusions}

As presented in this chapter, two FE models were developed mainly for SCC and ECC composite slabs. It was found that the FE model using displacement control method was the best model to simulate the experimental composite slab with respect to load-displacement response and also in terms of the computational running time. Results obtained from SCC/ECC finite element models are relatively close to the experimental results in terms of load-deformation response, ultimate load and shear bond prediction. 


\section{CHAPTER 7 - SUMMARY, CONCLUSIONS AND RECOMMENDATIONS}

\subsection{Summary and Conclusions}

Two nonlinear finite element (FE) models for ECC and SCC profiled steel-deck composite slabs were developed using ABAQUS/Explicit. Experimental results of ECC and SCC composite slabs are used to develop and verify the performance of two FE models. Load-displacements of experimental slabs tested under four point loading with variable shear spans are primarily used to fine tune the numerical parameters and material properties. Simulating ultimate load capacity with acceptable mid-span displacement, while preventing the early longitudinal shear failure and interface slip was the main aim for developing the FE models for SCC and ECC profiled steel-deck composite slabs. The composite action between the steel and concrete was solely achieved with steel deck embossments. Develop FE models are used to simulate the behavior of numerical ECC/SCC composite slabs having variable total and shear span to evaluate ultimate load/moment resistance and the shear bond characteristics. The following conclusions are drawn from the study:

- Extensive parametric studies suggested that nonlinear finite element models for composite slabs using ABAQUS/Explicit should employ the following:

- Displacement control analysis with coupling load constraint

- Element type C3D8R for concrete and S4R for steel deck with mesh element size of $25 \mathrm{~mm}$

- Modified concrete damage plasticity model to define the compression and tension behaviour of SCC and ECC

- Surface-to-surface explicit penalty contact interaction between profiled concrete and steel sheet allowing for finite sliding at the interface

- The tangential behaviour with penalty friction coefficient of 0.5 and normal interface behaviour with hard contact pressure-overclosure

- Implementing smooth step amplitude for gradual application of loading

- Load-displacement response of obtained from experiment and FE analysis verified superior ductile failure behavior of ECC composite slabs compared to their SCC counterparts. Normally shear strength and ultimate failure load capacity of composite slab decreased with the increase of shear span. 
- FE models are found good in simulating load-displacement response, ultimate load/moment capacity and steel deck-concrete shear bond compared to experimental test data. These models can be used reliably to simulate the structural behaviour of composite slabs.

- Design aids presented the form tables for the prediction of load/moment resistance and steelconcrete shear bond of ECC and SCC composite slabs can be used for practical design applications. However, these aids are valid only for P3623 Canam profiled steel deck used in the development of FE models.

\subsection{Recommendations for Future Research Studies}

The following recommendations are suggested for future research studies:

1) More experimental and numerical ABAQUS FE modeling works should be performed on profiled steel-deck composite slab by using additional interface connections (such as shear studs) in addition to the embossments to generate better steel concrete composite action.

2) The available "concrete damage plasticity" model in ABAQUS/CAE was designed with "concrete softening" behaviour for post-cracking. ECC behaviour is more or less like a ductile metal, ABAQUS concrete model should be modified to suite ECC. ECC should be modeled as steel rather than concrete to account for its post-tensioning performance in future studies.

3) FE models should be developed with more experimental data employing more shear span generating more points to prove more accurate prediction of shear bond parameters ( $\mathrm{m}$ and $\mathrm{k}$ ) and hence steel-concrete shear bond capacity.

4) One limitation of the proposed nonlinear ABAQUS FE models is due to their development based on insufficient concrete-steel deck interaction (only embossments). FE models should be developed by using sufficient concrete-steel deck connections (use of embossments and shear studs) simulating better structural behavior of composite slabs that can differentiate shear bond capacity of ECC and SCC composite slabs. 


\section{REFERENCES}

Abdullah, R. (2004). Experimental Evaluation and analytical modeling of shear bond in composite slabs (Doctoral dissertation, Virginia Polytechnic Institute and State University).

Abdullah, R., and Easterling, W. S. (2007). Determination of composite slab strength using a new elemental test method. Journal of Structural Engineering, 133(9), 1268-1277.

Afefy, H.M.E.D., and Mahmoud, M. H. (2014). Structural performance of RC slabs provided by pre-cast ECC strips in tension cover zone. Construction and Building Materials, 65, 103-113.

ASCE (1984). Specifications for the design and construction of composite slabs, ASCE, NY.

ASTM C39 (2012). Standard method for Compressive Strength of Cylindrical Concrete Specimens. Annual Book of ASTM Standard, ASTM International, West Conshohocken, PA, USA.

ASTM C78 / C78M (2010). Standard Test Method for Flexural Strength of Concrete. Annual Book of ASTM Standard, ASTM International, West Conshohocken, PA, USA.

Bouzoubaâ, N. and Lachemi, M. (2001). Self-compacting concrete incorporating high volumes of class F fly ash: Preliminary results. Cement and Concrete Research, 31(3), 413-420.

Canam Group. (2006). Canam - Steel Deck Catalogue. Canada: CANAM, pp. 14-17. http://files.canamconstruction.com/files/canam-steel-deck-catalogue-canada.pdf (Accessed date: 14-10-2014).

Chen, S. (2003). Load carrying capacity of composite slabs with various end constraints. Journal of Constructional Steel Research, 59(3), 385-403.

Chen, S., and Shi, X. (2011). Shear bond mechanism of composite slabs - A universal FE approach. Journal of Constructional Steel Research, 67(10), 1475-1484.

CSA-S16 (2009). Limit state design of steel structures. Canadian Standards Association, Etobicoke, Ontario, Canada.

Daniels, B. J., and Crisinel, M. (1993a). Composite slab behaviour and strength analysis. Part I: Calculation procedure. Journal of Structural Engineering, 119(1), 16-35. 
Daniels, B. J., and Crisinel, M. (1993b). Composite slab behaviour and strength analysis. Part II: Comparisons with test results and parametric analysis. Journal of Structural Engineering, 119(1), 36-49.

Dassault Systèmes Simulia Corp. (2013). ABAQUS/CAE Documentation, Version 6.13-3. Providence, RI, USA (www.simulia.com).

Davis, R. O., and Selvadurai, A. P. S. (2002). Plasticity and geo-mechanics. Cambridge University Press, Cambridge.

Ekberg, C. E., and Schuster, R. M. (1968). Floor systems with composite form-reinforced concrete slabs. Final report, IABSE, 8th congress, New York, NY, 385-394.

Eurocode 4 (1994). Design of composite steel and concrete structures, British Standard Institution, London.

Ferror, M., Marimon, F., and Crisinel, M. (2006). Designing cold-formed steel sheets for composite slabs: An experimentally validated FEM approach to slip failure mechanics. Thin-walled structures, 44(12), 1261-1271.

Gholamhoseini, A., Gilbert, R. I., Bradford, M. A., and Chang, Z. T. (2014). Longitudinal shear stress and bond-slip relationships in composite concrete slabs. Engineering Structures, 69, 37-48.

Hayakawa, M., Matsuoka, Y., and Shindoh, T. (1994). Development and application of superworkable concrete. In RILEM PROCEEDINGS, 183-190.

Hossain, K. M. A. (1995). In-plane shear behaviour of composite walling with profiled steel sheeting, PhD Thesis, University of Strathclyde, Glasgow, UK.

Hossain, K. M. A. (2014). Behaviour of ECC link slab for joint-free bridge construction. Proc. Structural Faults + Repair, Imperial College, London, UK.

Hossain, K. M. A., Alam, S., Meugoufu, H., Anwar, M. S., and Julkarnine, K. M. (2014). High-performance composite flooring systems with CANAM profiled steel decks. NSERC, Engage Report, Department of Civil/Eng., Ryerson University, 30P.

Hossain, K. M. A., and N. Vinay, N. (2012). Shear bond resistance of composite slabs with high performance concrete. The 6th International Conference on Advanced Composite Materials in Bridges and Structures, ACMBS-VI, Kingston, Ontario, Canada. 
Hossain, K. M. A. and Wright, H. D. (1998). Performance of profiled concrete shear panels. Journal of Structural Engineering, ASCE, 124(4), 368-381.

Hossain, K. M. A. and Wright, H. D. (2004a). Performance of double skin-profiled composite shear walls experiments and design equations, Can. J. Civ. Eng. 31, 204-217.

Hossain, K. M. A. and Wright, H. D. (2004b). Experimental and theoretical behavior of composite walling under in-plane shear, Journal of Constructional Steel Research 60, 59-83.

Khayat, K. H. (1999). Workability, testing, and performance of self-consolidating concrete. ACI Materials Journal, 96(3), 346-353.

King MS-S10 SCC (2014). http://industrial.kpmindustries.com/Product_Catalogue/products/Concrete/MS-S10_SelfConsolidating Concrete.aspx (Accessed date: 10-09-2014).

Lachemi, M., Hossain, K. M. A., Lambros, V. and Bouzoubaa, N. (2003). Development of cost-effective selfcompacting concrete incorporating fly ash, slag cement or viscosity modifying admixtures. $\mathrm{ACl}$ Materials Journal, 100(5), 419-425.

Lam, D. and Qureshi, J. (2008) Prediction of longitudinal shear resistance of composite slabs with profile sheeting to Eurocode 4. In: The Regency Steel Asia International Symposium on innovations in structural steel, RSA-ISISS 2008, 1 December, 2008, Singapore.

Lee, J., and Fenves, G. L. (1998). Plastic-damage model for cyclic loading of concrete structures. Journal of Engineering Mechanics, ASCE, 124(8), 892-900.

$\mathrm{Li}, \mathrm{V}$. C. (1993). From micromechanics to structural engineering: the design of cementitious composites for civil engineering applications. Journal of Structural Mechanics and Earthquake Engineering, 10(2), 37-48.

Li, M., and Li, V. C. (2011). Cracking and healing of engineered cementitious composites under chloride environment. ACI Materials Journal, 108(3).

Lublinear, J., Oliver, J., Oller, S., and Onate, E. (1989). A Plastic-Damage Model for Concrete. International Journal of Solids and Structures, 25(3), 299-326.

Lubliner, J. (1990). PLASTICITY THEORY (Revised Edition). Berkeley: University of California. 
Makelainen, P. and Sun, Y. (1999). The longitudinal shear behavior of a new steel sheeting profile for composite floor slabs, Journal of Constructional Steel Research, 49, 117-128.

Marimuthu, V., Seetharaman, S., Arul Jayachandran, Chellappan, A., Bandyopadhyay, T. K. and Dutta, D. (2007). Experimental studies on composite deck slabs to determine the shear-bond characteristic $m-k$ values of the embossed profiled sheet, Journal of Constructional Steel Research, 63, 791803.

Mohammed, B.S. (2010). Structural behavior and $m-k$ value of composite slab utilizing concrete containing crumb rubber, Construction and Building Materials, 24 (7), 1214-1221.

Mohammed, B.S., Al-Ganad M.A. and Abdullahi, M. (2011). Analytical \& experimental studies on composite slabs utilising palm oil clinker, Construction and Building Materials, 25(8) 3550-3560.

Nawy, E.G. (2008). Concrete Construction Engineering Handbook. 2ed Edition, Taylor \& Francis Group.

Porter, M. L. and Ekberg, C. E. (1971). Investigation of cold-formed steel-deck reinforced concrete floor slabs. First specialty conference on cold-formed steel structures - University of Missouri-Rolla, 17985.

Porter, M. L. and Ekberg, C. E. (1976). Design recommendations for steel deck floor slabs. Journal of Structural Division, ASCE, 102(11), 2121-36.

Rafiei, S. (2011). Behaviour of double skin profiled composite shear wall system under in-plane monotonic, cyclic and impact loadings. (Order No. NR93387, Ryerson University (Canada)). ProQuest Dissertations and Theses, 338.

Rafiei, S., Hossain, K. M. A., Lachemi, M., Behdinan, K., and Anwar, M. S. (2013). Finite element modeling of double skin profiled composite shear wall system under in-plane loadings. Engineering Structures, 56(1), 46-57.

Sahmaran, M., Li, M., \& Li, V. C. (2007). Transport properties of engineered cementitious composites under chloride exposure. ACI Materials Journal, 104(6).

Sahmaran, M., Lachemi, M., Hossain, K.M.A. and Li, V.C. (2009a). Internal curing of engineered cementitious composites for prevention of early age autogenous shrinkage cracking. Cement and Concrete Research, Elsevier Ltd., 39(10) 893-901. 
Sahmaran, M., Lachemi, M., Hossain, K.M.A., Ranade, R., and Li, V.C. (2009b), "Influence of Aggregate Type and Size on Ductility and Mechanical Properties of Engineered Cementitious Composites," ACl Materials Journal, 106(3), 308-316.

Schuster, R. M. (1976). Composite steel-deck concrete floor systems. Journal of Structural Division, ASCE, 102(5), 899-917.

Sherir, M. A. A., Hossain, K.M.A. and Lachemi, M. (2014). Fracture energy characteristics of engineered cementitious composites incorporating different aggregates. 4th International Structural Specialty Conference, CSCE, Halifax, NS.

Veljkovic, M. (1996). Behaviour and Resistance of Composite Slabs. Phd Thesis, Lulea University of Technology, Lulea, Sweden.

Wright, H. D., Evans, H. R., and Harding, P.W. (1987). The use of profiled steel sheeting in floor construction. Journal Construction Steel Research, 7(4), 279-295.

Widjaja, B. R. (1997). “Analysis and Design of Steel Deck-Concrete Composite Slabs," PhD Dissertation, Virginia Polytechnic Institute and State University, Blacksburg.

Zhou, J., Quian, S., Van Breugel, K., and Ye, G. (2010). Engineered cementitious composites with low volume of cementitious materials. Proceedings FramCos-, 7(1), 1551-1556. 


\section{APPENDICES}

A.1 ABAQUS model results for ECC composite slab (Total Span of $1800 \mathrm{~mm}$ ):

\begin{tabular}{|c|c|c|c|c|c|}
\hline \multicolumn{2}{|c|}{ ABAQUS Curve for Shear Span = $300 \mathrm{~mm}$} & \multicolumn{2}{|c|}{ ABAQUS Curve for Shear Span $=450 \mathrm{~mm}$} & \multicolumn{2}{|c|}{ ABAQUS Curve for Shear Span $=600 \mathrm{~mm}$} \\
\hline $\begin{array}{c}\text { Displacement at } \\
\text { center }(\mathrm{mm})\end{array}$ & $\begin{array}{l}\text { Total Reaction } \\
\text { Force (kN) }\end{array}$ & $\begin{array}{c}\text { Displacement at } \\
\text { center }(\mathrm{mm})\end{array}$ & $\begin{array}{l}\text { Total Reaction Force } \\
\text { (kN) }\end{array}$ & $\begin{array}{c}\text { Displacement at } \\
\text { center }(\mathrm{mm})\end{array}$ & $\begin{array}{l}\text { Total Reaction } \\
\text { Force (kN) }\end{array}$ \\
\hline 0 & -.00006 & 0 & -.000001 & 0 & $-5.8 \mathrm{E}-05$ \\
\hline $3.19 \mathrm{E}-05$ & -.00687 & 0.000563 & -.155384 & $1.92 \mathrm{E}-05$ & 0.033232 \\
\hline 0.000906 & -.0999 & 0.001244 & -.158525 & 0.000173 & 0.020035 \\
\hline 0.001597 & .15281 & 0.000965 & .155229 & 0.000155 & 0.021018 \\
\hline 0.002707 & -.20152 & 0.001399 & -.165737 & 0.000948 & -0.00603 \\
\hline 0.003132 & -.20091 & 0.002764 & .1907 & 0.002031 & -0.06928 \\
\hline 0.005253 & .24132 & 0.00541 & -.067484 & 0.003926 & 0.03907 \\
\hline 0.008213 & -.32472 & 0.008666 & -.064128 & 0.006419 & -0.0163 \\
\hline 0.012898 & .21879 & 0.012248 & .274808 & 0.009388 & 0.001265 \\
\hline 0.016896 & .62712 & 0.016956 & -.224424 & 0.013465 & 0.276755 \\
\hline 0.023663 & .94061 & 0.022837 & -.538944 & 0.018301 & 0.045737 \\
\hline 0.0323 & .50828 & 0.029275 & -.040904 & 0.024293 & -0.07082 \\
\hline 0.041951 & .33626 & 0.03754 & .021579 & 0.031267 & 0.173335 \\
\hline 0.053176 & .95412 & 0.045616 & -.162988 & 0.039505 & 0.172767 \\
\hline 0.065766 & .95469 & 0.057056 & .55525 & 0.048684 & 0.272245 \\
\hline 0.080872 & 2.22069 & 0.06883 & .454367 & 0.059493 & -0.07668 \\
\hline 0.098562 & .83062 & 0.082271 & .657226 & 0.071398 & 0.270975 \\
\hline 0.116769 & 2.22239 & 0.097161 & .558878 & 0.084758 & 0.280929 \\
\hline 0.138053 & 2.27498 & 0.113203 & 1.144694 & 0.099188 & 0.218717 \\
\hline 0.160305 & 3.47767 & 0.131101 & 1.110878 & 0.115436 & 0.616306 \\
\hline 0.185496 & 3.87623 & 0.15241 & 1.090205 & 0.133623 & 0.798528 \\
\hline 0.211666 & 2.34779 & 0.174648 & 1.326821 & 0.153528 & 1.026614 \\
\hline 0.241667 & 3.48759 & 0.199102 & 1.603656 & 0.174956 & 0.766814 \\
\hline 0.27332 & 3.99458 & 0.224869 & 1.631155 & 0.198164 & 0.934205 \\
\hline 0.307967 & 5.30822 & 0.253835 & 1.824648 & 0.223156 & 1.353802 \\
\hline 0.346174 & 4.69462 & 0.285295 & 2.339837 & 0.250357 & 0.903811 \\
\hline 0.385755 & 4.3281 & 0.316658 & 2.764723 & 0.279008 & 1.355395 \\
\hline 0.427776 & 5.784 & 0.352446 & 2.796499 & 0.309633 & 1.361323 \\
\hline 0.473552 & 6.07133 & 0.389096 & 3.357475 & 0.342329 & 1.947898 \\
\hline 0.522613 & 7.42541 & 0.428267 & 3.172843 & 0.377133 & 2.115293 \\
\hline 0.573833 & 8.47219 & 0.469711 & 4.161653 & 0.413864 & 2.027669 \\
\hline 0.626952 & 8.45054 & 0.513461 & 4.719494 & 0.45275 & 2.089445 \\
\hline 0.683989 & 10.61189 & 0.557183 & 5.56464 & 0.493645 & 2.665666 \\
\hline 0.704726 & 9.67488 & 0.604491 & 5.598864 & 0.536985 & 2.854042 \\
\hline
\end{tabular}




\begin{tabular}{|c|c|c|c|c|c|}
\hline 0.649095 & -4.52227 & 0.655442 & 6.20112 & 0.58221 & 3.367718 \\
\hline 0.665029 & 5.87563 & 0.70694 & 6.77304 & 0.629478 & 3.288547 \\
\hline 0.748987 & 9.98266 & 0.761416 & 7.568544 & 0.679164 & 3.749376 \\
\hline 0.790178 & 11.00957 & 0.819245 & 7.898208 & 0.730961 & 4.015733 \\
\hline 0.83917 & 10.31674 & 0.877153 & 8.591952 & 0.784847 & 4.147219 \\
\hline 0.897118 & 11.22245 & 0.878896 & 12.295872 & 0.840928 & 4.772208 \\
\hline 0.965957 & 11.65954 & 0.920458 & 4.08719 & 0.89944 & 5.496192 \\
\hline 1.02166 & 12.80885 & 0.971975 & 7.021872 & 0.956778 & 4.893552 \\
\hline 1.09079 & 13.63234 & 1.03584 & 6.679488 & 1.0088 & 4.504056 \\
\hline 1.15998 & 15.25747 & 1.1027 & 7.112784 & 1.06971 & 4.59252 \\
\hline 1.23042 & 16.33901 & 1.16986 & 7.158912 & 1.13429 & 1.290653 \\
\hline 1.30436 & 17.56186 & 1.23812 & 7.879632 & 1.20158 & 3.723811 \\
\hline 1.37869 & 18.59078 & 1.30721 & 8.34072 & 1.26796 & 5.042976 \\
\hline 1.45446 & 19.80691 & 1.37984 & 8.849904 & 1.3392 & 4.396858 \\
\hline 1.53374 & 22.05509 & 1.4542 & 9.782208 & 1.41279 & 4.235966 \\
\hline 1.61566 & 22.5625 & 1.5303 & 10.439136 & 1.48864 & 4.071341 \\
\hline 1.70313 & 23.53718 & 1.6078 & 11.070864 & 1.56687 & 5.077536 \\
\hline 1.78938 & 24.69101 & 1.68999 & 11.49312 & 1.64716 & 5.234256 \\
\hline 1.88068 & 26.47584 & 1.7737 & 12.186912 & 1.72966 & 5.192736 \\
\hline 1.97195 & 28.27402 & 1.8601 & 12.7992 & 1.81413 & 5.74224 \\
\hline 2.06639 & 29.5847 & 1.94801 & 13.620864 & 1.90061 & 5.964672 \\
\hline 2.16335 & 31.78013 & 2.03595 & 14.559312 & 1.98916 & 6.433344 \\
\hline 2.26289 & 33.34248 & 2.12849 & 14.926224 & 2.08009 & 6.889344 \\
\hline 2.36317 & 35.97758 & 2.22268 & 15.948 & 2.17287 & 7.280304 \\
\hline 2.46572 & 38.02565 & 2.31898 & 16.622496 & 2.26767 & 7.684656 \\
\hline 2.57028 & 38.49696 & 2.41648 & 17.44008 & 2.36426 & 7.903872 \\
\hline 2.67996 & 40.23787 & 2.51526 & 17.965392 & 2.46277 & 8.368704 \\
\hline 2.79152 & 42.40714 & 2.61671 & 19.03896 & 2.56317 & 8.538096 \\
\hline 2.90417 & 43.70458 & 2.72099 & 20.093664 & 2.66559 & 9.191232 \\
\hline 3.01957 & 45.60024 & 2.82665 & 20.833824 & 2.76985 & 9.434688 \\
\hline 3.13569 & 47.88298 & 2.9351 & 21.745152 & 2.87612 & 9.921312 \\
\hline 3.25341 & 48.16368 & 3.04391 & 22.610544 & 2.9837 & 10.2624 \\
\hline 3.34491 & 58.21536 & 3.15563 & 23.972928 & 3.09327 & 10.90867 \\
\hline 3.44975 & 54.26112 & 3.26887 & 25.060944 & 3.20453 & 11.01538 \\
\hline 3.58778 & 54.86736 & 3.38347 & 26.603424 & 3.31755 & 11.70619 \\
\hline 3.70752 & 56.86704 & 3.49912 & 27.559776 & 3.4325 & 12.18331 \\
\hline 3.83563 & 58.59072 & 3.6172 & 28.013184 & 3.54881 & 12.11309 \\
\hline 3.95611 & 59.07792 & 3.73691 & 29.463024 & 3.66659 & 12.72686 \\
\hline 4.4049 & 56.40528 & 3.85898 & 29.855712 & 3.78614 & 12.9445 \\
\hline 4.61365 & 57.17568 & 3.98087 & 31.283664 & 3.90714 & 13.82866 \\
\hline 4.93157 & 59.87184 & 4.1049 & 32.076624 & 4.02961 & 13.91774 \\
\hline
\end{tabular}




\begin{tabular}{|c|c|c|c|c|c|}
\hline 5.09411 & 61.1016 & 4.22922 & 33.165216 & 4.15323 & 14.95843 \\
\hline 5.26451 & 59.22672 & 4.35654 & 34.226208 & 4.27809 & 15.68405 \\
\hline 5.41118 & 56.7456 & 4.48406 & 34.986576 & 4.40476 & 16.07986 \\
\hline 5.56783 & 57.624 & 4.6144 & 36.297408 & 4.53229 & 16.07011 \\
\hline 5.72288 & 57.44928 & 4.74407 & 37.615248 & 4.66085 & 16.18373 \\
\hline 5.86831 & 59.30016 & 4.87626 & 38.74464 & 4.79033 & 18.63163 \\
\hline 6.01475 & 59.98752 & 5.00506 & 39.12648 & 4.92142 & 17.72688 \\
\hline 6.15886 & 62.24688 & 5.13666 & 40.237488 & 5.05306 & 19.6272 \\
\hline 6.30285 & 61.97328 & 5.27049 & 39.05136 & 5.18589 & 19.40592 \\
\hline 6.44725 & 63.5184 & 5.40624 & 40.429248 & 5.31959 & 19.31419 \\
\hline 6.58833 & 66.97056 & 5.54176 & 41.290704 & 5.45422 & 19.35096 \\
\hline 6.74598 & 68.43072 & 5.67657 & 42.189792 & 5.58959 & 19.70621 \\
\hline 6.89543 & 68.49216 & 5.8135 & 42.856608 & 5.72532 & 21.36274 \\
\hline 7.04233 & 71.9328 & 5.95203 & 42.96456 & 5.86137 & 23.49374 \\
\hline 7.1888 & 69.16896 & 6.08944 & 45.152064 & 5.99825 & 24.89074 \\
\hline 7.33527 & 70.30992 & 6.22693 & 44.668416 & 6.13656 & 26.08699 \\
\hline 7.49049 & 74.05152 & 6.3676 & 45.168336 & 6.27516 & 26.13749 \\
\hline 7.64197 & 72.87504 & 6.50639 & 44.974176 & 6.41446 & 27.20122 \\
\hline 7.79274 & 72.50784 & 6.64646 & 40.692624 & 6.55433 & 27.40637 \\
\hline 7.94895 & 76.78224 & 6.7835 & 42.180864 & 6.69412 & 27.56117 \\
\hline 8.10437 & 76.32768 & 6.9249 & 42.75552 & 6.83421 & 27.39254 \\
\hline 8.2602 & 73.34736 & 7.0651 & 42.810672 & 6.97451 & 28.27642 \\
\hline 8.41519 & 78.39312 & 7.20591 & 44.276784 & 7.11481 & 28.43011 \\
\hline 8.57026 & 81.2688 & 7.34763 & 42.488016 & 7.25572 & 28.8263 \\
\hline 8.72638 & 81.22128 & 7.48893 & 43.058976 & 7.39649 & 28.75248 \\
\hline 8.8857 & 77.83392 & 7.6298 & 43.256592 & 7.53702 & 29.31413 \\
\hline 9.05089 & 79.48944 & 7.77385 & 44.62296 & 7.6794 & 29.88379 \\
\hline 9.21377 & 78.88176 & 7.91492 & 43.6128 & 7.82168 & 30.30946 \\
\hline 9.3802 & 80.72688 & 8.05665 & 42.414096 & 7.9637 & 30.42413 \\
\hline 9.54431 & 77.17872 & 8.19734 & 44.2932 & 8.1057 & 30.93965 \\
\hline 9.70642 & 79.97664 & 8.338 & 43.108416 & 8.24754 & 32.04134 \\
\hline 9.86847 & 78.94848 & 8.47684 & 44.764896 & 8.38865 & 31.37232 \\
\hline 10.0329 & 80.45232 & 8.61979 & 44.055456 & 8.5301 & 32.18237 \\
\hline 10.1881 & 81.00336 & 8.75913 & 44.57568 & 8.67073 & 32.67403 \\
\hline 10.3467 & 80.07456 & 8.8989 & 43.072176 & 8.8108 & 33.72374 \\
\hline 10.5025 & 80.34768 & 9.03808 & 45.843888 & 8.95041 & 34.40914 \\
\hline 10.6529 & 80.61792 & 9.17774 & 46.695072 & 9.08916 & 33.51379 \\
\hline 10.8076 & 86.48928 & 9.31683 & 45.540672 & 9.22765 & 34.80581 \\
\hline 10.9691 & 85.7688 & 9.45409 & 45.170736 & 9.36493 & 30.19589 \\
\hline 11.1172 & 80.43312 & 9.58877 & 44.565648 & 9.50234 & 29.87669 \\
\hline 11.2699 & 81.62544 & 9.72661 & 43.188672 & 9.63859 & 29.69952 \\
\hline
\end{tabular}




\begin{tabular}{|c|c|c|c|c|c|}
\hline 11.4069 & 85.41936 & 9.86158 & 45.138192 & 9.77457 & 30.68352 \\
\hline 11.542 & 90.32832 & 9.99711 & 46.3656 & 9.90952 & 30.42149 \\
\hline 11.6776 & 98.36736 & 10.1312 & 47.883696 & 10.0361 & 31.84224 \\
\hline 11.8178 & 97.7136 & 10.263 & 45.464688 & 10.1702 & 31.89355 \\
\hline 11.9552 & 100.47456 & 10.3941 & 47.994288 & 10.3019 & 33.35074 \\
\hline 12.0908 & 98.29728 & 10.5252 & 48.03744 & 10.4329 & 33.00686 \\
\hline 12.2303 & 97.81008 & 10.6535 & 47.673984 & 10.5624 & 32.95262 \\
\hline 12.3631 & 104.38224 & 10.7798 & 49.42224 & 10.6913 & 33.02621 \\
\hline 12.4899 & 102.5952 & 10.9087 & 47.204544 & 10.8187 & 34.44869 \\
\hline 12.6271 & 99.42432 & 11.0336 & 51.34896 & 10.9447 & 34.36646 \\
\hline 12.7582 & 101.98464 & 11.1573 & 47.825328 & 11.0694 & 34.85611 \\
\hline 12.8827 & 103.54416 & 11.2801 & 50.7648 & 11.1924 & 35.97072 \\
\hline 13.0165 & 102.94848 & 11.4018 & 48.45264 & 11.3137 & 35.54501 \\
\hline 13.152 & 107.78544 & 11.5206 & 49.20576 & 11.4335 & 36.84086 \\
\hline 13.2785 & 105.9024 & 11.6367 & 48.98016 & 11.5511 & 36.04186 \\
\hline 13.406 & 108.09792 & 11.7531 & 46.588176 & 11.6681 & 36.8088 \\
\hline 13.5479 & 106.03776 & 11.8684 & 48.05088 & 11.7832 & 37.28275 \\
\hline 13.6711 & 114.37728 & 11.9791 & 44.214144 & 11.8965 & 36.73272 \\
\hline 13.7898 & 107.62128 & 12.0901 & 44.214 & 12.0086 & 36.47246 \\
\hline 13.9096 & 110.39232 & 12.2026 & 46.303824 & 12.119 & 36.14778 \\
\hline 14.0218 & 105.46464 & 12.3119 & 47.34888 & 12.228 & 36.63315 \\
\hline 14.1293 & 109.80336 & 12.4172 & 46.686 & 12.3351 & 37.48141 \\
\hline 14.238 & 110.59872 & 12.5218 & 46.541424 & 12.4395 & 37.97595 \\
\hline 14.3484 & 110.70048 & 12.6259 & 46.697712 & 12.5429 & 38.42347 \\
\hline 14.455 & 105.72 & 12.7258 & 47.412 & 12.6448 & 38.54198 \\
\hline 14.5558 & 106.43184 & 12.8263 & 47.692128 & 12.7447 & 38.60827 \\
\hline 14.6534 & 106.26096 & 12.9244 & 46.218768 & 12.8422 & 39.11198 \\
\hline 14.736 & 109.73232 & 13.0202 & 51.08448 & 12.9379 & 38.79682 \\
\hline 14.822 & 104.93232 & 13.115 & 48.39792 & 13.0315 & 38.23563 \\
\hline 14.9138 & 112.5024 & 13.2053 & 45.296784 & 13.123 & 38.98582 \\
\hline 15.0047 & 108.39696 & 13.2962 & 46.638192 & 13.2124 & 38.17765 \\
\hline 15.0937 & 109.06368 & 13.3841 & 44.085264 & 13.2998 & 38.52542 \\
\hline 15.1827 & 113.12304 & 13.4704 & 45.34224 & 13.3846 & 38.48261 \\
\hline 15.2692 & 106.6128 & 13.5553 & 45.672912 & 13.4647 & 37.96738 \\
\hline 15.3553 & 107.23728 & 13.6369 & 46.847904 & 13.5452 & 37.71173 \\
\hline 15.4388 & 106.9776 & 13.714 & 46.86816 & 13.6242 & 35.52864 \\
\hline 15.5181 & 96.22992 & 13.7911 & 46.48224 & 13.7 & 36.3005 \\
\hline 15.5993 & 103.59888 & 13.8657 & 48.81456 & 13.7743 & 38.2397 \\
\hline 15.6824 & 101.75808 & 13.9388 & 48.33408 & 13.8471 & 38.22187 \\
\hline 15.7606 & 100.58736 & 14.0101 & 45.957072 & 13.9169 & 38.7248 \\
\hline 15.8343 & 104.56368 & 14.0779 & 49.06176 & 13.9848 & 38.01026 \\
\hline
\end{tabular}




\begin{tabular}{|c|c|c|c|c|c|}
\hline 15.9047 & 110.71056 & 14.1423 & 48.38112 & 14.0507 & 38.28078 \\
\hline 15.9713 & 95.71632 & 14.2052 & 45.311328 & 14.1133 & 38.10587 \\
\hline 16.0365 & 104.79072 & 14.2665 & 47.192208 & 14.1736 & 38.28914 \\
\hline 16.0982 & 108.20448 & 14.3258 & 50.99328 & 14.2332 & 38.77192 \\
\hline 16.1586 & 97.39296 & 14.3844 & 48.2304 & 14.2901 & 38.53376 \\
\hline 16.2174 & 103.57056 & 14.4384 & 50.29152 & 14.3446 & 38.38478 \\
\hline 16.2736 & 97.32672 & 14.4919 & 48.32256 & 14.3984 & 38.32248 \\
\hline 16.3202 & 99.264 & 14.5419 & 46.56816 & 14.4487 & 39.29386 \\
\hline 16.3649 & 104.27376 & 14.5903 & 48.49872 & 14.4961 & 38.1588 \\
\hline 16.4148 & 97.9992 & 14.6366 & 44.712096 & 14.5429 & 38.22955 \\
\hline 16.4575 & 93.15024 & 14.6812 & 45.461904 & 14.5875 & 38.00427 \\
\hline 16.4967 & 97.28208 & 14.7233 & 48.76416 & 14.6296 & 38.98912 \\
\hline 16.5294 & 101.76384 & 14.7642 & 48.32976 & 14.6697 & 39.97051 \\
\hline 16.5674 & 105.54192 & 14.8005 & 47.273904 & 14.7082 & 38.69394 \\
\hline 16.6004 & 104.2992 & 14.8368 & 44.91432 & 14.7434 & 38.82478 \\
\hline 16.6327 & 113.6688 & 14.87 & 47.8224 & 14.7775 & 39.80971 \\
\hline 16.6668 & 102.2784 & 14.9029 & 48.1728 & 14.8095 & 39.14002 \\
\hline 16.6964 & 101.71008 & 14.933 & 45.244752 & 14.8392 & 39.15077 \\
\hline 16.7238 & 104.03712 & 14.9609 & 48.35664 & 14.8674 & 38.60562 \\
\hline 16.7486 & 110.87088 & 14.9868 & 46.878384 & 14.8933 & 38.0039 \\
\hline 16.7705 & 103.48128 & 15.0107 & 44.28576 & 14.918 & 38.34886 \\
\hline 16.7934 & 98.61936 & 15.0331 & 46.610592 & 14.9398 & 38.13317 \\
\hline 16.8101 & 111.08832 & 15.0546 & 46.253568 & 14.9609 & 38.64938 \\
\hline 16.832 & 108.44784 & 15.0735 & 48.05712 & 14.9797 & 38.32462 \\
\hline 16.8467 & 103.19904 & 15.0917 & 48.828 & 14.9969 & 38.65147 \\
\hline 16.8604 & 103.64496 & 15.1079 & 48.8784 & 15.0134 & 39.4823 \\
\hline 16.8742 & 104.99664 & 15.1224 & 46.790496 & 15.028 & 39.22326 \\
\hline 16.8861 & 103.11744 & 15.1354 & 47.189904 & 15.0415 & 39.16963 \\
\hline 16.8988 & 107.40048 & 15.1461 & 47.662176 & 15.0525 & 33.8929 \\
\hline 16.9105 & 110.62032 & 15.1561 & 45.466992 & 15.0629 & 34.3117 \\
\hline 16.9196 & 109.68816 & 15.1656 & 43.833744 & 15.0721 & 38.29795 \\
\hline 16.9264 & 106.03488 & 15.1725 & 45.956496 & 15.0793 & 38.57707 \\
\hline 16.9345 & 104.77248 & 15.1791 & 44.196816 & 15.0867 & 37.21834 \\
\hline 16.9359 & 102.17712 & 15.1851 & 48.94752 & 15.0916 & 39.7332 \\
\hline 16.9405 & 102.36816 & 15.1896 & 44.496528 & 15.0974 & 36.29304 \\
\hline 16.9432 & 107.12016 & 15.1922 & 45.524112 & 15.1007 & 39.13147 \\
\hline 16.9457 & 112.73568 & 15.1961 & 46.486608 & 15.1035 & 37.05917 \\
\hline 16.9458 & 111.46416 & 15.1982 & 46.49928 & 15.1055 & 35.18525 \\
\hline 16.947 & 110.29728 & 15.1991 & 46.812192 & 15.1073 & 37.89984 \\
\hline 16.9471 & 114.00144 & 15.2002 & 45.931008 & 15.1077 & 34.53845 \\
\hline 16.945 & 105.5016 & 15.202 & 44.664864 & 15.1096 & 38.82698 \\
\hline
\end{tabular}




\begin{tabular}{|l|c|c|c|c|c|}
\hline 16.9466 & 105.56352 & 15.2019 & 44.99592 & 15.1094 & 38.11522 \\
\hline 16.9475 & 110.4384 & 15.2019 & 45.838896 & 15.11 & 37.74302 \\
\hline 16.9465 & 106.40256 & 15.2025 & 42.83352 & 15.1102 & 34.87301 \\
\hline
\end{tabular}

A.2 ABAQUS model results for SCC composite slab (Total Span of $1800 \mathrm{~mm}$ ):

\begin{tabular}{|c|c|c|c|c|c|}
\hline \multicolumn{2}{|c|}{ ABAQUS Curve for Shear Span $=300 \mathrm{~mm}$} & \multicolumn{2}{|c|}{ ABAQUS Curve for Shear Span $=450 \mathrm{~mm}$} & \multicolumn{2}{|c|}{ ABAQUS Curve for Shear Span $=600 \mathrm{~mm}$} \\
\hline $\begin{array}{l}\text { Displacement at } \\
\text { center }(\mathrm{mm})\end{array}$ & $\begin{array}{l}\text { Total Reaction Force } \\
(\mathbf{k N})\end{array}$ & $\begin{array}{c}\text { Displacement } \\
\text { at center } \\
(\mathrm{mm})\end{array}$ & $\begin{array}{l}\text { Total Reaction Force } \\
(\mathbf{k N})\end{array}$ & $\begin{array}{c}\text { Displacement at } \\
\text { center }(\mathrm{mm})\end{array}$ & $\begin{array}{l}\text { Total Reaction } \\
\text { Force (kN) }\end{array}$ \\
\hline 0 & 0.020733 & 0 & . & 0 & 0.020502 \\
\hline $1.3 \mathrm{E}-05$ & 0.028074 & -0.00068 & -.07761 & -0.00011 & -0.04148 \\
\hline-0.00017 & 0.127533 & -0.00095 & -.02681 & 0.000105 & -0.11659 \\
\hline-0.00024 & 0.429996 & -0.00085 & -.34552 & 0.000331 & 0.007826 \\
\hline-0.00015 & 0.2434 & 0.000538 & -.02623 & 0.000296 & 0.085318 \\
\hline 0.000189 & 0.47443 & 0.00096 & -.11218 & 0.00049 & -0.02901 \\
\hline 0.002894 & 0.937402 & 0.000803 & -.33307 & 0.000903 & 0.265219 \\
\hline 0.002852 & 1.020811 & 0.001779 & -.10551 & 0.001566 & 0.077564 \\
\hline 0.005369 & 0.75191 & 0.00204 & .04069 & 0.002267 & 0.065889 \\
\hline 0.007893 & 1.308125 & 0.004053 & -.09832 & 0.002957 & 0.139847 \\
\hline 0.009666 & 1.76004 & 0.005677 & -.06584 & 0.00378 & 0.09089 \\
\hline 0.01217 & 1.777541 & 0.007165 & .0259 & 0.004921 & 0.156761 \\
\hline 0.015159 & 2.304413 & 0.008582 & .35371 & 0.006233 & 0.273515 \\
\hline 0.019828 & 2.363443 & 0.012288 & .8886 & 0.007599 & 0.345349 \\
\hline 0.023746 & 2.392978 & 0.015954 & .54224 & 0.009587 & 0.293499 \\
\hline 0.029273 & 3.202483 & 0.018646 & 1.11509 & 0.011457 & 0.297626 \\
\hline 0.035893 & 2.800992 & 0.023821 & .97523 & 0.013824 & 0.271641 \\
\hline 0.042115 & 3.086203 & 0.028904 & 1.07074 & 0.016776 & 0.449674 \\
\hline 0.050235 & 3.219125 & 0.034678 & 1.76524 & 0.019885 & 0.466973 \\
\hline 0.059138 & 3.807062 & 0.041001 & 1.93391 & 0.023103 & 0.810946 \\
\hline 0.067879 & 4.33705 & 0.048606 & 1.94576 & 0.02696 & 0.913147 \\
\hline 0.078136 & 4.850112 & 0.056035 & 2.08974 & 0.031059 & 1.075752 \\
\hline 0.089095 & 5.453616 & 0.063621 & 2.34739 & 0.035449 & 1.127717 \\
\hline 0.101145 & 6.237792 & 0.072959 & 2.66712 & 0.03986 & 1.258008 \\
\hline 0.113501 & 6.656064 & 0.082676 & 2.69419 & 0.044921 & 1.562251 \\
\hline 0.127363 & 7.29336 & 0.091596 & 2.95051 & 0.049971 & 1.504123 \\
\hline 0.141113 & 8.415168 & 0.102757 & 3.05765 & 0.055849 & 1.83444 \\
\hline 0.157274 & 9.148848 & 0.114267 & 4.09141 & 0.062126 & 2.015352 \\
\hline 0.174046 & 10.12205 & 0.127993 & 4.1312 & 0.068849 & 2.206939 \\
\hline
\end{tabular}




\begin{tabular}{|c|c|c|c|c|c|}
\hline 0.192091 & 10.38538 & 0.140402 & 4.88088 & 0.075932 & 2.439168 \\
\hline 0.211251 & 11.78798 & 0.153741 & 5.20037 & 0.083371 & 2.499202 \\
\hline 0.231203 & 12.20794 & 0.169633 & 5.86699 & 0.091228 & 2.78941 \\
\hline 0.252847 & 13.32427 & 0.184658 & 6.52488 & 0.099597 & 3.232454 \\
\hline 0.274893 & 14.17186 & 0.200434 & 7.07966 & 0.107784 & 3.452674 \\
\hline 0.298009 & 15.30955 & 0.216979 & 7.62878 & 0.117204 & 3.635328 \\
\hline 0.321686 & 16.72157 & 0.236028 & 8.27275 & 0.126788 & 4.218797 \\
\hline 0.347627 & 18.01195 & 0.25412 & 9.66744 & 0.136735 & 4.409318 \\
\hline 0.371997 & 19.75493 & 0.274298 & 9.89698 & 0.147169 & 4.527634 \\
\hline 0.397151 & 22.0464 & 0.293853 & 10.86475 & 0.158201 & 5.02152 \\
\hline 0.42281 & 24.14904 & 0.314916 & 12.13642 & 0.169566 & 5.340576 \\
\hline 0.449503 & 27.02942 & 0.337352 & 12.55277 & 0.181414 & 5.615328 \\
\hline 0.478629 & 29.09645 & 0.359214 & 13.07179 & 0.193756 & 6.091392 \\
\hline 0.750355 & 16.75853 & 0.38404 & 13.99392 & 0.206352 & 6.5352 \\
\hline 0.732624 & 16.42733 & 0.408543 & 15.3119 & 0.219374 & 6.953664 \\
\hline 0.792962 & 12.7873 & 0.432903 & 16.10717 & 0.233065 & 7.256064 \\
\hline 0.838295 & 16.94347 & 0.45976 & 17.03194 & 0.247053 & 7.611744 \\
\hline 0.84797 & 19.08456 & 0.485866 & 18.87106 & 0.261216 & 8.08128 \\
\hline 0.886394 & 16.91467 & 0.514448 & 18.78941 & 0.276267 & 8.710128 \\
\hline 0.928592 & 18.97488 & 0.541638 & 20.76859 & 0.291664 & 8.683152 \\
\hline 0.961889 & 19.63258 & 0.571666 & 22.12411 & 0.307151 & 9.663264 \\
\hline 0.997009 & 20.24362 & 0.601792 & 23.89267 & 0.323191 & 10.15978 \\
\hline 1.03258 & 21.14194 & 0.632567 & 24.7811 & 0.339581 & 10.51421 \\
\hline 1.07148 & 22.04126 & 0.665091 & 25.95802 & 0.356848 & 11.30462 \\
\hline 1.10827 & 22.86739 & 0.698758 & 26.96102 & 0.374524 & 11.83315 \\
\hline 1.1467 & 24.17798 & 0.732402 & 28.02605 & 0.392249 & 12.60331 \\
\hline 1.18552 & 24.72394 & 0.766427 & 30.12811 & 0.410972 & 13.11374 \\
\hline 1.22687 & 25.67914 & 0.80115 & 31.63589 & 0.429744 & 13.70952 \\
\hline 1.26707 & 26.89272 & 0.767103 & 22.14398 & 0.448729 & 14.20814 \\
\hline 1.30858 & 28.19597 & 0.802994 & 11.2392 & 0.468413 & 14.9401 \\
\hline 1.35169 & 29.13864 & 0.827207 & 10.44389 & 0.488295 & 15.77342 \\
\hline 1.39395 & 30.33547 & 0.864948 & 13.07453 & 0.50892 & 16.28813 \\
\hline 1.43595 & 31.00205 & 0.901094 & 14.89666 & 0.529657 & 16.98547 \\
\hline 1.477 & 32.44325 & 0.935307 & 15.40066 & 0.908912 & 17.3779 \\
\hline 1.52235 & 33.70776 & 0.972381 & 15.56554 & 0.915439 & 4.701197 \\
\hline 1.56818 & 34.63877 & 1.00888 & 16.35706 & 0.943242 & 7.40808 \\
\hline 1.61215 & 34.76635 & 1.046 & 16.96286 & 0.96747 & 7.651392 \\
\hline 1.65793 & 35.52302 & 1.08396 & 17.46211 & 0.99383 & 9.403392 \\
\hline 1.7043 & 36.53765 & 1.12247 & 18.26794 & 1.01967 & 10.25366 \\
\hline 1.75137 & 36.81614 & 1.162 & 18.60888 & 1.0452 & 11.75395 \\
\hline 1.79985 & 38.28014 & 1.20086 & 18.99288 & 1.07124 & 12.06946 \\
\hline
\end{tabular}




\begin{tabular}{|c|c|c|c|c|c|}
\hline 1.84849 & 40.73458 & 1.24164 & 19.66406 & 1.09804 & 12.36998 \\
\hline 1.89526 & 40.89187 & 1.2829 & 20.31653 & 1.12516 & 12.73675 \\
\hline 1.94229 & 43.55256 & 1.32456 & 20.87395 & 1.1515 & 12.63485 \\
\hline 1.98721 & 44.71195 & 1.36685 & 21.62578 & 1.17885 & 13.18498 \\
\hline 2.0354 & 44.07907 & 1.40942 & 22.14984 & 1.20653 & 13.21128 \\
\hline 2.08604 & 45.68429 & 1.45217 & 22.67419 & 1.23387 & 13.31232 \\
\hline 2.13542 & 46.42565 & 1.49634 & 23.1347 & 1.26145 & 13.45747 \\
\hline 2.18714 & 49.09344 & 1.54038 & 23.84347 & 1.28925 & 13.99786 \\
\hline 2.23895 & 49.5024 & 1.58515 & 24.43997 & 1.31723 & 14.2655 \\
\hline 2.29215 & 52.32384 & 1.63003 & 25.20422 & 1.34573 & 14.68666 \\
\hline 2.34231 & 52.18416 & 1.67557 & 25.82779 & 1.37361 & 14.70086 \\
\hline 2.39425 & 54.66768 & 1.72169 & 26.71555 & 1.40208 & 15.1152 \\
\hline 2.44503 & 55.38624 & 1.7683 & 27.26549 & 1.43024 & 15.5245 \\
\hline 2.49456 & 56.0856 & 1.81434 & 27.81341 & 1.45866 & 15.76426 \\
\hline 2.54773 & 57.7296 & 1.86035 & 28.66296 & 1.487 & 16.14245 \\
\hline 2.59959 & 59.49312 & 1.90715 & 29.18794 & 1.51505 & 16.45862 \\
\hline 2.65315 & 61.05168 & 1.95378 & 29.99232 & 1.54394 & 16.69786 \\
\hline 2.70574 & 62.77776 & 2.00035 & 30.73512 & 1.57244 & 17.1193 \\
\hline 2.75634 & 62.70144 & 2.04813 & 31.32178 & 1.60111 & 17.30568 \\
\hline 2.80916 & 64.48848 & 2.0964 & 32.00894 & 1.62963 & 17.50056 \\
\hline 2.86132 & 64.5984 & 2.1445 & 32.62469 & 1.65834 & 17.87414 \\
\hline 2.91419 & 67.6992 & 2.19347 & 33.02438 & 1.68665 & 18.23179 \\
\hline 2.96848 & 68.70048 & 2.24087 & 33.9371 & 1.71511 & 18.57221 \\
\hline 3.01951 & 69.67104 & 2.2896 & 34.87646 & 1.74344 & 18.75178 \\
\hline 3.07033 & 70.74144 & 2.33878 & 35.57333 & 1.77172 & 19.05811 \\
\hline 3.22587 & 71.90976 & 2.38898 & 36.35525 & 1.8 & 19.36186 \\
\hline 3.53113 & 71.4736 & 2.43867 & 36.86842 & 1.82803 & 19.6715 \\
\hline 3.53204 & 72.15216 & 2.48789 & 37.74034 & 1.85583 & 19.87666 \\
\hline 3.64523 & 72.58112 & 2.53792 & 38.06064 & 1.88371 & 20.28422 \\
\hline 3.6939 & 73.19104 & 2.58747 & 39.18514 & 1.91135 & 20.70346 \\
\hline 3.78816 & 73.3152 & 2.63755 & 39.38803 & 1.93896 & 20.84813 \\
\hline 3.84695 & 75.1728 & 2.68627 & 40.65734 & 1.96611 & 21.21302 \\
\hline 3.92091 & 76.23552 & 2.73703 & 40.78234 & 1.99339 & 21.32851 \\
\hline 3.98831 & 78.53808 & 2.78831 & 41.62243 & 2.0204 & 21.81874 \\
\hline 4.05387 & 80.71248 & 2.8391 & 42.50846 & 2.04713 & 22.07083 \\
\hline 4.11772 & 81.88752 & 2.88949 & 43.21934 & 2.0736 & 22.35245 \\
\hline 4.18059 & 83.98368 & 2.93971 & 43.87085 & 2.09983 & 22.56797 \\
\hline 4.23605 & 85.0992 & 2.98796 & 44.45285 & 2.1259 & 22.74917 \\
\hline 4.2919 & 83.74656 & 3.0384 & 45.45418 & 2.15184 & 23.22014 \\
\hline 4.35024 & 86.59344 & 3.08887 & 45.79608 & 2.17742 & 23.5199 \\
\hline 4.40773 & 86.75664 & 3.13873 & 46.83744 & 2.20271 & 23.79979 \\
\hline
\end{tabular}




\begin{tabular}{|c|c|c|c|c|c|}
\hline 4.46385 & 87.204 & 3.18823 & 47.15304 & 2.22798 & 24.0756 \\
\hline 4.5181 & 89.11584 & 3.23719 & 48.08352 & 2.25279 & 24.25555 \\
\hline 4.57473 & 90.43776 & 3.28655 & 48.74496 & 2.27744 & 24.59856 \\
\hline 4.62929 & 92.23344 & 3.33525 & 49.62096 & 2.30163 & 24.79214 \\
\hline 4.68369 & 91.58448 & 3.51254 & 49.75008 & 2.32568 & 25.13251 \\
\hline 4.73631 & 93.81552 & 3.57227 & 47.33501 & 2.34921 & 25.30147 \\
\hline 4.78733 & 93.69168 & 3.6214 & 50.49264 & 2.3726 & 25.38341 \\
\hline 4.82674 & 91.17264 & 3.68442 & 50.12448 & 2.39563 & 25.88117 \\
\hline 4.87768 & 91.24176 & 3.74451 & 51.04608 & 2.41837 & 26.20066 \\
\hline 4.92517 & 92.34096 & 3.82282 & 50.66448 & 2.44061 & 26.50685 \\
\hline 4.9734 & 93.57744 & 3.88279 & 51.58224 & 2.46241 & 26.80277 \\
\hline 5.01846 & 92.16096 & 3.94644 & 52.24464 & 2.48399 & 27.02496 \\
\hline 5.05878 & 95.15376 & 4.00294 & 53.35344 & 2.50513 & 27.15427 \\
\hline 5.10872 & 97.0464 & 4.05583 & 53.92464 & 2.52598 & 27.23606 \\
\hline 5.15473 & 97.44288 & 4.1075 & 54.55536 & 2.54632 & 27.41222 \\
\hline 5.19192 & 97.8048 & 4.15832 & 55.00944 & 2.56632 & 27.72173 \\
\hline 5.23577 & 100.1645 & 4.20741 & 56.11056 & 2.5869 & 27.96946 \\
\hline 5.27783 & 99.20688 & 4.25657 & 56.8752 & 2.60643 & 28.51949 \\
\hline 5.31792 & 101.1451 & 4.31986 & 57.35616 & 2.62582 & 28.89115 \\
\hline 5.35649 & 101.6654 & 4.36067 & 56.85264 & 2.64441 & 28.77374 \\
\hline 5.39637 & 102.5678 & 4.40593 & 57.46704 & 2.66257 & 28.99598 \\
\hline 5.43302 & 103.7477 & 4.45058 & 58.54224 & 2.68051 & 29.30102 \\
\hline 5.47117 & 102.6019 & 4.49574 & 58.63248 & 2.69766 & 29.53886 \\
\hline 5.50489 & 102.6451 & 4.54128 & 58.98192 & 2.71447 & 29.49029 \\
\hline 5.53973 & 104.4874 & 4.58566 & 59.67456 & 2.73094 & 29.75026 \\
\hline 5.57522 & 104.7821 & 4.62975 & 59.61984 & 2.74684 & 29.71354 \\
\hline 5.60867 & 104.0424 & 4.67277 & 60.21216 & 2.76241 & 30.08059 \\
\hline 5.64245 & 103.9848 & 4.71512 & 60.468 & 2.77755 & 30.24134 \\
\hline 5.68635 & 106.0685 & 4.75632 & 61.24128 & 2.79208 & 30.58162 \\
\hline 5.7165 & 106.1779 & 4.79678 & 61.1112 & 2.8064 & 30.49776 \\
\hline 5.74657 & 108.4858 & 4.83591 & 61.96656 & 2.8203 & 30.53208 \\
\hline 5.77663 & 106.7875 & 4.87558 & 62.38512 & 2.83365 & 31.10746 \\
\hline 5.8056 & 106.6507 & 4.91422 & 62.6568 & 2.84667 & 31.28458 \\
\hline 5.83246 & 107.3035 & 4.95131 & 62.66832 & 2.85902 & 31.1939 \\
\hline 5.8576 & 106.2317 & 4.98716 & 62.92368 & 2.87107 & 31.26864 \\
\hline 5.88294 & 109.4683 & 5.02298 & 63.32064 & 2.88265 & 31.30416 \\
\hline 5.90826 & 109.5504 & 5.05696 & 64.05744 & 2.89378 & 31.85731 \\
\hline 5.93314 & 109.0493 & 5.0914 & 64.03584 & 2.90437 & 31.55851 \\
\hline 5.95387 & 110.7202 & 5.12487 & 64.25808 & 2.91468 & 31.92994 \\
\hline 5.97735 & 111.9221 & 5.15759 & 64.71936 & 2.92447 & 32.02142 \\
\hline 5.99998 & 110.1706 & 5.18904 & 65.03136 & 2.93378 & 32.47867 \\
\hline
\end{tabular}




\begin{tabular}{|c|c|c|c|c|c|}
\hline 6.019 & 108.2909 & 5.22019 & 65.556 & 2.94273 & 32.29286 \\
\hline 6.03819 & 110.3808 & 5.24968 & 65.6856 & 2.95113 & 32.23536 \\
\hline 6.05689 & 108.301 & 5.27953 & 66.06432 & 2.95927 & 32.3604 \\
\hline 6.0718 & 111.2208 & 5.3079 & 66.07008 & 2.967 & 32.63333 \\
\hline 6.08907 & 111.3802 & 5.33528 & 66.53232 & 2.97413 & 32.6677 \\
\hline 6.10542 & 110.9702 & 5.36176 & 66.93408 & 2.98073 & 32.51798 \\
\hline 6.12044 & 111.9562 & 5.38741 & 67.04352 & 2.98716 & 32.90285 \\
\hline 6.13474 & 111.8146 & 5.41186 & 67.6296 & 2.99325 & 32.76864 \\
\hline 6.14941 & 112.3646 & 5.43532 & 67.57536 & 2.99884 & 32.80651 \\
\hline 6.16218 & 111.731 & 5.45775 & 67.9824 & 3.00411 & 32.79365 \\
\hline 6.17451 & 111.323 & 5.48017 & 68.12928 & 3.00903 & 32.87458 \\
\hline 6.18548 & 111.5784 & 5.50081 & 68.43552 & 3.01361 & 32.5573 \\
\hline 6.1955 & 113.0011 & 5.52091 & 68.55456 & 3.01797 & 33.02232 \\
\hline 6.20549 & 110.4878 & 5.54014 & 68.79936 & 3.0217 & 33.46325 \\
\hline 6.21518 & 111.371 & 5.55856 & 69.096 & 3.02522 & 32.994 \\
\hline 6.22379 & 112.0042 & 5.57623 & 69.27504 & 3.0285 & 33.23683 \\
\hline 6.23159 & 111.9566 & 5.593 & 69.52176 & 3.03136 & 33.37766 \\
\hline 6.23791 & 112.0642 & 5.60873 & 69.5496 & 3.03404 & 33.40224 \\
\hline 6.24376 & 112.813 & 5.62357 & 69.8136 & 3.03657 & 33.26832 \\
\hline 6.24948 & 112.3262 & 5.63791 & 70.01904 & 3.03858 & 33.22128 \\
\hline 6.25514 & 113.0458 & 5.65134 & 70.01568 & 3.04032 & 33.16694 \\
\hline 6.26267 & 112.524 & 5.66413 & 70.272 & 3.04192 & 33.13075 \\
\hline 6.26713 & 111.0835 & 5.67592 & 70.32432 & 3.04332 & 32.97965 \\
\hline 6.26977 & 111.2573 & 5.68499 & 69.8856 & 3.04452 & 33.17026 \\
\hline 6.27296 & 112.5475 & 5.6957 & 70.5264 & 3.04556 & 33.31018 \\
\hline 6.27275 & 111.8395 & 5.70552 & 70.35792 & 3.04625 & 33.23491 \\
\hline 6.276 & 112.8298 & 5.71424 & 70.31664 & 3.04695 & 33.22416 \\
\hline 6.27784 & 113.2224 & 5.72229 & 70.65456 & 3.04736 & 33.20851 \\
\hline 6.28013 & 112.2859 & 5.72961 & 70.98336 & 3.04765 & 33.18422 \\
\hline 6.28144 & 110.4797 & 5.73714 & 71.0136 & 3.04786 & 33.19046 \\
\hline 6.28318 & 110.0808 & 5.74308 & 70.58928 & 3.0477 & 33.3215 \\
\hline 6.28416 & 113.9578 & 5.74922 & 70.94688 & 3.04786 & 33.25397 \\
\hline 6.28465 & 111.4104 & 5.75483 & 70.91136 & 3.0478 & 33.22392 \\
\hline 6.28454 & 111.3288 & 5.75941 & 70.7664 & 3.04787 & 33.43363 \\
\hline 6.28604 & 111.8314 & 5.76356 & 71.18928 & & \\
\hline 6.2839 & 111.3701 & 5.76721 & 71.08944 & & \\
\hline 6.2853 & 112.3742 & 5.77042 & 71.40864 & & \\
\hline \multirow[t]{4}{*}{6.28393} & 111.4512 & 5.77308 & 70.98144 & & \\
\hline & & 5.77492 & 70.92192 & & \\
\hline & & 5.77656 & 70.90032 & & \\
\hline & & 5.77806 & 71.07456 & & \\
\hline
\end{tabular}




\begin{tabular}{|l|l|l|l|l|l|}
\hline & & 5.77898 & 70.84704 & & \\
\hline & & 5.78003 & 70.96752 & & \\
\hline & & 5.78075 & 71.6232 & & \\
\hline & & 5.78082 & 71.3136 & & \\
\hline & & 5.78138 & 71.39472 & & \\
\hline & & 5.78129 & 71.25504 & & \\
\hline & & 5.78128 & 71.13408 & & \\
\hline & & 5.78128 & 71.3424 & & \\
\hline
\end{tabular}

